\title{
Advancing the implementation of evidence in public health systems in Europe and globally
}

Citation for published version (APA):

Vincenten, J. A. (2020). Advancing the implementation of evidence in public health systems in Europe and globally: a model interlinking targets, actors, knowledge transfer, barriers and facilitators. [Doctoral Thesis, Maastricht University]. ProefschriftMaken. https://doi.org/10.26481/dis.20200923jv

Document status and date:

Published: 01/01/2020

DOI:

10.26481/dis.20200923jv

Document Version:

Publisher's PDF, also known as Version of record

\section{Please check the document version of this publication:}

- A submitted manuscript is the version of the article upon submission and before peer-review. There can be important differences between the submitted version and the official published version of record. People interested in the research are advised to contact the author for the final version of the publication, or visit the DOI to the publisher's website.

- The final author version and the galley proof are versions of the publication after peer review.

- The final published version features the final layout of the paper including the volume, issue and page numbers.

Link to publication

\footnotetext{
General rights rights.

- You may freely distribute the URL identifying the publication in the public portal. please follow below link for the End User Agreement:

www.umlib.nl/taverne-license

Take down policy

If you believe that this document breaches copyright please contact us at:

repository@maastrichtuniversity.nl

providing details and we will investigate your claim.
}

Copyright and moral rights for the publications made accessible in the public portal are retained by the authors and/or other copyright owners and it is a condition of accessing publications that users recognise and abide by the legal requirements associated with these

- Users may download and print one copy of any publication from the public portal for the purpose of private study or research.

- You may not further distribute the material or use it for any profit-making activity or commercial gain

If the publication is distributed under the terms of Article $25 \mathrm{fa}$ of the Dutch Copyright Act, indicated by the "Taverne" license above, 


\section{Advancing the implementation of evidence in public health systems in Europe and globally: a model interlinking targets, actors, knowledge transfer, barriers and facilitators}


The research for this dissertation was performed at the Department of International Health within the School for Public Health and Primary Care (CAPHIR), Faculty of Health, Medicine and Life Sciences, Maastricht University.

Dissertation: Advancing the implementation of evidence in public health systems in Europe and globally: a model interlinking targets, actors, knowledge transfer, barriers and facilitators

Author: Joanne Adrienne Vincenten

Cover design: Adobe Stock Photo

(C) Joanne Adrienne Vincenten, 2020

All rights reserved. No part of this publication may be reproduced without permission of the copywrite owner.

ISBN: 978-94-6380-947-4

Layout and printing by: ProefschriftMaken || www.proefschriftmaken.nl 


\section{Advancing the implementation of evidence in public health systems in Europe and globally: a model interlinking targets, actors, knowledge transfer, barriers and facilitators}

Dissertation

To obtain the degree of Doctor at the Maastricht University, on the authority of the Rector Magnificus Prof. dr. Rianne Letschert, in accordance with the decision of the Board of Deans to be defended in public on Wednesday September 23, 2020 at 10:00 hours

by Joanne Adrienne Vincenten 


\section{Supervisor:}

Prof. dr. Helmut Brand

\section{Co-supervisor:}

Dr. Peter Schröder-Bäck

\section{Assessment Committee:}

Prof. dr. Silvia Evers, Chair

Prof. dr. José María Martín-Moreno, University of Valencia, Spain

Prof. dr. Milena Pavlova

Dr. Katarzyna Czabanowska

Dr. Odile Mekel, NRW Centre for Health, Bocum, Germany 


\section{Table of Contents}

Summary

Chapter - 1

Introduction

Chapter - 2

Structure and process components needed for evidence implementation in public health systems

Chapter - 3

Role of key stakeholders involved in evidence implementation in public health systems

Chapter -4

Knowledge transfer to support evidence implementation in public health systems

Chapter - 5

Barriers and facilitators to evidence implementation in public health systems

Chapter - 6

General Discussion and Conclusion

Chapter - 7

Valorisation

Acknowledgements

Curriculum Vitae

Joanne Adrienne Vincenten 
Summary

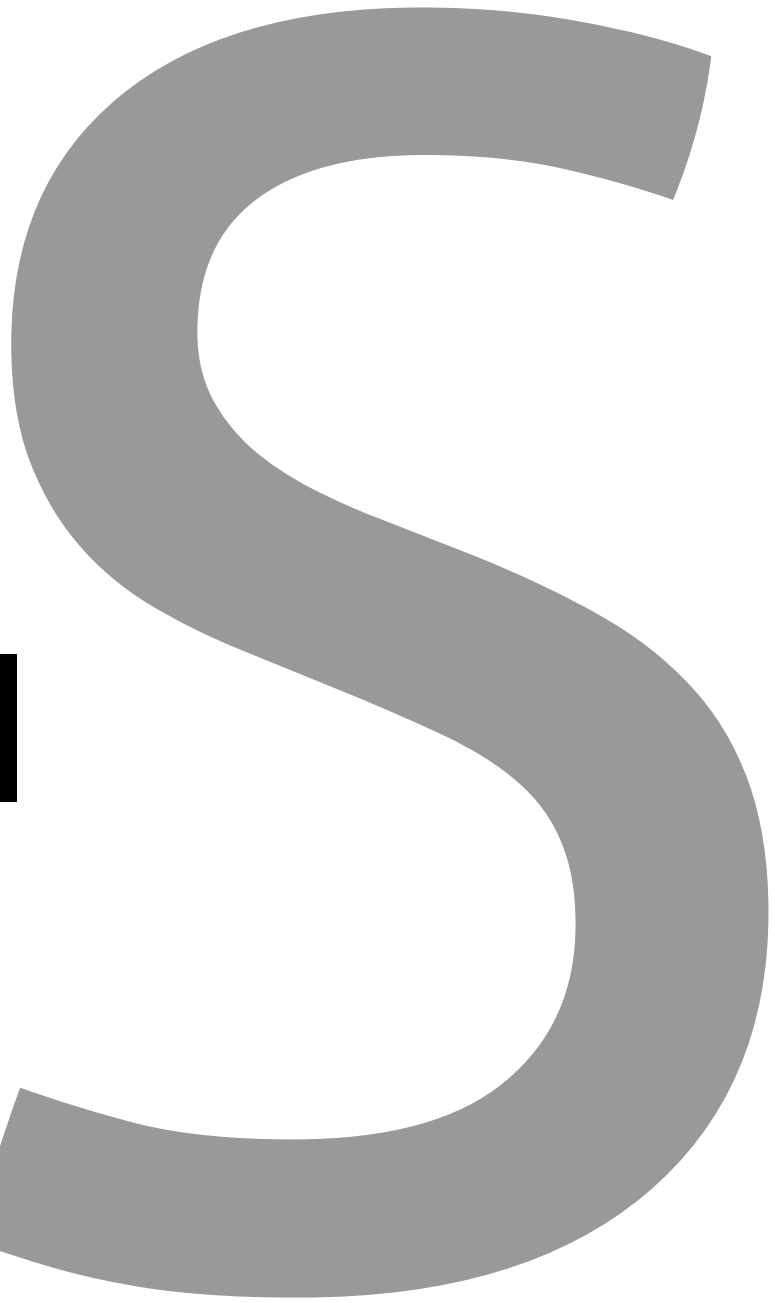


Summary 
Implementing evidence-based public health interventions supports the improved health and wellbeing of communities, countries and regions. Effective and efficient implementation of evidence will reduce duplication, foster innovation, move more knowledge into practice and increase the transfer of lessons learned, as well as the process of scaling up. Unfortunately, existence of evidence-based public health interventions alone is often not convincing enough to ensure their implementation within the complexity of public health systems. This is because public health entails multi-layered actions in cross-sectoral domains and interdependent processes that interlink. A number of models and theories exist to support evidence implementation within public health systems, however, gaps remain that impact the effectiveness and efficiency of uptake. These include the use of simplistic models, unclear or no measurable targets, limited engagement of diverse actors and sectors, non-tested knowledge translation processes and undefined determinants of barriers and use of facilitators to evidence implementation. Therefore, the aim of this thesis was to determine the key components, conditions and factors relevant to advance the knowledge base for the implementation of evidence in public health systems.

The research approaches in this thesis included qualitative studies using critical review and mixed method studies that were both qualitative and explorative. The following four research areas of focus were investigated.

1. To determine what key components, factors and concepts have an influence on the evidence implementation process within public health systems that need to be better understood.

2. To determine the roles and responsibilities of key stakeholders involved in evidence implementation, and how these actors influence setting targets and priorities for improving the use of evidence.

3. To determine the role policy can have to support knowledge transfer in existing evidence-based interventions.

4. To determine which barriers and facilitators impact the implementation of evidencebased interventions.

Through the investigations of this thesis, a model was created composed of four concepts: evidence implementation target; actors involved; knowledge transfer; and barriers and 
facilitators to evidence implementation. These concepts were identified through a critical review of published and grey literature, combined with an analysis of 32 case studies of injury prevention good practice interventions from 24 European countries to build the model. The broad framework of the model highlights multiple factors and interlinkages, within and between the concepts that influence the uptake of evidence into public health systems policy and practice. The model proposes to move this field of study beyond simplistic linear models while providing "how-to" support for evidence implementation in complex public health systems.

Setting targets and priorities can differ by actor depending on the knowledge level, professional background and stakeholder type. Factors influencing priority identification and targets at the national level include international and global context, information available, knowledge of the current situation and evidence-based good practice, and risks and priorities identified through national assessments. In the case example of chemicals management in the World Health Organization (WHO) European Region, early, active, and respectful sustained engagement of diverse actors, sectors and key stakeholders was determined to be a requirement to understand actors' views and values, which influence the setting of targets and priorities. Further, active engagement was reported to support enhancement of actors knowledge, capacity, leadership and commitment for effective evidence implementation. Achievement of effective evidence implementation also requires the participation of diverse actors, which includes the engagement of knowledge brokers and practitioners to support local implementation, in addition to the collaboration of researchers and decision makers.

Throughout the knowledge transfer process, comprehensive understanding and application of the who, what, where, when, why and how of evidence-based interventions is essential to ensure action moves from theory to practice. Knowledge transfer includes stages in a recursive process that have no set start or ending, but rather stages that are continually examined and addressed while moving back and forth between each of the stages: 1) identifying and assessing the problem, 2) gathering, analysing and synthesising evidence, 3) using evidence and 4) assessing evidence uptake. Knowledge transfer can be influenced by actors, key stakeholders and/or barriers at any point in the proccess. Policy can have a very influential role in supporting knowledge transfer. Policy sets the groundwork upon which 
actions will take place, serving as a key component to how we conduct ourselves in daily life. In the case example of global drowning prevention and water safety, evidence-based policies and legislation should provide "practical wisdom" to guide governments, individuals and communities towards positive outcomes. Public health and water safety advocates can use policy and legislation as powerful tools in conjunction with engineering and education to build and maintain safe and enjoyable environments for all. Thus, introducing policies for evidencebased good practice interventions should be investigated to determine their level of success in specific locations and settings to support knowledge transfer and evidence implementation.

Clear identification of barriers to evidence implementation require strategic and innovative thoughts and actions in order to transfer these barriers into facilitators throughout the entire evidence implementation process. Therefore, it is critical to identify barriers that impact the uptake of policies and programmes of evidence-based interventions and standardise and harmonise the ways these are addressed in the form of facilitators. These facilitators reduce barriers and can be used to advance achievement of evidence-based policy development and comprehensive diverse actions. In the case example of the elimination of asbestos related diseases in the WHO European Region, barriers identified by key stakeholders included: business, economic, and political interests; lack of leadership and commitment; gaps in data; and insufficient support and funding for the transition from asbestos to safe alternatives. In the case of asbestos, completion and maintenance of national profiles and the development, implementation, and monitoring of a National Program for the Elimination of AsbestosRelated Diseases, including time bound, measurable targets in each country are essential to effectively address barriers and serve as facilitators for a strategic approach to addressing asbestos-related diseases in Europe.

Further suggestions are provided in the thesis for a number of advancing conditions that could occur in societies to support the advancement of the knowledge base for the implementation of evidence in public health systems. These include good governance, context setting, investment in public health, and the use of multisectoral approaches. First, inclusive, accountable, transparent and equitable actions of those governing will enhance environments for successful evidence implementation. Second, it must also be understood that even though an evidence-based intervention has be proven to work, it may not be 
successfully taken up if the intervention is not adequately adapted to the context and setting of the community, country or region it is intended for. Third, commitment to invest in public health at all levels of information and operation is required by leaders and decision makers. This investment is needed to maintain and improve country knowledge, capacity and quality, including the ability to bring evidence-based interventions and innovations more rapidly to scale in a sustainable manner. Fourth, all this work needs to occur collectively, beyond the traditional silos of sectors, by using a multisectoral approach to gain broader information and a wider scope of operation. This approach will foster and support innovation across the stages of planning, implementation, evaluation, sustainability and scalability throughout the overall process of evidence implementation.

In conclusion, public health systems would greatly benefit from increased uptake of evidencebased interventions in Europe and globally. Evidence implementation provides guidance to support such action and this thesis research recommends interlinking the key factors and components of targets, actors, knowledge transfer, barriers and facilitators to drive successul implementation forward. To date the Evidence Implementation Model for Public Health Systems and the related main findings of this thesis have been applied for use to support WHO studies and policy maker workshops, Master thesis preparations at Maastricht University and recommendations for the Ostrava Declaration of the Sixth Ministerial Conference on Environment and Health in the WHO European Region. The work undertaken in this thesis has advanced the knowledge base for the implementation of evidence in public health systems. 


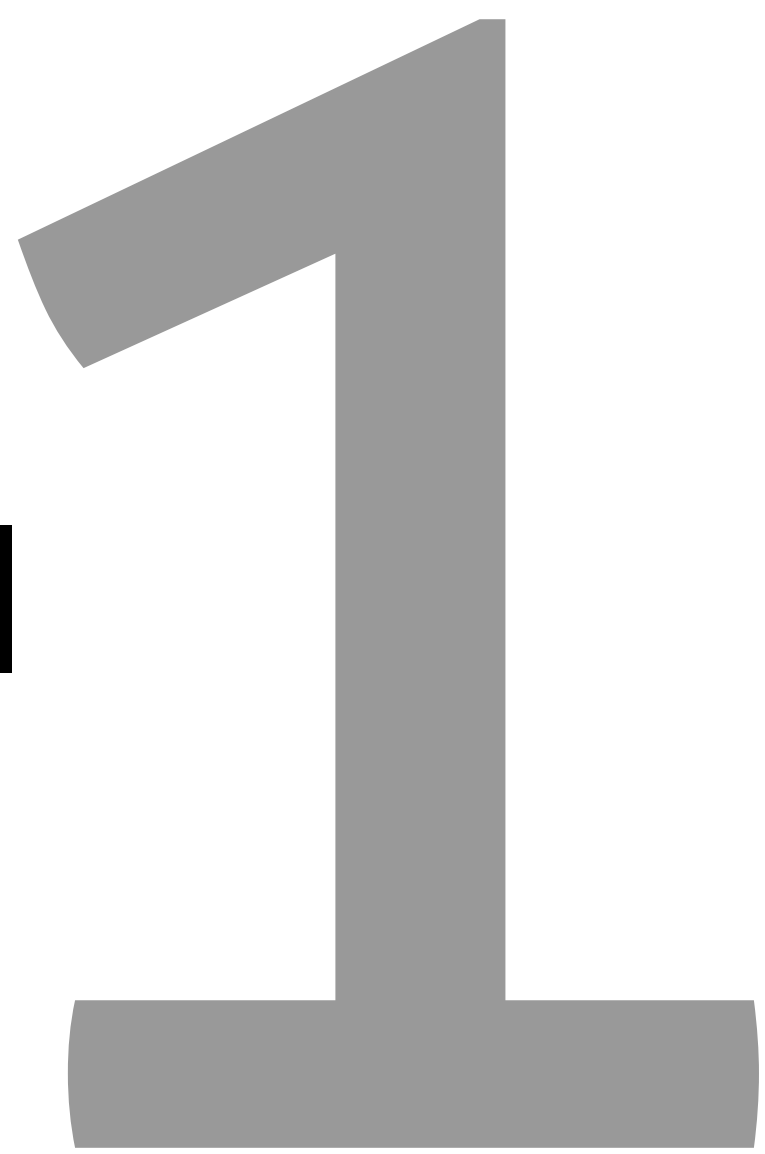


Introduction 


\subsection{Background}

"No democracy is complete without access to transparent and reliable information. It is the cornerstone for building fair and impartial institutions, holding leaders accountable and speaking truth to power." UN Secretary General Antonio Guterres, 2019[1]

Societies will only be able to continue to exist, flourish and truly be sustainable when their populations are healthy.[2] A critical component to achieving and maintaining health in societies is the availability and use of transparent and reliable information, such as evidence within public health initiatives. Public health is defined by the World Health Organization (WHO) as "the art and science of preventing disease, prolonging life and promoting health through the organized efforts of society."[3] These efforts aim to strengthen public health capacities, so people and communities can maintain and improve their health and wellbeing or prevent their health from deteriorating. This includes advocating for healthy lifestyles and promoting healthcare quality, equity and accessibility; researching and addressing disease and injury prevention; and detecting, preventing and responding to infectious and noncommunicable diseases.[4]

Overall, the focus of public health is to protect the health of entire populations. Such populations may be residential communities, countries, or even regions within the world. Public health systems refer to the organization of people, intuitions and resources that deliver public health services to meet the health needs of the target population.[4] The role public health plays within societies has been paramount to combat and address numerous health issues over the centuries.[5] Public health actions affect people and communities every day in every part of the world.[6] We only need to reflect on the current impact of the coronavirus disease 2019 (COVID-19) pandemic, touching not only the health of the world's population, but also every society's level of wellbeing, safety and security. $[7,8]$

When proven public health interventions based on evidence, are effectively implemented, there are multiple benefits to individuals and societies.[9] Public health plays a major contribution in the fight against some of the largest killers humans face in the world, providing a preventative role which in many cases is far more effective and far less expensive than a 
cure.[10] This includes prolonging more years in good health, detecting health issues early and responding with appropriate actions for the whole population, not only individuals. In doing so, public health aims to ensure everyone is aware of health hazards, supports continuous building of new knowledge and skills for healthy and sustainable living. Health is also a human right and public health works to reduce inequality and promote equity.[11,12]

Based on the multiple benefits of public health, implementation of what has been demonstrated to work in this field should in principle improve the overall health and wellbeing of society.[13] However, the existence of evidence-based public health interventions alone does not seem to be convincing or compelling enough to have decision makers put evidence into practice.[14-17] Recent work by Fahard and Hoffman have indicated that a more holistic view is needed for the decision-making process, where evidence is only one of many factors of consideration.[18] Several authors have also recognized that improving public health outcomes through successful uptake of evidence-based interventions is not a simple or quick task.[14,16,19-22] This is in large part because public health systems are complex.[19,23-27] They entail multi-layered actions in cross-sectoral domains and interdependent processes that interlink. In 2017, a Lancet publication called for a complex systems model of evidence for public health in order to move away from the linear models of cause and effect used for clinical interventions.[23] Addressing complexity within public health creates challenges, such as framing key questions appropriately, identifying relevant types of evidence, synthesizing both qualitative and quantitative evidence, determining the applicability of studies to varied contexts and forming meaningful recommendations.[28-33] Furthermore, recently published results from Hayes and colleagues in 2020 indicated that systems thinking to address complex public health issues should be put into action as joint work of decision makers and researchers to create impacts on policy processes.[34] Thus, the complexity of public health systems requires more diverse actions beyond a single intervention, to include multiple components, conditions and factors that are interlinked in order to effectively take up evidence.[19-21,26,27,35,36] 
Therefore, the thesis aimed to determine the key components, conditions and factors relevant to advance the knowledge base for the implementation of evidence in public health systems.

The thesis' four areas of interest in the implementation of evidence within public health systems were:

1) Structural and process components to support evidence implementation;

2) Key stakeholders involved in evidence implementation and impacts on target setting;

3) Knowledge transfer to support evidence implementation; and

4) Barriers and facilitators to evidence implementation.

\subsection{Potential gaps within the thesis' four areas of focus}

Upon investigation of the four areas of interest noted above, a number of potential gaps to evidence implementation in public health have been identified and described as follows:

1. Structural and process components to support evidence implementation in public health systems gaps requiring further investigation.

Although at present there is an abundant number of theories, models and frameworks on the theme of knowledge translation/transfer and implementation science, several issues and gaps still remain on this theme and require further investigation. Gentry states translating research into policy is difficult because many literature and policy documents continue to focus on the use of overly simplistic linear and cyclical models of research impact, despite improved conceptualization from social and political science.[37,38] Also, most frameworks provide limited "how-to" support for carrying out implementation endeavours since the determinants are usually too generic to provide sufficient detail for guiding an implementation process.[20] Furthermore, knowledge translation approaches in public health policy are rarely designed for the complex political realities of policy making, including diffused decision-making, institutional hierarchies and policy networks, and multiple inputs and types of evidence that are part of policy-making.[18] Damschroder recently states that 
well-designed frameworks support needed structure and a common language to move evidence implementation forward.[39] Furthermore, a review of components found in most models do not include or detail the need to set targets, define actors to be involved, and facilitators to support best practice implementation.[40,41]

2. Actors and key stakeholders involved in evidence implementation and impacts on target setting in public health systems gaps requiring further investigation.

Despite most researchers indicating that engagement of actors and key stakeholders is an important component to the implementation of evidence [42-45], a number of points still require further investigation. Practitioners and communities are often not fully integrated as partners within the process of implementing public heath interventions, which increases the research to practice gap.[46] There is also a need to understand more about the leadership priorities, values, preferences and perspectives of diverse actors and key stakeholders engaged in the process of evidence implementation and how this can impact setting targets and priorities.[46] As well, other key actors need to be included in the evidence implementation process besides researchers and decision makers, such as knowledge brokers and practitioners. $[47,48]$

3. Knowledge transfer to support evidence implementation in public health systems gaps requiring further investigation.

While a large selection of knowledge translation and implementation science models are available for choice to support the implementation of public health interventions, this may not necessarily be useful. Authors have noted that the development of the fields of knowledge translation and implementation science has been hindered by the proliferation of theories, models and frameworks, for implementation, transfer and improvement without testing, refinement and integration.[49,50] Researchers have stated that there are few full spectrum theories, models and frameworks with all four knowledge translation phases: 1) planning/design, 2) implementation, 3) evaluation and 4) sustainability and scalability, which are considered important for users when implementing knowledge translation projects or interventions. [49] 
4. Barriers and facilitators to evidence implementation in public health systems gaps requiring further investigation.

While the relevance of addressing barriers and enablers to translating research into practice is mentioned in many process models, these do not identify or systematically structure specific determinants associated with implementation success.[20] Further, many models focus on barriers, but they do not adequately go beyond these to address appropriate enablers to serve as facilitators to the process or create solutions to counter such barriers.[20,51-55]

These identified gaps requiring further investigation have been considered within the thesis chapters 2 through 5 and examined further within the general discussion of this thesis. 


\section{Box 1 - Terms used in this thesis}

In public health a number of terms are repetitively used within the literature and field examining the area of evidence and its uptake but are done so with inconsistent definitions.[49] To address this gap and set a clear context, relevant common terms are provided to set a frame of reference for this thesis.

Evidence: In the broadest sense, evidence can be defined as facts or testimony in support of a conclusion, statement or belief and something serving as proof.[56]

Evidence-based public health: Evidence-based approaches to address health problems are recognized as best practice.[57] Evidence based public health can be defined as a public health endeavour in which there is an informed, explicit, and judicious use of evidence that has been derived from any of a variety of science and social science research and evaluation methods.[58]

Evidence-informed public health: The process of distilling and disseminating the best available evidence from research, context and experience, and using that evidence to inform and improve public health practice and policy. Put simply, it means finding, using, and sharing what works in public health.[59,60]

Knowledge translation/transfer of evidence: These terms are used interchangeably [49] and have been defined as the synthesis, exchange, and application of knowledge by relevant stakeholders to accelerate the benefits of global and local innovation in strengthening health systems and improving people's health.[61]

Implementation science: The scientific study of methods to promote the systematic uptake of research findings and other evidence-based practices into routine practice, and, hence, to improve the quality and effectiveness of health services.[62] Where knowledge translation differs from implementation science is that it does not cover how to implement knowledge.[63] Implementation research requires trans-disciplinary research teams that include members who are not routinely part of most health services research.

Public health intervention: An initiative that is applied to many, most, or all members in a community, with the aim of delivering a net benefit to the community or population, as well as benefits to individuals. Public health interventions include policies of governments and non-government organisations; laws and regulations; organisational development; community development; education of individuals and communities; engineering and technical developments; service development and delivery; and communication, including social marketing. [64] 


\subsection{Structure of the thesis, research aim and methodological approaches}

The overall aim of this thesis was to find the ways and means to maximise the implementation of evidence-based public health interventions to provide greater health and wellbeing to communities and societies as a whole. The thesis chapters and details of the research aims, purpose of investigation and methods used are described in the following thesis outline and summarised in Table 1 below.

\section{Thesis outline}

\section{Chapter 1 - Introduction}

Chapter 2 - Structure and process components needed for evidence implementation in public health systems

Research question: What key components, factors and concepts have an influence on the evidence implementation process within public health systems that need to be better understood?

Overall, this investigation was undertaken to understand the factors and concepts, and the interlinking of these concepts, that influence the implementation of evidence within public health systems. The method used was a literature review that was conducted to explore factors that influence the process of evidence implementation in complex public health systems. Concepts and themes were identified through a critical review, were organised, ordered and then interlinked to build the model. We wanted to do this investigation to create a model or framework that would support or even accelerate awareness, knowledge and uptake of evidence-based interventions into real world public health systems. 
Chapter 3 - Role of key stakeholders involved in evidence implementation in public health systems

Research question: What are the roles and responsibilities of key stakeholders involved, and how do these influence setting priorities and targets for improving chemicals management in the WHO European Region?

In this chapter, a specific case of chemicals management was investigated to understand if diverse stakeholders had different perspectives of evidence implementation on: 1) Priority issues to be addressed; 2) Roles and responsibilities of various stakeholders; and 3) How science and knowledge of chemicals can be translated into policies more effectively on chemical safety management, and which barriers were the greatest to overcome within the WHO European Region. The method used was semi-structured interviews undertaken with diverse stakeholders to determine their views within the WHO European Region for improving chemicals management and prevention. The interview questionnaire was developed using current WHO chemical meeting reports, the Evidence Implementation Model for Public Health Systems [19] and categories of the theory of diffusion.[43] This study was performed to further investigate and understand the role that diverse stakeholders and actors have to influence: priorities and target selection, actors' responsibilities for action and needed policy strategies to improve chemical safety management, as well as the broader role key stakeholders have to evidence implementation in public health systems.

\section{Chapter 4 - Knowledge transfer to support evidence implementation in public health systems}

Research question: What role can policy have to support knowledge transfer in existing evidence-based drowning prevention interventions?

Within this chapter the key components, conditions and factors relevant to knowledge transfer to support evidence implementation in public health systems was investigated. The study examined what evidence-based drowning prevention interventions existed and 
determined how polices and legislation could be applied to each intervention to further support drowning prevention measures globally. The method utilised consisted of collection and review of all evidence-based drowning prevention interventions as recognised by the World Health Organization and the International Life Saving Federation. Each intervention was then examined to apply policy and legislation actions related to the components of knowledge transfer cycle, identified within the Evidence Implementation Model for Public Health Systems including: 1) Identifying and assessing the problem; 2) Gathering and synthesising evidence; 3) Using evidence; and 4) Assessing evidence uptake. Further analysis was undertaken on all proposed policy and legislative actions to support drowning prevention and prepared global research and practice recommendations to advance and sustain water safety and drowning prevention policies. This investigation was undertaken in order to attempt to use the process of knowledge transfer to support and advocate the use of policies and legislations for evidence-based drowning prevention interventions globally.

\section{Chapter 5 - Barriers and facilitators to evidence implementation in public health systems}

Research question: What barriers and facilitators impact the implementation of evidencebased interventions to reduce and eliminate the harm caused by asbestos in the WHO European Region?

In this chapter, the aim was to gain greater understanding of which barriers and facilitators impact the implementation of evidence-based interventions. The study undertaken was to determine the specific type of barriers that impact evidence implementation to eliminate and reduce harm from asbestos and determine how these barriers can be transformed throughout the evidence implementation process into facilitators and solutions. The method used was qualitative and explorative, combining interviews and discussions with key stakeholders from the WHO European Region. The questionnaire for the semi-structured interviews was developed based on information from current Asbestos Related Disease WHO Reports and the Evidence Implementation Model for Public Health Systems [19] that offered insights into the barriers and facilitators for uptake of effective strategies. Furthermore, categories of the theory of diffusion were taken into account in formulating the interview questions. This investigation was conducted because despite the sound scientific knowledge 
and evidence that any exposure to asbestos fibers in all of its forms are carcinogenic to humans, their presence, use and trade is still substantial globally, including in the WHO European Region. Therefore, we wanted to gain greater understanding and knowledge of what specific barriers existed to the adoption, implementation and enforcement of evidencebased strategies in order to eliminate and reduce harm from asbestos within the WHO European Region.

\section{Chapter 6 - General Discussion and Conclusion}

In the general discussion the results of the conducted research from chapters 2-5 are summarised. The results are used for a deduction of key results for: a model for evidence implementation (Chapter 2), the role of key actors involved in evidence implementation and impacts on target setting (Chapter 3), the understanding of knowledge transfer to support evidence implementation (Chapter 4), and the identification of relevant barriers to be turned to facilitators for evidence implementation (Chapter 5). This is followed by a discourse (Chapter 6) sharing how this research addresses the value and complexities of evidence implementation, examples of current policy and programme actions supporting the thesis main findings, and suggested conditions that could support the advancement of the knowledge base for the implementation of evidence in public health systems in Europe and globally.

\section{Chapter 7 - Valorisation}

The valorisation describes actions taken to share and discuss the results of this thesis with researchers, decision makers, knowledge brokers, practitioners and the general public related to evidence implementation in public health systems. These actions include awareness raising, knowledge enhancement and advocacy of evidence implementation through journal publications, national and global reports, ministerial declarations, national resolutions, conference presentations, website postings, and policy-makers' workshop sessions. 
Table 1 - Four areas of thesis focus and associated research questions and methods

Main thesis question: What are the key components, conditions and factors relevant to advance the knowledge based for the implementation of evidence in public health systems in Europe and globally?

\begin{tabular}{|c|c|c|c|c|}
\hline $\begin{array}{l}\text { Thesis four areas } \\
\text { of focus }\end{array}$ & $\begin{array}{l}\text { Model/Framework } \\
\text { Chapter } 2\end{array}$ & $\begin{array}{l}\text { Actors/Targets } \\
\text { Chapter } 3\end{array}$ & $\begin{array}{l}\text { Knowledge } \\
\text { Transfer } \\
\text { Chapter } 4\end{array}$ & $\begin{array}{l}\text { Barriers/Facilitators } \\
\text { Chapter } 5\end{array}$ \\
\hline $\begin{array}{l}\text { Chapter titles of } \\
\text { the four focus } \\
\text { areas }\end{array}$ & $\begin{array}{l}\text { Structure and } \\
\text { process } \\
\text { components } \\
\text { needed for } \\
\text { evidence } \\
\text { implementation in } \\
\text { public health } \\
\text { systems }\end{array}$ & $\begin{array}{l}\text { Role of key } \\
\text { stakeholders } \\
\text { involved in } \\
\text { evidence } \\
\text { implementation } \\
\text { in public health } \\
\text { systems }\end{array}$ & $\begin{array}{l}\text { Knowledge transfer } \\
\text { to support } \\
\text { evidence } \\
\text { implementation in } \\
\text { public health } \\
\text { systems }\end{array}$ & $\begin{array}{l}\text { Barriers and } \\
\text { facilitators to } \\
\text { evidence } \\
\text { implementation in } \\
\text { public health } \\
\text { systems }\end{array}$ \\
\hline $\begin{array}{l}\text { Chapter } \\
\text { publication } \\
\text { titles }\end{array}$ & $\begin{array}{l}\text { Factors influencing } \\
\text { implementation of } \\
\text { evidence-based } \\
\text { interventions in } \\
\text { public health } \\
\text { systems - a model }\end{array}$ & $\begin{array}{l}\text { Priorities for } \\
\text { improving } \\
\text { chemicals } \\
\text { management in } \\
\text { the WHO } \\
\text { European Region } \\
\text { - Stakeholders' } \\
\text { views }\end{array}$ & $\begin{array}{l}\text { The role of policy in } \\
\text { prevention }\end{array}$ & $\begin{array}{l}\text { Barriers and } \\
\text { facilitators to the } \\
\text { elimination of } \\
\text { asbestos related } \\
\text { diseases - } \\
\text { stakeholders' } \\
\text { perspectives }\end{array}$ \\
\hline $\begin{array}{l}\text { Research } \\
\text { questions }\end{array}$ & $\begin{array}{l}\text { What key } \\
\text { components, } \\
\text { factors and } \\
\text { concepts have an } \\
\text { influence on the } \\
\text { evidence } \\
\text { implementation } \\
\text { process within } \\
\text { public health } \\
\text { systems that need } \\
\text { to be better } \\
\text { understood? }\end{array}$ & $\begin{array}{l}\text { What are the } \\
\text { roles and } \\
\text { responsibilities of } \\
\text { key stakeholders } \\
\text { involved, and } \\
\text { how do these } \\
\text { influence setting } \\
\text { priorities and } \\
\text { targets for } \\
\text { improving } \\
\text { chemicals } \\
\text { management in } \\
\text { the WHO } \\
\text { European } \\
\text { Region? }\end{array}$ & $\begin{array}{l}\text { What role can } \\
\text { policy have to } \\
\text { support knowledge } \\
\text { transfer in existing } \\
\text { evidence-based } \\
\text { drowning } \\
\text { prevention } \\
\text { interventions? }\end{array}$ & $\begin{array}{l}\text { What barriers and } \\
\text { facilitators impact } \\
\text { the implementation } \\
\text { of evidence-based } \\
\text { interventions to } \\
\text { reduce and } \\
\text { eliminate the harm } \\
\text { caused by asbestos } \\
\text { in the WHO } \\
\text { European Region? }\end{array}$ \\
\hline Methods used & $\begin{array}{l}\text { Qualitative study - } \\
\text { critical review }\end{array}$ & $\begin{array}{l}\text { Mixed method } \\
\text { study - } \\
\text { qualitative and } \\
\text { explorative }\end{array}$ & $\begin{array}{l}\text { Qualitative study - } \\
\text { critical review }\end{array}$ & $\begin{array}{l}\text { Mixed method } \\
\text { study - qualitative } \\
\text { and explorative }\end{array}$ \\
\hline
\end{tabular}




\section{References}

1. United Nations [Internet]. New York, United States of America: United Nations; 2015. Secretarygeneral's message on World Press Freedom Day [updated 2019 May 3; cited 2020 May 26]. Available from: https://www.un.org/sg/en/content/sg/statement/2019-05-03/secretarygenerals-message-world-press-freedom-day-scroll-down-for-french-version]

2. United Nations [Internet]. New York, United States of America: United Nations; 2015. Transforming Our World: the 2030 Agenda for Sustainable Development. [updated 2019 May 3; cited 2020 May 24]. Available from: https://www.un.org/sustainabledevelopment /sustainabledevelopment-goals/

3. World Health Organization. Health 21: The health for all policy framework for the WHO European Region, European Health for All Series. Copenhagen, Denmark: World Health Organization Regional Office for Europe; 1988. 224 p. Report No.: 6.

4. Centers for Disease Control and Prevention (CDC). Atlanta, GA: U.S. Department of Health and Human Services, CDC; 2014. Introduction to Public Health, Public Health 101 Series. [updated 2018 November 15; cited 2020 May 3] Available from: https://www.cdc.gov/publichealth101/public-health.html

5. Chave SP. The origins and development of public health. In: Holland WW, Detels R, Knox G, editors. Oxford Textbook of Public Health, Vol. 1: History, Determinants, Scope, and Strategies. New York: Oxford University Press; 1984. p.3-19.

6. Winslow CE. The untilled fields of public health. Science. 1920;51(1306):23-33. DOI: 10.1126/science.51.1306.23

7. Abrams EA, Szefler S. COVID-19 and the impact of social determinant of health. The Lancet, Respiratory Medicine. 2020 May 18 [cited 2020 May 10]:1-2. Available from: https://www.thelancet.com/journals/lanres/article/PIIS2213-2600(20)30234-4/fulltext DOI: 10.1016/S2213-2600(20)30234-4

8. International Labour Organization (ILO). A policy framework for tackling the economic and social impact of the COVID-19 crisis, Policy Brief. Geneva, Switzerland: ILO; 2020. p 17.

9. Verrecchia R, Thompson R, Yates R. Universal health coverage and public health: a truly sustainable approach. Lancet Public Health. 2019;4(1):E10-E11. DOI: 10.1016/ S24682667(18)30264-0

10. Heyman DL, Dar OA. Prevention is better than cure for emerging infectious diseases. BMJ. 2014; 348:g1499. DOI: 10.1136/bmj.g1499 
11. World Health Organization [Internet]. Geneva, Switzerland: WHO; 2017. Health is a fundamental human right. Statement by Dr Tedros Adhanom Ghebreyesus, WHO Director-General; 2017 Dec 10 [cited 2020 May 12]; [Human Rights Day 2017]. Available from: https://www.who.int/mediacentre/news/statements/fundamental-human-right/en/

12. Hancock T, McLaren L. Why public health matters today. Can J Public Health. 2019; 110:259-263. DOI: 10.17269/s41997-019-00220-5

13. Campos-Matos I, Stannard J, de Sousa E, O'Connor R, Newton JN. From health for all to leaving no-one behind: public health agencies inclusion health, and health inequalities. Lancet Public Health. 2019;4(12):E601-603. DOI: 10.1016/S2468-2667(19)30227-0

14. Orton L, Lloyd-Williams F, Taylor-Robinson D, O'Flaherty M, Capewell S. The use of research evidence in public health decision making processes: Systematic review. PLoS One. 2011;6(7):e21704. DOI: 10.1371/journal.pone.0021704

15. Kneale D, Rojas-García A, Thomas, J. Obstacles and opportunities to using research evidence in local public health decision-making in England. Health Res Policy Sys. 2019;17(61):1-11. DOI:10.1186/s12961-019-0446-x

16. Liverani M, Hawkins B, Parkhurst JO. Political and institutional influences on the use of evidence in public health policy. A systematic review. PLoS One. 2013;8(10):e77404. DOI: 10.1371/journal.pone.0077404

17. Oliver K, Lorenc T, Innvær S. New directions in evidence-based policy research: a critical analysis of the literature. Health Res Policy Systems. 2014;12(7):34-45. DOI: 10.1186/1478-4505-12-34

18. Fafard P, Hoffman SJ. Rethinking translation for public health policy. Evid Policy.2020;16(1):165175. DOI: 10.1332/174426418X15212871808802

19. Vincenten J, MacKay JM, Schröder-Bäck P, Schloemer T, Brand H. Factors influencing implementation of evidence-based interventions in public health systems-a model. Cent Eur J Public Health. 2019;27(3)198-203. DOI: 10.21101/cejph.a5234

20. Nilsen P. Making sense of implementation theories, models and frameworks. Implementation Sci. 2015;10:53. DOI: 10.1186/s13012-015-0242-0

21. Glasgow RE, Green LW, Taylor MV, Stange KC. An evidence integration triangle for aligning science with policy and practice. Am J Prev Med. 2012;42(6):646-654. DOI: 10.1016/j.amepre.2012.02.016

22. Head BW. Reconsidering evidence-based policy: Key issues and challenges. Policy Soc. 2010;29(2):77-94. DOI: 10.1016/j.polsoc.2010.03.001 
23. Rutter H, Savona N, Glonti K, Bibby J, Cummins S, Finegood DT, et al. The need for a complex systems model of evidence for public health. Lancet. 2017;390(10112):P2602-2604. DOI: 10.1016/S0140-

24. Holmes BJ, Best A, Davies $H$, Hunter D, Kelly MP, Marshall $M$, et al. Mobilising knowledge in complex health systems: a call to action. Evidence \& Policy. 2017;13(3):539-60. DOI: 10.1332/174426416X14712553750311

25. Rycroft J. From linear to complicated to complex; Comment on "Using complexity and network concepts to inform healthcare knowledge translation." Int J Health Policy Manag. 2018;7(6): 566568. DOI: 10.15171/IJHPM.2018.02

26. Kitson A, Brook A, Harvey G, et al. Using complexity and network concepts to inform healthcare knowledge translation. Int J Health Policy Manag. 2018;7(3):231-243. DOI: 10.15171/ijhpm.2017.79

27. Cairney P. Complexity theory in political science and public policy. Polit Stud Rev. 2012;10(3):34658. DOI: 10.1111/j.1478-9302.2012.00270.x

28. Norris SL, Rehfuess EA, Smith H, Tuncalp Ö, Grimshaw JM, Ford NP, et al. Complex health interventions in complex systems: improving the process and methods for evidence-informed health decisions. BMJ Glob Health. 2019;4:e000963. DOI: 10.1136/bmjgh-2018-000963

29. Petticrew M, Anderson L, Elder R, Grimshaw JM, Hopkins, Hahn R, et al. Complex interventions and their implications for systematic reviews: a pragmatic approach. J Clin Epidemiol. 2013;66(11):1209-14. DOI:10.1016/j.jclinepi.2013.06.004

30. Guise J, Chang C, Viswanathan M, Glick S, Treadwell J, Umscheid C, et al. Systematic reviews of complex multicomponent health care interventions. Research White Papers. Rockville, MD (USA): Agency for Healthcare Research and Quality; 2014. 24 p. Report No.: 14-EHC003-EF

31. Noyes J, Gough D, Lewin S, et al. A research and development agenda for systematic reviews that ask complex questions about complex interventions. J Clin Epidemiol. 2013;66:1262-70. DOI: 10.1016/j.jclinepi.2013.07.003

32. Anderson LM, Oliver SR, Michie S, Rehfuess EA, Noyes J, Shemilt I. Investigating complexity in systematic reviews of interventions by using a spectrum of methods. J Clin Epidemiol. 2013;66:1223-9. DOI: 10.1016/j.jclinepi.2013.06.014

33. Rehfuess EA, AkI EA. Current experience with applying the GRADE approach to public health interventions: an empirical study. BMC Public Health. 2013;13:9. DOI: 10.1186/1471-2458-13-9.

34. Haynes A, Garvey K, Davidson S, Milat A. What Can Policy-Makers Get Out of Systems Thinking? Policy Partners' Experiences of a Systems-Focused Research Collaboration in Preventive Health. Int J Health Policy Manag. 2020;9(2):65-76. DOI: 10.15171/ijhpm.2019.86 
35. Hanson D, Allegrante JP, Sleet DA, Finch CF. Research alone is not sufficient to prevent sport injuries. Br J Sports Med. 2014;48(8):682-684. DOI: 10.1136/bjsports-2012-091434

36. Best A, Holmes B. Systems thinking, knowledge and action: Towards better models and methods. Evidence \& Policy. 2010;6(2):145-159. DOI:10.1332/174426410X502284

37. Gentry S, Milden L, Kelly MP. Why is translating research into policy so hard? How theory can help public health researchers achieve impact? Public Health. 2020;178:90-96. DOI:10.1016/j.puhe.2019.09.009

38. Greenhalgh T, Fahy N. Research impact in the community-based health sciences: an analysis of 162 case studies from the 2014 UK Research Excellence Framework. BMC Med. 2015;13:232. DOI: $10.1186 / s 12916-015-0467-4$

39. Damschroder, LJ. Clarity out of chaos: Use of theory in implementation research. Psychiatry Research. 2020; 283:112461. DOI: 10.1016/j.psychres.2019.06.036.

40. Graham ID, Tetroe J, KT Theories Research Group. Some theoretical underpinnings of knowledge translation. Acad Emerg Med. 2007;14(11):936-941. DOI:10.1197/j.aem.2007.07.004

41. Tetroe J. A review of knowledge transfer conceptual frameworks and theories to facilitate best practice implementation [presentation on Internet]. Ottawa: University of Ottawa; 2015 [cited 2020 May 11]. Available from: https://www.yumpu.com/en/document/ view/30437847/areview-of-knowledge-transfer-conceptual-models-frameworks-

42. Damschroder LJ, Aron DC, Keith RE, Kirsh SR, Alexander JA, Lowery JC. Fostering implementation of health services research findings into practice: A consolidated framework for advancing implementation science. Implementation Sci. 2009;4(1):50-65. DOI: 10.1186/1748-5908-4-50

43. Greenhalgh T, Robert G, Macfarlane F, Bate P. Kyriakidou O. Diffusion of innovations in service organizations: Systematic review and recommendations. Milbank Q. 2004;82(4):581-629. DOI: 10.1111/j.0887-378X.2004.00325.x

44. Oliver K, Innvar S, Lorenc T, Woodman J, Thomas J. A systematic review of barriers to and facilitators of the use of evidence by policymakers. BMC Health Serv Res. 2014;14(1):2-14. DOI: $10.1186 / 1472-6963-14-2$

45. Lavis J, Moynihan R, Oxman A, Paulsen E. Evidence-informed health policy 4 - Case descriptions of organizations that support the use of research evidence. Implementation Sci. 2008;3(12): 1-9. DOI: $10.1186 / 1748-5908-3-56$

46. Smith LS, Wilkins NJ, McClure RJ. A systemic approach to achieving population-level impact in injury and violence prevention. Syst Res Behav Sci. 2020;10.1002/sres.2668. DOI: $10.1002 /$ sres. 2668 
47. Khalid AF, Lavis JN, El-Jardali F, Vanstone M. Supporting the use of research evidence in decisionmaking in crisis zones in low- and middle-income countries: a critical interpretive synthesis. Health Res Policy Sys. 2020;18(21):1-12. DOI: 10.1186/s12961-020-0530-2

48. Graham ID, McCutcheon C, Kothari A. Exploring the frontiers of research co-production: the Integrated Knowledge Translation Research Network concept papers. Health Res Policy Sys. 2019;17(88):1-4. DOI: 10.1186/s12961-019-0501-7

49. Esmail R, Hanson H, Holroyd-Leduc J. et al. A scoping review of full-spectrum knowledge translation theories, models, and frameworks. Implementation Sci. 2020:15(11):1-14. DOI: 10.1186/s13012-020-0964-5

50. Wensing $M$, Grol R. Knowledge translation in health: how implementation science could contribute more. BMC Med. 2019;17(88):1-14. DOI: 10.1186/s12916-019-1322-9

51. Moulin J, Sabater-Hernández D, Fernandez-Llimos F, Benrimoj S. A systematic review of implementation frameworks of innovations in healthcare and resulting generic implementation framework. Health Res Policy Sys. 2015;13(16): 1-11. DOI: 10.1186/s12961-015-0005-z.

52. Aarons GA, Hurlburt M, Horwitz SM. Advancing a conceptual model of evidence-based practice implementation in public service sectors. Adm Policy Ment Health. 2011;38(1): 4-23. DOI: 10.1007/s10488-010-0327-7

53. Grimshaw JM, Eccles MP, Lavis JN, Hill, SJ, Squires JE. Knowledge translation of research findings. Implementation Sci.2012;7(1):50-67. DOI: 10.1186/1748-5908-7-50

54. Field B, Booth A, Ilott I, Gerrish K. Using the knowledge to action framework in practice: a citation analysis and systematic review. Implementation Sci. 2014;9(172):1-14. DOI: 10.1186/s13012014-0172-2.

55. Ingold J, Monaghan M. Evidence translation: an exploration of policy makers' use of evidence. Policy \& Politics. 2016;44(2):171-90. DOI: 10.1332/147084414X13988707323088

56. Rychetnik L, Hawe $P$, Waters $E$, Barratt A, Frommer M. A glossary for evidence based public health. J Epi Comm Health. 2004;58(7):538-545. DOI:10.1136/jech.2003.011585

57. Rehfuess EA, Durão S, Kyamanywa P, Meerpohl J, Young T, Rohwer A. An approach for setting evidence-based and stakeholder-informed research priorities in low- and middle-income countries. Bull World Health Organ. 2016;94(4):297-305. DOI:10.2471/BLT.15.162966

58. Sackett DL, Rosenberg WM, Gray JA, Haynes RB, Richardson WS. Evidence based medicine: what it is and what it isn't. BMJ. 1996;312(7023):71-2. DOI: 10.1136/bmj.312.7023.71

59. Mackintosh J, Ciliska D, Tulloch K. Evidence-informed decision making in public health in action. Env Health Review. 2015;58(1):15-19. DOI: dx.doi.10.5864/d2015-006 
60. Brownson RC, Chriqui JF, Stamatakis KA. Understanding evidence-based public health policy. Am J Public Health. 2009;99(9):1576-1583. DOI:10.2105/AJPH.2008.156224

61. World Health Organization [Internet]. Knowledge Translation. Geneva: Switzerland; 2020 [updated 2020; cited 2020 May 27]. Available from: https://www.who.int/ageing/ projects/knowledge_translation/en/

62. Eccles MP, Mittman BS. Welcome to Implementation Science. Implementation Sci. 2006;1(1):1-3. DOI: $10.1186 / 1748-5908-1-1$

63. Khalil $\mathrm{H}$. Knowledge translation and implementation science: what is the difference? Int J Evid Based Healthc. 2016;14(2):39-40. DOI: 10.1097/XEB.0000000000000086

64. Frommer M, Rychetnik L. From evidence-based medicine to evidence-based public health. In: Lin V, Gibson B, editors. Evidence-based health policy; problems and possibilities. Melbourne: Oxford University Press; 2003. p. 65-89. 
CHAPTER 2

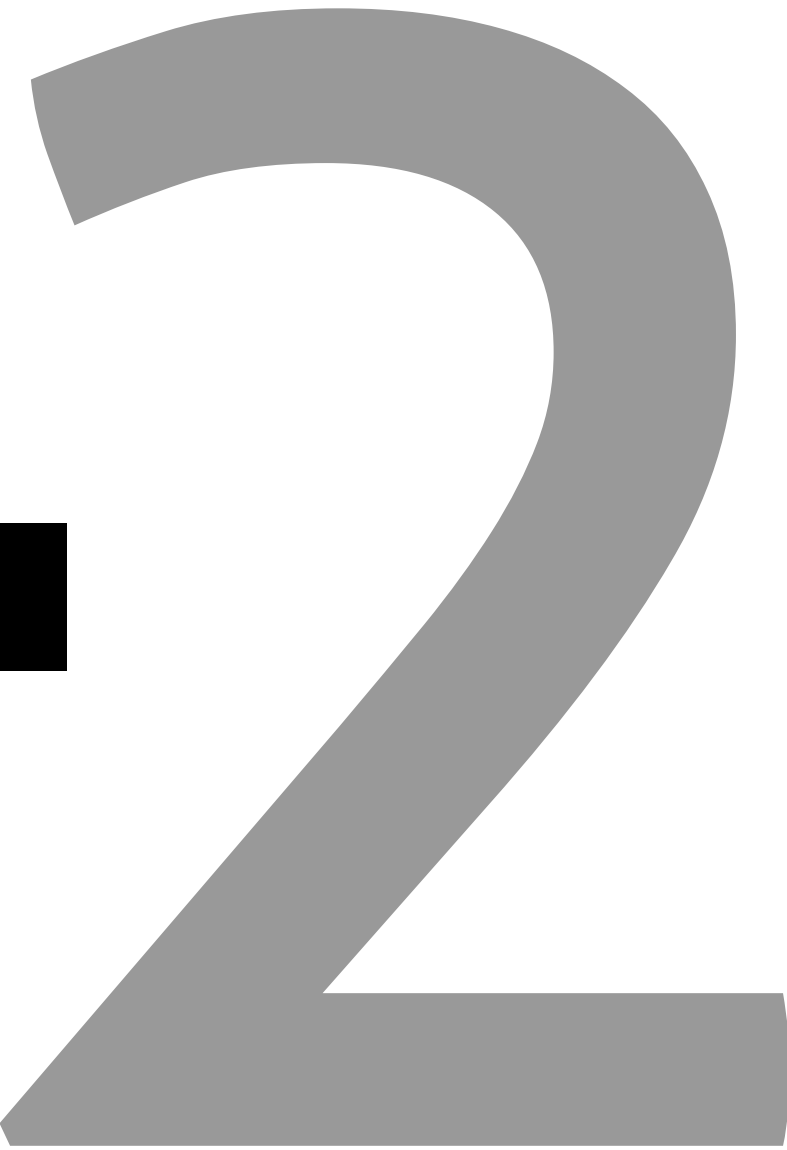




\section{Structure and process components needed for evidence implementation in public health systems}

Published in the Central European Journal of Public Health (IF 0.636)

Vincenten J, MacKay JM, Schröder-Bäck P, Schloemer T, Brand H.

Factors influencing implementation of evidence-based interventions in public health systems-a model. Cent Eur J Public Health 2019;27(3)198203. 


\begin{abstract}
Background: Evidence that health interventions work is not enough to ensure implementation into policy and practice. The complexity of public health systems requires more diverse actions.
\end{abstract}

Objectives: This paper proposes a conceptual model to enhance understanding of interlinking factors that influence the evidence implementation process.

Methods: A literature review was conducted to explore factors that influence the process of evidence implementation in complex public health systems, including research findings and observations from 32 case studies of injury prevention interventions underway in 24 countries and results from evidence research networks. Concepts and themes identified through a critical review were organised, ordered and interlinked to build the model.

Results: An Evidence Implementation Model for Public Health Systems and four concepts or themes: 1) Evidence implementation target; 2) Actors involved in implementation; 3) Knowledge transfer; and 4) Barriers and facilitators to evidence implementation were developed to provide a simplified, yet broad framework that highlights multiple factors and back and forth inter-linkages within and between the concepts that influence the uptake of evidence into public health systems policy and practice.

Conclusions: Understanding the factors discussed within and amongst the four concepts of this model should ultimately help to positively influence the uptake of evidence into real world public health systems. This model has relevance for decision makers, researchers, knowledge brokers and implementers. 


\section{Introduction}

Implementation of what has been demonstrated to work in public health should improve the health and wellbeing of society.[1-3] However, the existence of evidence-based public health strategies itself does not seem to be convincing or compelling enough to have decision makers put evidence into practice.[4-7] The complexity of public health systems requires more diverse actions.[7-12] In fact, several authors have reported barriers to achieving uptake of evidence within complex public health systems, including both policy and practice.[12-14] Others have indicated the need for research beyond identifying barriers and have suggested examination of broader concepts, such as setting targets, actors involved in implementation, and knowledge transfer and translation that influence the processes of evidence implementation within public health systems as a whole.[2,8,9,14-17] The conceptual model described in this paper, explores these broader factors and attempts to illustrate how they interlink and continually impact each other to influence the uptake of evidence into the development, implementation and monitoring of public health policies and practice. $[10,18,19]$

\section{Materials and Methods}

A critical review was conducted. This type of review aims to identify the contribution of concepts to embody existing knowledge or derive a new theory. A core characteristic of a critical review is conceptual innovation.[20] We used this methodology to explore the four concepts of 1) Evidence implementation target, 2) Actors involved in implementation, 3) Knowledge transfer, and 4) Barriers and facilitators that influence the process of evidence implementation in complex public health systems. This allowed us to understand, enrich and model these four concepts.

A key component of a critical review is to identify what is of value from the existing body of work.[20] To identify recent relevant literature from both general and specific sources, we searched PubMed and Google Scholar for articles published in English since 2010. The search terms used are listed in Box 1 and were used as single terms. As Grant and Booth (2009) also 
address the value of specified sources, we also searched the websites of four institutions known for generating, preparing and translating the evidence base for policy making: the Evidence Informed Policy Network (EVIPNet)[21], the Health Evidence Network (HEN),[22] McMaster Health Forum-Health Systems Evidence[23] and The National Institute for Health and Care Excellence (NICE).[24] These institutional websites served to provide valuable literature [20] and specified knowledge for the topic. Articles were selected if they described elements of one or more of the four concepts and the reference lists of those articles were reviewed for additional relevant articles without regard to publication date. In addition to published articles, research findings of the European Commission funded project "Tools to Address Childhood Trauma, Injury and Children's Safety" (TACTICS) [25] were reviewed and relevant findings and the authors' project experiences were taken into consideration. This included 32 case studies of injury prevention interventions underway in 24 countries. We included the results of this multinational qualitative study as it provided practical information on the application of the four concepts of interest.

The selected articles and case studies were analysed with regard to the four concepts of interest. Relevant information, including connections between the four concepts was extracted, compared and ordered by concept. As recommended for the synthesis of extracted evidence in a critical review [20], we used these results to develop a model around the core concept of "evidence implementation." For this, key information describing themes of the concepts was organised, ordered and interlinked to build the model. The results and the subsequent model were discussed between all authors in order to best conceptualise what is relevant and of value for evidence implementation in complex public health systems.

Many of the terms encountered within the literature examining evidence implementation are used repeatedly, but with inconsistent definitions.[3,13,16] Therefore brief working definitions were created by the authors to set a context for this work and are outlined below related to the circles of the model. 
Box 1: Search Terms

Search words were used as single terms and included the following:

evidence-based, facilitators, barriers, implementation, knowledge transfer, knowledge translation, implementation strategies, evidence implementation, research communication, public understanding of science, evidence research impact, communications theory, implementation models, policy models, complex adaptive systems, evidence implementation in public health systems, policy theory, systems thinking, complexity theory, critical theory, theory of change, complex adaptive systems theory, public health policy, policy making and health policy.

\section{Results}

The Evidence Implementation Model for Public Health Systems (Figure 1) was created to demonstrate the continuity and flow required for the implementation of evidence-based interventions in complex public health systems. The four concepts of the model: 1) Evidence implementation target, 2) Actors involved in implementation, 3) Knowledge transfer and 4) Barriers and facilitators to evidence implementation, are described below from the inner to the outer circle, including how they are interlinked.

\section{First circle - Evidence implementation target}

To be successful at any given task, one needs to begin with the end in mind.[10,19] What is it that one wants to achieve? As a result, at the centre of the model is the desired target to be achieved through evidence implementation. For the purpose of this paper, evidence implementation was defined as the act of implementing or putting a set of specific actions in place to achieve a desired evidence-based intervention. This target could be defined with either a qualitative and/or quantitative target measure, for the uptake of an evidenced-based intervention into policy or practice or both (e.g. introducing and enforcing minimum drinking age limits or forcing a reduction of speed around schools, residential areas, play areas). 
Second circle - Actors involved in evidence implementation

The second circle of the model reflects the key actors involved in the evidence implementation process. $[17,26]$ Rather than proceeding as a linear process, a back and forth interplay between all actors continually occurs, ideally resulting in clarity, agreement and where necessary compromise. This indicates the need for on-going information exchange throughout the entire process, as well as emphasising the potential influence of both individual actors' professional and personal values, beliefs and preferences on the process and the evidence implementation target.[3,14,15] The actors (described below) form the circle immediately adjacent to the evidence implementation target to highlight the importance of early, sustained and collaborative engagement of all key stakeholders in the evidence implementation process. $[7,10,13,27]$ Decision makers are those who decide on matters in public health systems and may be individuals, groups or organisations. Funders can often be part of the decision-making group directly, as may be the case for initiatives supported by governmental agencies.[17] Funders may also have direct influence on those responsible for taking decisions, such as foundations that have set funding criteria.[15,19,26,28]

Researchers are those individuals or teams that systematically investigate a specific subject matter. The results of their research often serve as the basis for evidence-based interventions. Researchers may need to provide different kinds of evidence information for decision makers and implementers at various points in the implementation process.[29,30] Knowledge brokers are a diverse set of individuals, groups or organisations that contribute to transitioning knowledge between researchers, decision makers and implementers, such as specialised applied research units, international governmental organisations, nongovernmental organisations, media, think tanks or consultancies. They help bridge the research to practice gap by sharing and translating knowledge, information, networks, tools, resources and capacity building means that contribute to the uptake of the evidence-based intervention. $[1,13,14,31]$

Implementers are those individuals and their respective organisations, as well as the public in general, that ultimately will be putting the evidence into practice in the real world. This 
includes addressing availability, accessibility and affordability of the intervention by the desired target audience.[15]

Information moves back and forth between the actors, assisting them to gain further understanding, constantly adapt to change, solve problems, monitor results and consider further options and solutions to improve effectiveness and acceptability of delivery for the context, setting and target audience.[11,26]

\section{Third circle - Knowledge transfer}

The third circle of the model addresses knowledge transfer; that includes stages in a recursive process that has no set start or ending, but rather stages that are continually examined and addressed while moving back and forth between each of the stages: 1) Identifying and assessing the problem, 2) Gathering, analysing and synthesising evidence, 3) Using evidence and 4) Assessing evidence uptake.[27,31-33]

1) Identifying and assessing the problem: to define a problem and determine the needed actions to achieve identified priorities.

2) Gathering, analysing and synthesising evidence: to systematically undertake investigation to attain best available and preferably local information to support decision-making processes and then to combine and summarise gathered evidence into an accessible and condensed format.

3) Using evidence: to translate, disseminate and apply evidence. Translate evidence: transfer and adapt the key facts and concepts of the synthesised research evidence and integrate these strategically into targeted tools, resources, and processes for each of the identified target audiences. Disseminate evidence: to distribute evidence and its translated versions in the form of tools, resources, and processes that maximise the target audiences' exposure to the results, key messages, outputs and outcomes, and supports their uptake. Apply evidence: the stage of taking up the stated evidence, adapting, integrating and sustaining its basis into the real world setting with the support of the target audience appropriate tools, resources and processes. 
4) Assessing evidence uptake: the interpretation and evaluation of the level of uptake of the evidence-based intervention into policy or practice to determine a range of lessons learned and benefits that have or have not been achieved (e.g., increased knowledge, positive behaviour change, health improvement, cost reductions, sustainability).

The knowledge transfer process is adjacent to the actor's circle in this model to highlight the strong relationships of the different actors to various stages of this process. Not only is it important to involve all the stakeholders early in the knowledge transfer process to enhance the opportunity for evidence implementation, but maintenance of that involvement throughout the process increases the likelihood of success.[1,28] For example, continued engagement of researchers to support the accurate translation of research evidence during the formation of targeted tools and their communication, dissemination and application, is an important action beyond peer reviewed publication. [29,31] Active engagement of all actors in all stages of knowledge transfer should: a) broaden the knowledge, understanding, values and perspectives of the key actors regarding the evidence-based intervention, $b$ ) support the management of barriers in the process that could derail the intended policy or practice, and c) guide collective work to enhance facilitators to support the uptake of the evidence-based intervention, described in the next circle of the model.[10] Double headed arrows are used between the stages to represent the constant interchange, revisiting and linking that occurs throughout knowledge transfer.

\section{Fourth circle - Barriers and facilitators to evidence implementation}

The outermost circle of the model is a diverse set of factors that at any point in the knowledge transfer process can influence the success of evidence implementation. These include leadership, management and collaboration, funding, capacity, data, visibility of the issue being addressed, the evidence-based intervention itself and the context setting. Each of these eight factors, identified through a systematic analysis of 32 case studies from 24 countries examining evidence uptake, implementation and monitoring of interventions to prevent child injury, can present potential barriers to the process, yet if effectively managed, can facilitate success.[25] For example, the actions of a competent leader can bring together 
diverse stakeholders towards a common vision and targets, while the absence of leadership can leave policies and practice with no direction or momentum.[29,31] Sound management and collaboration, including ensuring the right partners with clearly delineated roles and responsibilities, will support implementation.[34] On the other hand, a lack of communication and or collaboration can bring implementation to a grinding halt.[13] Without adequate funding to implement an intervention, the challenges to successfully reach the implementation target become daunting.[34] Lack of funding creates a never-ending treadmill to find financial resources, which consumes time and human resources needed for technical aspects of policy and practice work.[30] Having sufficient work force with the right capacities is also required to effectively move through the knowledge transfer process.[35] Capacity deficiencies create gaps in needed skill sets and trigger further barriers.[2] Data are also essential for planning, implementing and monitoring.[30] Without adequate, accurate data, there will be little opportunity to demonstrate the effectiveness of the evidence being implemented and make the case for further investment. In addition, some level of visibility of the issue and the evidence-based intervention selected as the "best solution" is required to raise further awareness, garner support and stimulate a call to action.[1,30,36] It is also important to recognise that the evidence-based intervention itself can be a facilitator or barrier.[18] It is essential that the fit between the intervention and context and setting into which it will be introduced has been examined, re-examined and found to be appropriate, i.e. the intervention is acceptable and adaptable to the context and setting.[33] 


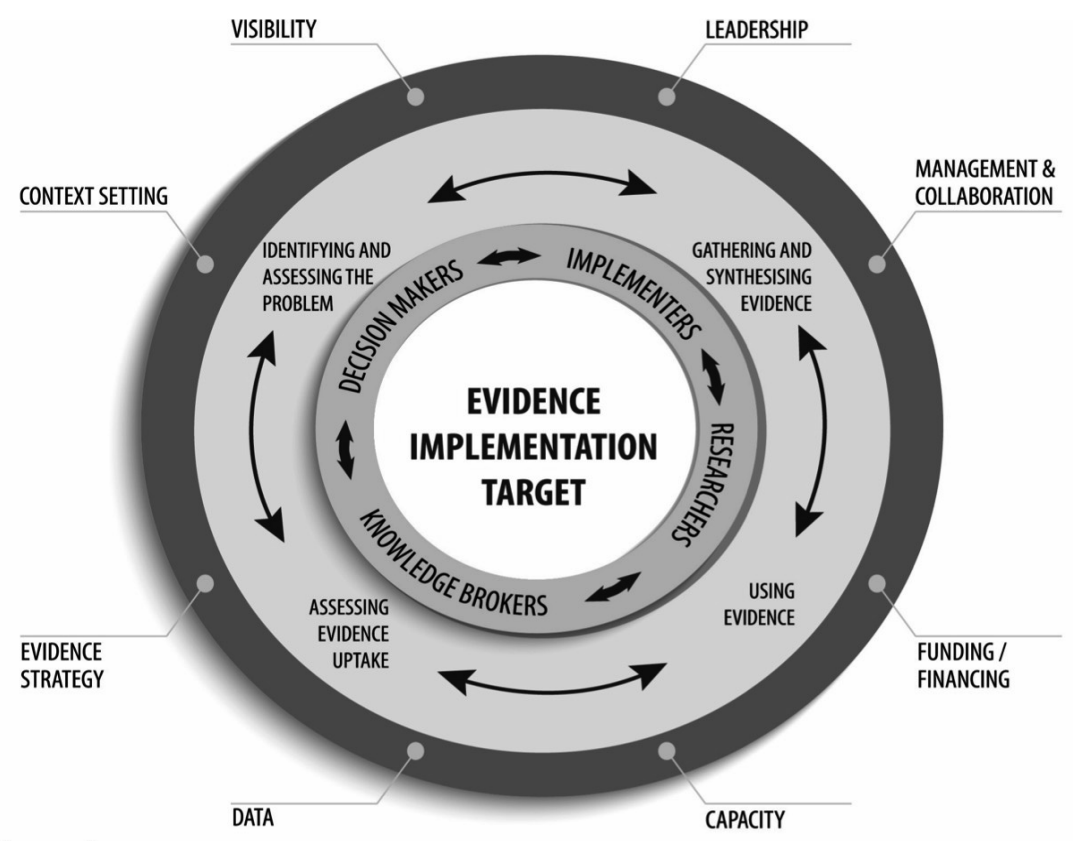

\section{Legend}

Circle 1 Evidence Implementation Target

Circle 2 Actors Involved

Circle 3 Knowledge Transfer

Circle 4 Barriers and Facilitators to Evidence Implementation

Figure I: Evidence Implementation Model for Public Health Systems 


\section{Discussion:}

What is already known on this topic?

Improving public health outcomes through successful uptake of evidence-based interventions is not a simple or quick task.[1,2,9,10,15] This is in large part because public health systems are complex.[4,5,8,12] There are many barriers and interdependencies involved that are embedded in the system as a whole, as noted in reviews of implementation frameworks and models.[16,32] Addressing the complexity of such systems requires an understanding of the system dynamics including the many actors, factors and stages influencing the entire system.[4,11,15]

\section{What does this study add?}

This model provides a broad, integrated and practical approach to begin to understand the complexity of such systems as they relate to evidence implementation by examining the interrelationship of four conceptual circles representing key aspects of implementation identified in the scientific literature. While initially developed using case studies from child injury, the model has since been used by the lead author within World Health Organization projects. $[37,38]$ This model has differences over other existing implementation frameworks and knowledge transfer models by not only demonstrating the theoretical complexities of knowledge translation,[9] but also provides some practical guidance. This includes more focus on a practical approach to operationalise and work with the interplay between the factors influencing implementation, such as setting agreed upon targets, early and sustained engagement of diverse actors and addressing context specific barriers and facilitators identified within this model.[5,8,10,16,27,32,33]

Regarding the role of actors in evidence implementation, Greenhalgh et al.'s model [17] and Damschroeder's framework [13] note the importance that individuals, in addition to organisations, can play in implementation processes. However, they do not directly include individual actors in their models or acknowledge the key role that their experience and biases 
can contribute to the public health system as a whole. Several frameworks and models authors have noted the importance of researchers and decision makers working together to enhance the uptake of evidence.[14,39] However, it must be emphasised that within the field of public health, an even broader set of actors need to be regularly engaged to increase the likelihood of success. $[6,8,25,37,38]$ Therefore this model also includes knowledge brokers and implementers, whose role is to fill information gaps/facilitate communication between researchers and policy makers, support informed decisions and implement practical actions.[28,33]

The eight key barriers/facilitators included in the model were identified through an analysis of 32 case studies of active interventions conducted by some of the authors,[25] as well as verified in the literature.[14,17,30,35] The breadth of barriers/facilitators that can influence the uptake of evidence at any point during knowledge transfer, have not been specifically identified within a number of other implementation and knowledge transfer frameworks and models. $[9,10,16,19,27,32,33]$ The barriers/facilitators inclusion is to encourage the proactive identification and resolution of barriers and maximisation of facilitators throughout the process as practical guidance and essential actions in real world settings. $[9,25,37,38]$ The barriers/facilitators are not necessarily independent of one another - i.e. there is interplay and co-dependencies also between them.[37,38] For example, funding and resources will relate to and be dependent on the intervention itself, as well as the context and setting into which it is to be implemented.

Actors' values, beliefs and preferences can directly influence evidence implementation, highlighting the critical need to purposively target tools and resources, their dissemination and application to the appropriate audiences at key times within the implementation process. $[5,8,37,38]$ This is particularly true, where for example decision makers need and prefer brief, plain and common language policy support tools that include specific evidence for the relevant stage of the policy cycle (e.g., risk and impact assessments or start up, versus sustainability costs).[1,14,25,28-31] While policy support tools, such as policy briefs may be based on systematic reviews or other peer reviewed publications, putting them in a concise, 
engaging and relevant format, with competent facts and values, specific to the target audience, greatly increases their utility.[36,39]

\section{Limitations of this study}

Some limitations must be kept in mind when viewing this model. Presently the Evidence Implementation Model for Public Health Systems is at the conceptual stage. First, the authors compiled many of the definitions used within the four concepts, as one definitive resource defining all relevant concepts has not been acknowledged at this time. Further, while the model is based in part on an analysis of 32 case studies of interventions in 24 countries and builds on empirical findings through a critical review of the literature, the model has had limited application. The model has found its first applications and use, $[37,38]$ yet requires further testing and validation in practice. Finally, the critical review was limited to English language documents and thus some bias may have been introduced.

\section{Conclusions:}

Evidence-based public health interventions exist, but in many cases their uptake, implementation and monitoring need to be enhanced in order achieve greater health benefits for all. This Evidence Implementation Model for Public Health Systems provides a broad, integrated and practical framework to help decision makers, researchers, knowledge brokers and implementers identify opportunities to strengthen needed action. This model builds on previous models by identifying additional concepts that need consideration and providing more specific practical guidance through the identification of the key factors where action is needed to enhance implementation. A question the model raises is how we attain a better understanding of the influence of key actors' values, beliefs and preferences on the various stages of the process in order to successfully support their needs and thereby increase evidence implementation and improve public health systems for both policy and practice. The model has implications for research, policy and practice that emphasises: 1) the importance of setting measurable evidence implementation targets to focus action; 2) the need for early, sustained collaboration of researchers, decision makers, knowledge brokers 
46 | Chapter 2

and implementers; 3 ) the importance to engage all actors in all stages of knowledge transfer to increase shared aim and reduce barriers; 4) that context specific barriers can continually effect evidence implementation, yet if adequately addressed can become facilitators; and 5) that a broad, yet simplified framework supports real world evidence implementation. 


\section{References}

1. Liverani M, Hawkins B, Parkhurst JO. Political and institutional influences on the use of evidence in public health policy. A systematic review. PLoS One. 2013;8(10):e77404. DOI: 10.1371/journal. pone. 0077404

2. Orton L, Lloyd-Williams F, Taylor-Robinson D, O'Flaherty M, Capewell S. The use of research evidence in public health decision making processes: Systematic review. PLoS One. 2011;6(7):e21704. DOI: 10.1371/journal.pone.0021704

3. Oliver K, Innvar S, Lorenc T, Woodman J, Thomas J. A systematic review of barriers to and facilitators of the use of evidence by policymakers. BMC Health Serv Res. 2014;14(1):2-14. DOI: 10.1186/1472-6963-14-2

4. Holmes BJ, Best A, Davies H, Hunter D, Kelly MP, Marshall M, et al. Mobilising knowledge in complex health systems: a call to action. Evid Pol. 2017;13(3):539-60. DOI: 10.1332/ $174426416 \times 14712553750311$

5. Rycroft J. From linear to complicated to complex; Comment on "Using complexity and network concepts to inform healthcare knowledge translation" Int J Health Policy Manag. 2018;7(6): 566568. DOI: 10.15171/IJHPM.2018.02

6. Straus SE, Tetroe JM, Graham ID. Knowledge translation is the use of knowledge in health care decision making. J Clin Epidemiol. 2011;64(1):6-10. DOI: 10.1016/j.jclinepi.2009.08.016

7. Hanson D, Allegrante JP, Sleet DA, Finch CF. Research alone is not sufficient to prevent sport injuries. Br J Sports Med. 2014;48(8):682-684. DOI: 10.1136/bjsports-2012-091434

8. Kitson A, Brook A, Harvey G, et al. Using complexity and network concepts to inform healthcare knowledge translation. Int J Health Policy Manag. 2018;7(3):231-243. DOI: 10.15171/ ijhpm.2017.79

9. Nilsen P. Making sense of implementation theories, models and frameworks. Implementation Sci. 2015;10:53. DOI: 10.1186/s13012-015-0242-0

10. Glasgow RE, Green LW, Taylor MV, Stange KC. An evidence integration triangle for aligning science with policy and practice. Am J Prev Med. 2012;42(6):646-654. DOI: 10.1016/j.amepre.2012.02.016

11. Best A, Holmes B. Systems thinking, knowledge and action: Towards better models and methods. Evidence \& Policy. 2010;6(2):145-159. DOI:10.1332/174426410X502284

12. Cairney P. Complexity theory in political science and public policy. Polit Stud Rev. 2012;10(3):34658. DOI: $10.1111 /$ j.1478-9302.2012.00270.x 
13. Damschroder LJ, Aron DC, Keith RE, Kirsh SR, Alexander JA, Lowery JC. Fostering implementation of health services research findings into practice: A consolidated framework for advancing implementation science. Implementation Sci. 2009;4(1):50-65. DOI: 10.1186/1748-5908-4-50

14. Oliver K, Innvar S, Lorenc T, Woodman J, Thomas J. A systematic review of barriers to and facilitators of the use of evidence by policymakers. BMC Health Serv Res. 2014;14(1):2-14. DOI:10.1186/1472-6963-14-2

15. Head BW. Reconsidering evidence-based policy: Key issues and challenges. Policy Soc. 2010;29(2):77-94. DOI:10.1016/j.polsoc.2010.03.001

16. Moulin J, Sabater-Hernández D, Fernandez-Llimos F, Benrimoj S. A systematic review of implementation frameworks of innovations in healthcare and resulting generic implementation framework. Health Res Policy Sys. 2015;13(16): 1-11. DOI: 10.1186/s12961-015-0005-z.

17. Greenhalgh T, Robert G, Macfarlane F, Bate P, Kyriakidou O. Diffusion of innovations in service organizations: systematic review and recommendations. Milbank Q. 2004;82(4):581-629. DOI:10.1111/j.0887-378X.2004.00325.x

18. Kreindler SA. What if implementation is not the problem? Exploring the missing links between knowledge and action. Int J Health Planning Manag. 2016;31(2):208-26. DOI: 10.1002/hpm.2277

19. Aarons GA, Hurlburt M, Horwitz SM. Advancing a conceptual model of evidence-based practice implementation in public service sectors. Adm Policy Ment Health. 2011;38(1): 4-23. DOI: 10.1007/s10488-010-0327-7

20. Grant MJ, Booth A. A typology of reviews: an analysis of 14 review types and associated methodologies. Health Info Libr J. 2009;26(2):91-108. DOI: 10.1111/j.1471-1842.2009.00848.x.

21. World Health Organization (WHO) [Internet]. Evidence Informed Policy Network (EVIPNet). Copenhagen: WHO; 2020 [updated 2020; cited 2019 July 15]. Available from: http://www.euro.who.int/en/data-andevidence/evidence-informed-policy-making/evidenceinformed-policy-network-evipnet

22. World Health Organization Regional Office for Europe [Internet]. Health Evidence Network. Copenhagen, Denmark: WHO; 2020 [updated 2020; cited 2019 July 16]. Available from: http://www.euro.who.int/en/data-and-evidence/evidenceinformed-policy-making/healthevidence-network-hen

23. Health Systems Evidence (HSE) [Internet]. About HSE. Ontario: McMaster University; 2019 [cited 2019 July 19]. Available from: https://www.healthsystemsevidence.org/about?lang=en

24. National Institute for Health and Care Excellence (NICE) [Internet]. Improving health and social care through evidence-based guidance. London: NICE; 2020 [updated 2020; cited 2019 July 15]. Available from: https://www.nice.org.uk/ 
25. Scholtes B, Schröder-Bäck P, MacKay J M, Vincenten J, Förster K, Brand H. Facilitators and Barriers for the Adoption, Implementation and Monitoring of Child Safety Interventions: a multinational qualitative analysis. Inj Prev. 2017;23(3):197-204. DOI:10.1136/injuryprev-2016-042138.

26. Smits PA, Denis JL. How research funding agencies support science integration into policy and practice: An international overview. Implementation Sci. 2014;9(1):1-12. DOI: 10.1186/17485908-9-28

27. Grimshaw JM, Eccles MP, Lavis JN, Hill, SJ, Squires JE. Knowledge translation of research findings. Implementation Sci. 2012;7(1):50-67. DOI: 10.1186/1748-5908-7-50

28. Milat AJ, King L, Newson R, Wolfenden L, Rissel C, Bauman A, Redman S. Increasing the scale and adoption of population health interventions: Experiences and perspectives of policy makers, practitioners, and researchers. Health Res Policy Sys. 2014;12(1):18-29. DOI: 10.1186/1478-4505$12-18$

29. Innis J, Dryden-Palmer K, Perreira T, Berta W. How do health care organizations take on best practices? A scoping literature review. Int J Evid Based Healthc. 2015;13(4):254272.DOI: $10.1097 /$ XEB.0000000000000049

30. Humphries S, Stafinski T, Mumtaz Z, Menon D. Barriers and facilitators to evidence-use in program management: A systematic review of the literature. BMC Health Serv Res. 2014;14(1):171-186. DOI: 10.1186/1472-6963-14-171

31. Yost J, Dobbins M, Traynor R, DeCorby K, Workentine S. Greco L. Tools to support evidenceinformed public health decision making. BMC Public Health. 2014;14(1):728-41. DOI: $10.1186 / 1471-2458-14-728$

32. Field B, Booth A, llott I, Gerrish K. Using the knowledge to action framework in practice: a citation analysis and systematic review. Implementation Sci. 2014;9(172):1-14. DOI: 10.1186/s13012014-0172-2

33. Ingold J, Monaghan M. Evidence translation: an exploration of policy makers' use of evidence. Policy Polit. 2016;44(2):171-90. DOI: 10.1332/147084414X13988707323088

34. Gagliardi AR, Webster F, Brouwers, MC, Baxter NN, Finelli A, Gallinger S. How does context influence collaborative decision-making for health services planning, delivery and evaluation? BMC Health Serv Res. 2014;14(545):1-12. DOI: 10.1186/s12913-014-0545-x

35. Ellen ME, Léon G, Bouchard G, Ouimet M, Grimshaw JM, Lavis JN. Barriers, facilitators and views about next steps to implementing supports for evidence informed decision-making in health systems: a qualitative study. Implementation Sci. 2014;9(1):179-191. DOI: 10.1186/s13012-0140179-8 
36. Dietz T. Bringing values and deliberation to science communication. Proc Natl Acad Sci USA. 2013;110(3):1408-14087. DOI: 10.1073/pnas.1212740110

37. Vincenten J, George F, Martuzzi M, Schröder-Bäck, P, Paunovic E. Barriers and facilitators to the elimination of asbestos related diseases-stakeholders' perspectives. Int J Environ Res Public Health. 2017;14(10). pii: E1269. DOI: 10.3390/ijerph14101269

38. Vincenten JA, Zastenskaya I, Jarosinska DI. Analysis of stakeholder views on future development in chemical safety in the WHO European Region. Copenhagen, Denmark: World Health Organization Regional Office for Europe; 2017. 38 p.

39. Lavis J, Moynihan R, Oxman A, Paulsen E. Evidence-informed health policy 4 - Case descriptions of organizations that support the use of research evidence. Implementation Sci. 2008;3(12): 1-9. DOI: 10.1186/1748-5908-3-56 
CHAPTER 3

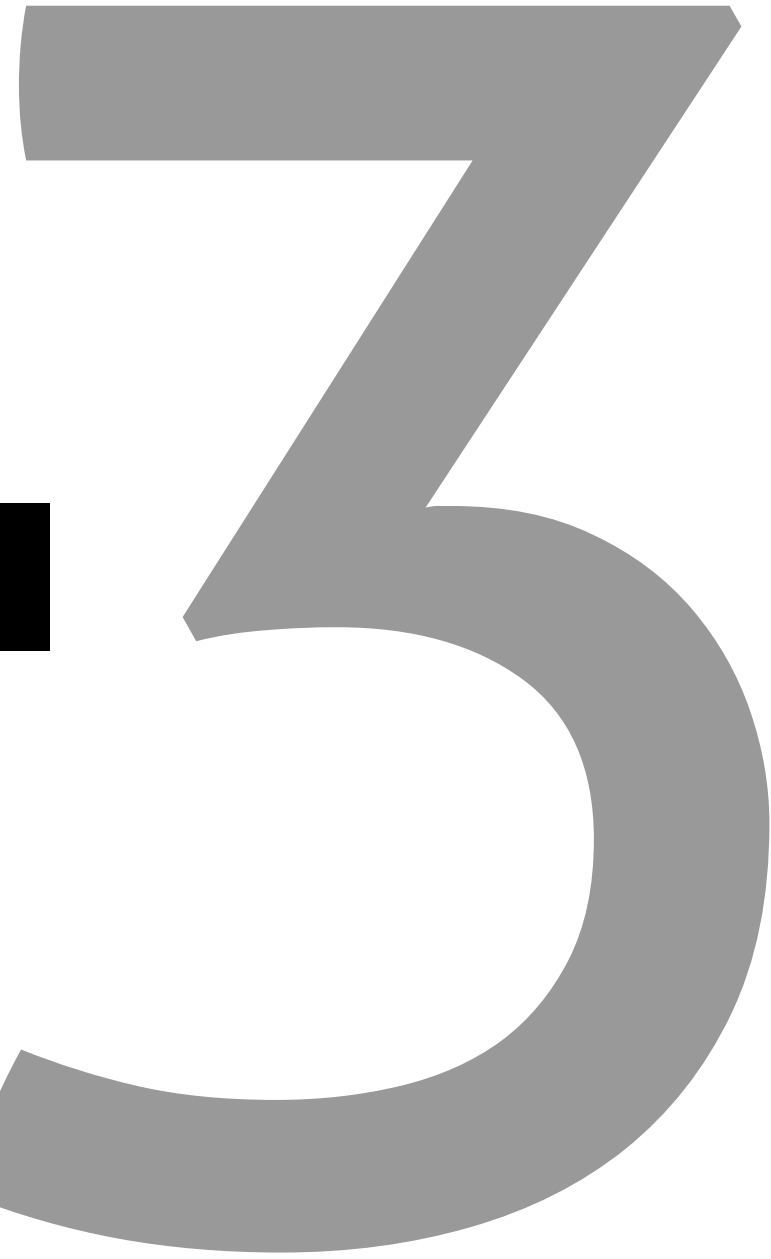




\section{Role of key stakeholders involved in evidence implementation in public health systems}

Published in the European Journal of Public Health (5 year IF: 3.134)

Vincenten J, Zastenskaya I, Schröder-Bäck P, Jarosinska DI. Priorities for improving chemicals management in the WHO European Regionstakeholders' views [published online ahead of print, 2020 May 8]. Eur J Public Health. 2020 May 8; ckaa074. 


\section{Abstract}

Background: Prevention of the impact of chemicals on human health and the environment is an increasing focus of public health polices and policy makers. The World Health Organization (WHO) European Centre for Environment and Health wanted to know what stakeholders' priorities were for improving chemicals management and prevention.

Methods: Semi-structured interviews were undertaken with 18 diverse stakeholders to answer this question. The interview questionnaire was developed using current WHO chemical meeting reports, the Evidence Implementation Model for Public Health Systems and categories of the theory of diffusion. Stakeholder views were attained on three main questions within the questionnaire. 1) What priority actions should be undertaken to minimise the negative impact of chemicals? 2) Who needs to be more involved and what roles should they have? 3) How can science and knowledge on chemicals and health be translated into policies more effectively and what are the greatest barriers to overcome?

Results: Cross cutting issues, such as legislation strengthening and enforcement, further collection of information, capacity building, education and awareness raising were considered priorities. The responders had the same vision on roles and responsibilities of different stakeholders. The greatest barrier to adoption, implementation and enforcement of evidence-based policies reported was leadership and political commitment to chemical safety.

Conclusion: Priorities raised differed depending on knowledge, professional background and type of stakeholder. Factors influencing priority identification at the national level include international and global context, availability of information, knowledge of the current situation and evidence-based good practice, and risks and priorities identified through national assessments. 


\section{Introduction}

Prevention of the impact of chemicals on human health and the environment is an increasing focus of the international community and governments today. Since the United Nations Conference on the Human Development in 1972 [1], significant progress has been reached in phasing out hazardous chemicals.[2] However, actions are still needed to ensure chemical safety.[3-9] Given the broad chemical safety agenda, prioritisation of effective actions and allocation of resources is critical [4,10-12]. International chemical safety policies provide a framework to implement evidence-based policy actions in countries. For example, the United Nations 2030 Agenda for Sustainable Development and its Sustainable Development Goals (SDGs) commit to "substantially reduce the number of deaths and illnesses from hazardous chemicals" by 2030 (SDG 3.9), "improve water quality by reducing pollution" by 2030 (SDG 6.3) and to "achieve the environmentally sound management of chemicals and all wastes throughout their life cycle in order to minimise their adverse impacts on human health and the environment" by 2020 (SDG 12.4).[6,13]

In preparation for the Sixth Ministerial Conference on Environment and Health in Ostrava, Czech Republic (June, 2017), the World Health Organization (WHO) Regional Office for Europe organised a meeting with national and international experts to identify short- and medium term actions to be implemented.[14] As a follow-up to this meeting, the WHO European Centre for Environment and Health (WHO ECEH) called for a consultation to investigate stakeholder views on the future development of chemical safety in the WHO European Region. As chemical safety management is multi-stakeholder in nature, WHO ECEH sought to gain a better understanding of the needs of a broad group of stakeholders.[3] This included attaining deeper insights as to how international policy actions are interlinked with country specific priorities and how the diversity of national stakeholder views influences the chemical safety agenda on a national and European regional level. This stakeholder analysis contributed to the planning of the implementation of the commitments of the Ostrava Declaration on Environment and Health. $[15,16]$ 


\section{Methods}

This is an explorative study using a qualitative design that combined interviews and discussions with key stakeholders in the field of chemical safety management in the WHO European Region. The questionnaire for the semi-structured interviews was developed by the lead author taking into account the outcomes of the WHO chemicals policy and programmes meeting (4-5 July 2016 in Bonn, Germany) [14] and reviewed by the co-authors. The questionnaire was used to obtain stakeholder views on priority actions in the area of chemical safety in the European region.[14, 17] The Evidence Implementation Model for Public Health Systems was utilised to formulate questions addressing key stakeholders' involvement, knowledge transfer, and barriers and facilitators to the uptake of effective strategies.[18] Furthermore, categories of the theory of diffusion were included.[19] Three main questions were asked in the questionnaire:

1) What priority actions should be undertaken to minimise the negative impact of chemicals?

2) Who needs to be more involved and what roles should they have?

3) How can science and knowledge on chemicals and health be translated into policies more effectively, and what are the greatest barriers to overcome?

A complete questionnaire and subset questions for each theme are available in a corresponding WHO report.[20]

Purposive sampling was used by WHO ECEH to invite the participation of stakeholders to ensure geographical representation of the WHO European Region. This included at least three countries from each of the WHO European Region, sub regions (European Union Member States; Central Asia; Central (non-EU) and Eastern Europe), as well as, targeted European organisations, professionals affiliated with diverse key agencies, and representatives of different stakeholder groups in chemicals management. A total of 18 stakeholders participated. The respondents were from ministries of health (2) and environment (2), institutes of public health (4), academics (3) industry associations (2) media (1) and nongovernmental organisations (4) having experience in chemicals management at the national, EU, WHO European Region and global levels. Fewer stakeholders were attained from industry 
and media, as the focus of the WHO interviews was to contribute to Member States policy guidance and the decision-making planning process for the implementation of the commitments of the Ostrava Declaration on Environment and Health. All interviewees gave their informed consent for inclusion before they participated in the interviews and the study was conducted in accordance with the Declaration of Helsinki and WHO protocol.[21] Confidentiality of interviews was communicated to the interviewee and agreed upon. All interviews were conducted using telephone or Skype by the first author in English or Russian (with the assistance of a Russian interpreter). The average interview duration was 30 minutes. The first interview conducted also served as a pilot test and adjustments were made to the questionnaire by the first author to increase clarity. Probing took place to obtain information about the professional role of each stakeholder interviewed, country context and views relating to chemical safety in their countries, and their values and beliefs were taken into consideration with respect to each question. Interviews were transcribed verbatim into a corresponding questionnaire template. Clarifications to the stakeholders' comments were attained by email when required. Content analysis of the interviews was undertaken to provide concise summaries of stakeholders' responses. Findings were grouped corresponding to the three interview themes, categorised based on interviewees' most frequent responses by key words and analysed to create a final stakeholders analysis report.

\section{Results}

Data that were obtained from the 18 interviewees are presented on the three main questions within the interview questionnaire: 1) What priority actions should be undertaken to minimise the negative impact of chemicals? 2) Who needs to be more involved and what roles should they have? 3) How can science and knowledge on chemicals and health be translated into policies more effectively, and what are the greatest barriers to overcome? 


\subsection{Priorities}

Priority chemical safety actions identified by stakeholders interviewed were analysed, grouped and reported below by the four stakeholder groupings of government, industry, academia and researchers, and non-governmental organisations.

\section{(i) Governments priorities}

Interviewees identified monitoring and control as the priority area, and adoption, implementation and enforcement of legislation. Despite the many laws and regulations that exist in the Member States, a framework for and commitment to their implementation and enforcement are not always in place nationally and should be urgently addressed. The most frequently cited hazardous substances by interviewees were endocrine disrupting chemicals (EDCs), pesticides as a priority in connection with monitoring and managing obsolete pesticides stockpiles, and other priority groups of chemicals including heavy metals, such as mercury and asbestos.

(ii) Industry/private sector priorities

Interviewees stated the priority need for capacity and expertise necessary to ensure chemical safety requires facilitated enhancement and collaboration across all sectors. They stressed the need for more private sector and scientific involvement for information sharing in research and innovation. Programmes that support and encourage the implementation of the Responsible Care initiative should be promoted, as well as sharing of national experiences involving industry in chemicals management.

(iii) Academia and researchers' priorities

Interviewees identified increased research in chemical safety as priority and specifically called for filling of data gaps through innovation, early identification of hazards and causes of harm, monitoring and control of hazardous substances, and establishing exposure limits and standards for vulnerable groups. They also highlighted the need for increased capacity of human and financial resources for research and innovation at the national, regional and local levels across various disciplines to support knowledge transfer. 
(iv) Non-governmental organisations (NGOs) priorities

A wide scope of priorities was proposed by NGOs, particularly reduction of air pollution followed by chemicals in food and water. They also stated the need for increased awareness of evidence-based strategies and targeted tools to enhance knowledge of stakeholders and society including decision-makers. NGO interviewees strongly expressed the publics' right to transparency, including knowing what substances are contained in products and banning, removal and replacement of unsafe products in all Member States of the WHO European Region. Another priority identified was improvement of chemical management legislation, implementation and enforcement. As well, Member States should consider use of effective regulations and chemical instruments, such as improving classification and labelling through the Globally Harmonized System of Classification and Labelling of Chemicals (GHS) and the precautionary principle. They emphasised the need to address chemical safety issues in the wider context of environment and health and as an integral component of a comprehensive action plan on environment and health.

\subsection{Roles of key stakeholders}

Interviewees from all sectors (government, industry, academia and researchers, and NGOs) expressed their views on how to reach a whole-of-government, whole-of-society approach to improve chemicals management. Overall, they collectively defined the roles of "who is responsible" and "who does what" to successfully address chemical safety as follows:

(i) Role of governments

At all levels of government (national, subnational, municipal) the interviews stated the need for greater involvement of senior policy makers in raising the priority of and commitment to chemical safety action could be supported and enhanced through establishing interministerial committees in all the WHO European Member States. They stressed chemical safety needs to be placed higher on the political agenda and in a more concrete way, rather than primarily administrative tasks. For example, policy actions need to be undertaken and designated budgets secured. Also, they identified the need for stronger links and shared action across the different government levels, and multisectoral and multidisciplinary 
approaches to coordinate the adoption, implementation and enforcement of evidence-based priority actions. The example of legislation and regulations aimed at identifying, monitoring, banning, restricting, limiting, and replacing hazardous substances with safer alternatives was provided (i.e. asbestos). In addition, the role of government is to balance the immediate financial and political demands or interests that chemicals appear to evoke, and the impact of chemicals on population health.

(ii) Role of industry/private sector

The interviews emphasised that industry is an important stakeholder and has a key role in enhancing chemical safety through specialists, technical information and specific skills related to chemical safety that could be shared to build the capacity of diverse stakeholders. However, they stressed that industry needs to enhance transparency, and innovation in materials and technology, increase the use of green chemistry, and use safer alternatives to replace hazardous chemicals. Examples given to initiate win-win situations with industry included establishing joint actions and ways of collaborating, such as structured agreements, memoranda of understanding, and public/private partnerships. Interviewees also raised the development of a fund for independent research in chemical safety with financial support from industry for agreed upon priority areas.

(iii) Role of Academia and researches

According to the interviews, opinion research must be independent, forward thinking and focus on safer innovation and design. They stated the need for knowledge translation from research results towards informative and educational tools and resources to support science to policy communications. Concise, plain-language summaries tailored to target audiences including decision-makers would assist in this process.

(iv) Role of non-governmental organisations (NGOs)

The interviewees stated that NGOs could enhance collaboration to raise greater awareness on chemical safety, call for the adoption, implementation and enforcement of good practice, and share victims' stories. For example, sharing human bio-monitoring case studies and 
advocating for the removal of, bans on, and promotion of safer alternatives to harmful chemical products was raised.

(v) Role of intergovernmental organisations

According to the interviews performed, intergovernmental organisations need to strengthen their role in communicating knowledge about evidence-based good practices in chemical safety more widely, and to support development, adoption and enforcement of chemical safety evidence-based policies and programmes.

3.3. Concepts on how science and knowledge on chemicals and health can be translated into policies more effectively and which barriers are the greatest to overcome.

Stakeholders interviewed agreed that transferring and translating knowledge into policy as a difficult and complex process, which requires an understanding of the system dynamics including needed targets, stakeholders involved and the factors and stages influencing the entire process. Concepts discussed and stakeholders' views shared to support knowledge transfer included: 1) having a clear, time-bound target from the start of the process; 2) ensuring that all key stakeholders were engaged early in the process, that their views and roles towards shared aims were defined, and that there was mutual respect for the collaborative work to be carried out; 3) raising awareness about research evidence and creating educational tools and resources for specific target audiences to support the transfer of knowledge into policy; and 4) reviewing and addressing barriers to and facilitators of the translation of evidence into policy needed to be addressed on an on-going basis to facilitate policy development.

The lack of leadership and political commitment was considered to be the major barrier by the majority of those interviewed. This was not only for adopting evidence-based chemical safety policy, legislation and regulation, but also and more importantly at the moment, for implementing and enforcing these policies. Overall, there were diverse views as to how to effectively implement evidence-based policies for chemical safety. The views depended on 
individual stakeholder knowledge, experience, beliefs and preferences rather than professional background.

\section{Discussion}

The views stated by the interviewees as a whole supported and corresponded to international policy frameworks and priorities to increase chemical safety adopted by the United Nations, WHO and the Strategic Approach to International Chemicals Management (SAICM) policy frameworks (Figure 1). [13, 22-26] Cross cutting issues, such as legislation strengthening and enforcement, further collection of information, capacity building, education and awareness raising were considered priorities by all interviewees. Many interviewees shared that the knowledge and technical skills required to implement evidence-based policies are lacking, indicating a need for more capacity building among key stakeholders. However, national context and settings influenced interviewees' views in terms of the group of chemicals and specific areas of concern.[27] For example, interviewees from the countries of Central Asia and Caucasus most commonly reported the collection and safe disposal of mercurycontaining bulbs, and the sound management and removal of pesticide stockpiles; they also stated the need for assistance in data monitoring, awareness campaigns and uptake of good practice; while Western European countries focused on reduction of endocrine disrupting chemicals (EDCs), air pollution management, and early identification of hazardous chemicals. These responses mirror the level of legislation and institutional structure, and established policies in the respondents' countries.[14] Furthermore, these correspond to actions addressed in international policies [15,16,28-30], which confirm the important role international policies play to support priority action adoption and implementation for chemical safety within nations and regions.[27]

To ensure national priorities are reflected in international policy frameworks, it is essential that national chemical safety assessments are readily available, shared and properly communicated at the national and international levels.[5,31] Stakeholders from national governments, industry, academics, non-governmental and intergovernmental organisations have key roles to play in chemical safety management.[3] Within this study the interviewees 
agreed on the roles and responsibilities of the key stakeholders. However, each stakeholder carries their own levels of awareness and knowledge of chemical safety issues in addition to their professional and personal values, perspectives and interests. $[27,32,33]$ Therefore, wider distribution and sharing of chemical safety knowledge, perspectives, expertise and experience by all key stakeholders, including the public is essential.[34] Science to policy communication is also critical. Here, academics can provide support to enhance knowledge translation.[18] As well, common knowledge of agreed facts by all stakeholders is also an important foundation for information and determining priority needs.[35]

Analyses of the national priorities identified through the interviews echoed the need by all stakeholders for consistent use of standardised tools developed by international organisations.[36-39] Such tools create a basis for collecting information needed to identify and implement priority actions.[18,36-39] Furthermore, agreement of the overall aims and associated measurable targets by all stakeholders is critical for attaining a high level of stakeholder commitment [18], in particular that of senior policy-makers.

Knowledge of best practices available was an important factor influencing the identification of priorities. For example, the majority of interviews stressed the need for strengthening national chemical legislation and full implementation of to the European Union regulation REACH (Registration Evaluation, Authorisation and Restriction of Chemicals). Currently, $\mathrm{REACH}$ is considered to be the most advanced legislation for reduction of the negative impact of chemicals on human health and the environment, resulting in a decrease of social and economic costs.[40] More countries from the WHO Europe geographical regions of Central Asia, Central and Eastern Europe, and Caucasus could adapt and adopt good practices like $\mathrm{REACH}$ to inform their national chemical policy development and implementation, particularly in relation to the reduction of hazardous chemical products.[40] Policy actions to improve chemical management would be best supported with clear messages of evidencebased good practices as part of awareness campaigns. These campaigns should also include information on who is responsible for what [34], as confirmed by the stakeholders interviewed in this survey. As well, actions should be supported at the regional and global levels to ensure wide circulation of case studies and assessment of effectiveness of different risk reduction measures.[18,31] 
This study is an explorative view of 18 key stakeholders in chemical safety management insights of priorities for the chemical safety agenda of the WHO European region but is not representative of the whole Region. However, a large and diverse variety of interviews were performed from various sectors, and individuals and organisations with representation at the national, EU and WHO European Region levels. Interviews were performed until saturation was achieved, based on no new themes being identified by the stakeholders.

To conclude, the priorities identified by all key stakeholders in the European region on chemical safety included: legislation strengthening and enforcement, further collection of information, capacity building, education and awareness raising. The priorities stated by the interviewees as a whole supported and corresponded to international policy frameworks and priorities to increase chemical safety adopted by the United Nations, WHO and SAICM policy frameworks (Figure 1). The priorities raised differed depending on national and regional context, knowledge, professional background and type of stakeholder (government, industry/private sector, academic or NGO). Understanding of roles and responsibilities of different stakeholders was agreed upon by all stakeholders. Factors influencing priority identification at the national level include: international and global context, knowledge on the current situation and the risks identified through national assessment, mostly in the frameworks of international legal and voluntary agreements, knowledge of good practice in the field of chemicals management and other areas related to human health and environmental factors.

\section{Key Points:}

- Priorities identified in the European region on chemical safety included: legislation strengthening and enforcement, further collection of information, capacity building, education and awareness raising.

- Priorities as a whole supported and corresponded to international policy frameworks and priorities to increase chemical safety adopted by the United Nations, WHO and SAICM policy frameworks. 
- Priorities raised differed depending on national and regional context, knowledge, professional background and type of stakeholder (government, industry/private sector, academic or NGO).

- Factors influencing priority identification at the national level include: international and global context, knowledge on the current situation and the risks identified through national assessment.

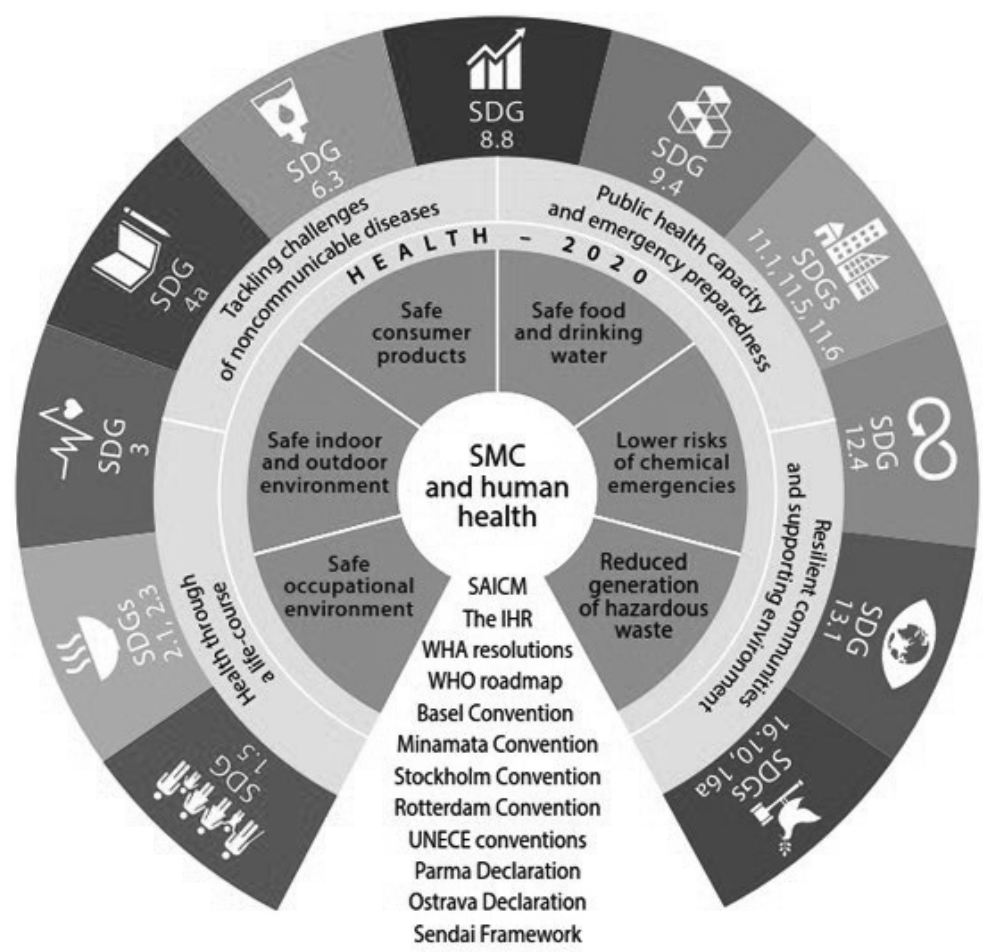

Notes: IHR: International Health Regulations; SMC: sound management of chemicals; UNECE: United Nations Economic Commission for Europe; WHA: World Health Assembly.

Source: Based on global and regional policies related to chemicals management, Health 2020 and the 2030 Agenda for Sustainable Development.

Figure 1. Sound management of chemicals and human health - WHO Europe [13] 


\section{References}

1. United Nations. Report of the United Nations Conference on the Human Environment, Stockholm, 5-16 June 1972; New York, United States: United Nations; 1973. 81 p. Report No.: A/CONF.48/14/Rev.1

2. World Health Organization. High-level Mid-term Review of the European Environment and Health Process, Haifa, Israel, 28-30 April 2015 Meeting Report. Copenhagen, Denmark: WHO Regional Office for Europe; 2015. 46 p.

3. World Health Organization. Strategic approach to international chemicals management: implementation and priorities in the health sector. Copenhagen, Denmark: WHO Regional Office for Europe; 2015. 32 p.

4. Word Health Organization. Target and indicators for Health 2020, version 3. Copenhagen, Denmark: WHO Regional Office for Europe; 2016. 86 p.

5. World Health Organization. Chemicals Road Map: Road map to enhance health sector engagement in the strategic approach to international chemicals management towards the 2020 goal and beyond. Geneva, Switzerland: World Health Organization; 2017. 8 p. Report No.: A70/36

6. United Nations [Internet]. New York, United States of America: United Nations; 2015. Transforming Our World: the 2030 Agenda for Sustainable Development. [updated 2019 May 3; cited 2020 May 24]. Available from: https://www.un.org/sustainabledevelopment/ sustainabledevelopment-goals/

7. Grandjean P, Landrigan P. Neurobehavioural effects of developmental toxicity. Lancet Neurol. 2014;13:330-8. DOI: 10.1016/S1474-4422(13)70278-3

8. Perera F, Herbstman J. Prenatal environmental exposures, epigenetics, and disease. Reprod Toxicol. 2011;31(3):363-73. DOI: 10.1016/j.reprotox.2010.12.055

9. Skinner MK, Guerrero-Bosagna C. Environmental signals and transgenerational epigenetics. Epigenomics. 2009;1(1):111-17. DOI: 10.2217/epi.09.11

10. Bartlett ES, Trasande L. Economic impacts of environmentally attributable childhood health outcomes in the European Union. Eur J Public Health. 2014;24(1):21-6. DOI: 10.1093/eurpub/ ckt063

11. Trasande L, Zoeller RT, Hass U, Kortenkamp A, Grandjean, P, Myers JP, et al. Burden of disease and costs of exposure to endocrine disrupting chemicals in the European Union: an updated analysis. Andrology. 2016;4(4):565-72. DOI: 10.1111/andr.12178 
12. Trasande L, Zoeller RT, Hass U, Kortenkamp A, Grandjean P, Myers JP, et al. Estimating burden and disease costs of exposure to endocrine-disrupting chemicals in the European Union. J Clin Endocrinol Metab. 2015;100(4):1245-55. DOI: 10.1210/jc.2014-4324.

13. World Health Organization [Internet]. Copenhagen, Denmark: WHO Regional Office for Europe. Infographic: Sound management of chemicals and human health; 2017 [updated 2020; cited 2020 Feb 18]. Available from: http://www.euro.who.int/en/health-topics/environment-andhealth/chemical-safety/data-and-statistics/infographic-sound-management-of-chemicals-andhuman-health

14. World Health Organization. Chemical policy and programmes to protect human health and environment in a sustainability perspective. Copenhagen, Denmark: World Health Organization Regional Office for Europe; 2017. 35 p.

15. World Health Organization. WHO Europe Parma Declaration on Environment and Health. Copenhagen, Denmark: World Health Organization Regional Office for Europe; 2010. 10 p. Report No.: EUR/55934/5.1 Rev. 2

16. World Health Organization. WHO Europe Ostrava Declaration on Environment and Health. Copenhagen, Denmark: World Health Organization Regional Office for Europe; 2017. 5 p. Report No.: EURO/Ostrava2017/6

17. World Health Organization. Overall orientation and guidance for achieving the 2020 goal of sound management of chemicals. Geneva, Switzerland: World Health Organization; 2015. 17 p.

18. Vincenten J, MacKay JM, Schröder-Bäck P, Schloemer T, Brand H. Factors influencing implementation of evidence-based interventions in public health systems-a model. Cent Eur J Public Health. 2019;27(3)198-203. DOI: 10.21101/cejph.a5234

19. Greenhalgh T, Robert G, Macfarlane F, Bate P, Kyriakidou O. Diffusion of innovations in service organizations: systematic review and recommendations. Milbank Q. 2004; 82(4): 581-629. DOI:10.1111/j.0887-378X.2004.00325.x

20. Vincenten JA, Zastenskaya I, Jarosinska D.I. Analysis of stakeholder views on future development in chemical safety in the WHO European Region Report. Copenhagen, Denmark: World Health Organization Regional Office for Europe; 2017. 38 p.

21. World Medical Association. WMA Declaration of Helsinki-Ethical principles for medical research involving human subjects. Ferney-Voltaire, France: World Medical Association; 2013. 4 p.

22. United Nations Environment Programme. Report of the International Conference on Chemicals Management on the work of its third session. Geneva, Switzerland: Strategic Approach to International Chemicals Management (SAICM); 2013. 71 p. Report No.: SAICM/ICCM.3/24 
23. United Nations Environment Programme. Overall orientation and guidance for achieving the 2020 goal of sound management of chemicals. Geneva, Switzerland: Strategic Approach to International Chemicals Management (SAICM); 2015. 21 p. Report No.: SAICM/ICCM.4/6

24. United Nations Environment Programme. Stockholm convention on persistent organic pollutants Texts and Annexes Revised in 2017. Châtelaine, Switzerland: Secretariat of the Stockholm Convention; 2018. 78 p.

25. United Nations Environment Programme. Report of the International Conference on Chemicals Management on the work of its first session. Geneva, Switzerland: Strategic Approach to International Chemicals Management (SAICM); 2006. 1004 p. Report No.: SAICM/ICCM.1/7

26. World Health Organization. Chemicals Road Map. Road map to enhance health sector engagement in the Strategic Approach to International Chemicals Management towards the 2020 goal and beyond. Geneva, Switzerland: Strategic Approach to International Chemicals Management (SAICM); 2018. 8 p. Report No.: WHO/FWC/PHE/EPE/17.03

27. Barr S. Knowledge, Expertise and Engagement. Environmental Values. 2017; 26:125-130. DOI: $10.3197 / 096327117 X 14847335385391$

28. United Nations Economic Commission for Europe (UNECE). Convention on the Protection and Use of Transboundary Watercourses and International Lakes as amended, along with decision VI/3 clarifying the accession procedure. Geneva, Switzerland: UNECE; 2013. 51 p. Report No.: [E/]ECE/MP.WAT/41

29. World Health Organization. Draft road map for an enhanced global response to the adverse health effects of air pollution. Geneva, Switzerland: World Health Organization; 2016. 9 p. Report No.: EB138/17

30. United Nations Environment Programme. Minamata Convention on Mercury Texts and Annexes. Geneva, Switzerland: United Nations Environment Programme; 2014. 61 p. Report No.: UNEP/CHEMICALS/2014/1

31. Pollard SJT, Davies GJ, Coley F, Lemon M. Better environmental decision making - Recent progress and future trends. Science Total Env. 2008; 400(1-3):20-31. DOI: 10.1016/j.scitotenv.2008.07.022

32. Oliver K, Innvar S, Lorenc T, Woodman J, Thomas J. A systematic review of barriers to and facilitators of the use of evidence by policymakers. BMC Health Serv Res. 2014;14(1):2-14. DOI: 10.1186/1472-6963-14-2

33. Büchs, ME, Hinton ED, Smith G. 'It helped me sort of face the end of the world': The role of emotions for third sector climate change engagement initiatives. Envir Values. 2015; 24: 621640. DOI:10.3197/096327115X14384223590177 
34. Vincenten J, George F, Martuzzi M, Schröder-Bäck, P, Paunovic E. Barriers and facilitators to the elimination of asbestos related diseases-stakeholders' perspectives. Int J Environ Res Public Health. 2017;14(10). pii: E1269. DOI: 10.3390/ijerph14101269

35. Lavis J, Moynihan R, Oxman A, Paulsen E. Evidence-informed health policy 4 - Case descriptions of organizations that support the use of research evidence. Implementation Sci. 2008;3(12): 19. DOI: $10.1186 / 1748-5908-3-56$

36. United Nations Institute for Training and Research (UNITAR) [Internet]. New York, New York: UNITAR. National Profiles Development [cited 2020 Feb 18]. Available from: http://cwm.unitar.org/publications/publications/inp.aspx

37. United Nations Institute for Training and Research (UNITAR). Developing and Sustaining an Integrated National Programme for the Sound Management of Chemicals (Guidance Document). New York, New York: UNITAR; 2004.; 66 p. Report No.: inp_gd_2004-05, v12$\operatorname{red}(\mathrm{r} 1)$

38. United Nations Environment Programme [Internet]. New York, New York: United Nations Environment Programme. National Implementation Plans of the Stockholm Convention [cited 2020 Feb 18]. Available from: http://chm.pops.int/Implementation/NationallmplementationPlans/NIPTransmission/tabid/253 /Default.aspx

39. United Nations Development Programme. Minamata Initial Assessment Report Suggested Structure and Contents. New York, New York: Inter-Organization Programme for the Sound Management of Chemicals (IOMC). $23 \mathrm{p}$.

40. European Chemicals Agency (ECHA) [Internet]. Helsinki, Finland: ECHA; 2020. Understanding REACH; 2020 [cited 2020 Feb 18]. Available from: https://echa.europa.eu/regulations/reach/understanding-reach 
CHAPTER 4

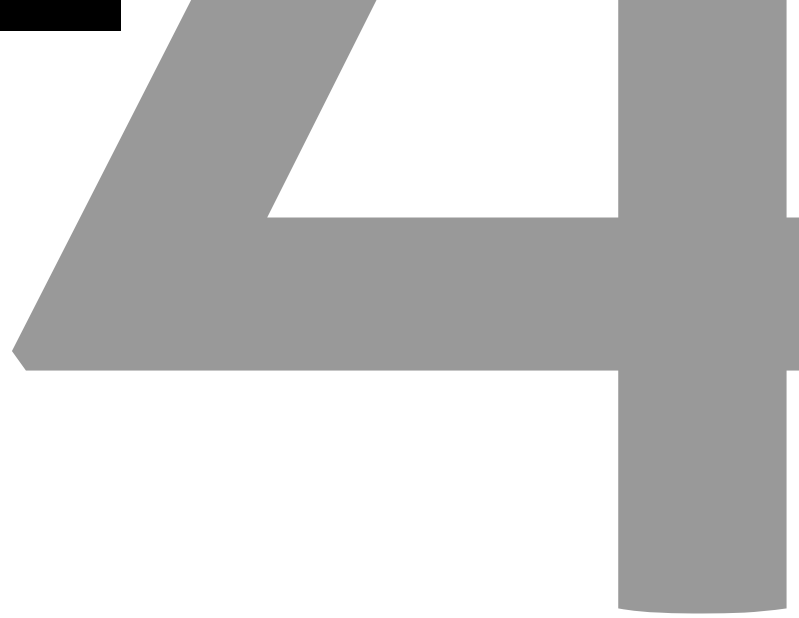




\section{Knowledge transfer to support evidence implementation in public health systems}

Book chapter published in Drowning - Prevention, Rescue, Treatment

Vincenten J, Gerdmongkolgan S. The role of policy in prevention. In: Bierens J, editor. Drowning - Prevention, Rescue, Treatment. Switzerland: Springer; 2014. p. 261-268. 


\section{What is Policy?}

Drowning is a major public health issue, which needs to be effectively addressed. Drowning prevention policies are a means to reduce the impact drowning has on individuals, families and communities as a whole. Policy can take the form of laws, regulations, standards, procedures or administrative frameworks that direct specific rules and or a plan of action. Therefore, policy sets the groundwork upon which actions will take place, serving as a key component to how we conduct ourselves in daily life. Public health policies have been in existence for many years and in some cases corresponding laws have been extremely effective in leading to changes in societal behaviours and norms that can save lives, such as the policies or laws that require the use of seatbelts.[1] The fact that something is the "law" will lead many people to comply with the legal requirements as part of social and moral expectations, which then can have an influence on behaviour. Activities to enforce laws, regulations and policies can further contribute to behaviour change by motivating through concrete consequences associated with the risk of being caught and punished. However, policies that are poorly constructed and difficult to monitor, have many exceptions and or are not actively enforced, will fail to result in the desired level of behaviour change.[2] Therefore it is essential that policies are well crafted and adapt evidence-based interventions to make them appropriate for the target group, setting and culture of the community in order to increase the probability of support and adoption by policy makers and the community.

In injury prevention, use of policy and legislation has been particularly successful in resulting in injury reductions when combined with education and engineering measures.[3] Policy uptake can be enhanced when followed by educational campaigning that attains support from the majority of the public. The World Report on Child Injury Prevention states there is evidence that legislation has increased the uptake of effective prevention measures and reduced childhood injuries in a number of areas including: child passenger restraints, seatbelts, bicycle helmets, motorcycle helmets, smoke alarms, child resistant containers, lower tap water temperature and isolation fencing of swimming pools.[4] Yet the overall number of evaluation studies on the effectiveness of injury prevention policies currently is low and in particularly in drowning prevention. 
Developing a specific drowning prevention policy, attaining uptake and ensuring effective enforcement can be a very challenging, political and lengthy process and therefore requires a base of support from individuals, community, professionals, coalitions and organisations with an understanding to support the value drowning prevention measures can bring.[5] Resistance to policies and legislation often occurs as a result of concerns about limiting individual autonomy, costs to implement or enforce the policy or perceived threats to the profit making opportunities of industry.[6] Yet governments have been given responsibility to intervene in order to protect the public when a clear risk of injury has been identified and evidence for an appropriate response is available.[2] Drowning prevention advocates can use policy as an important tool to increase the uptake of evidenced drowning prevention strategies. $^{1}$

\footnotetext{
1 Methods:

This chapter was prepared based on child injury prevention policy assessments conducted by the thesis author and co-authors as part of a broader Child Safety Report Card assessment project funded by the European Union. At the start of this project a narrative literature review was conducted to identify evidence-based drowning prevention policy interventions with a focus on the national level. Peer review literature was identified by searching PubMed and Google Scholar for articles published in English since 2000. Policy interventions known to be effective, but more likely to be established at the regional or local levels were not included. Search terms included: drowning prevention, water safety, good practice, evidence-based, evidence implementation, policies, legislations, regulations. Further good practice guidance from the grey literature was sought from two sources; the World Health Organization (WHO) and the Royal Life Saving Society were examined as drowning prevention experts. From this review 11 evidence-based drowning prevention policy interventions were identified. To determine the level of uptake of these policy interventions in European countries, an English language computer-based survey tool was developed with the support of a six-person expert advisory group composed of diverse researchers, academics and WHO specializing in injury prevention and water safety. The survey tool was used to collect data on the 11 drowning prevention policy interventions regarding levels of adoption, implementation and enforcement at the national level. To support the data collection, national liaisons were identified in order to contact the appropriate government departments to validate the information gathered from the survey. This policy assessment was undertaken in Europe with 18 countries in 2007, 24 countries in 2009 and 31 countries in 2011/2012. The results were reviewed and analysed for each data collection period following data collection. In 2012 a comparison between the assessment years was also undertaken to determine changes in policy uptake between countries, over time and to map this to national drowning rates. When preparing this thesis chapter, a narrative review was conducted to update the literature. A critical analysis was conducted of the complete report card process, results, assessments and comparisons and a reflection was made as to how these results are a key practice example as to the importance of uptake, or lack thereof, for evidence-based policies in a public health field.
} 


\section{What Type of Drowning Prevention Policies Exist?}

A diverse range of drowning prevention policies exists, but to date there is limited research measuring their effectiveness. Yet since experts agree that effective, well enforced policies are a valuable tool in reducing injuries and that there are proven or promising drowning prevention strategies involving engineering and educational approaches, introducing policies for these strategies should be investigated to determine their level of success in a specific location and setting. Therefore, a comprehensive approach to drowning prevention should consider policy adoption, implementation and enforcement in the following drowning prevention evidence-based measures:

Removing or covering water hazards (including, water drains, wells and cisterns) Governments, communities and private companies need to assume responsibility for ensuring that the environment is a safe place. Standards or legislation should be put in place to ensure adequate coverage of man-made water openings to reduce the risk of drowning. [7]

Requiring isolation fencing four-sided around swimming pools - In high-income countries, legislation on pool fencing that reduces exposure of unsupervised young children significantly reduces their risk of drowning. $[8,9]$ Such legislation should be prepared for not only public facilities but also private swimming pools as data in many countries have indicated both venues are locations for drowning.[10]

Reducing exposure to water sources - Drowning takes place as people go about their everyday activities, and this includes child drowning events that often take place in natural water sources.[11] Experts agree that reducing exposure to water sources can help prevent drowning. As a result, policies that support building safe crossings over canals and irrigation ditches, fencing in play areas near water and installing piped water systems to reduce exposure to open bodies of water, also help to reduce potential drowning incidents. This may be particularly true when such actions enhance the safety of children's routes to school.

Teaching children to swim - Research indicates that teaching children over the age of 5-years 
to swim for their own safety or survival is associated with reduced risk of drowning.[4, 10, 12] A cohort study in Bangladesh presented at the World Congress on Drowning Prevention in 2011, reported a 93\% reduction in drowning for children 4 years and older that learned to swim.[13] Mandating water safety education, including swimming lessons, as part of school curricula increases the likelihood that all children will receive swimming instruction, improve their swimming skills and increase their knowledge of water safety.

Promoting drowning prevention through physicians and community leaders - Advice from physicians and community leaders, as well as education programmes for parents and caregivers, can boost the awareness of drowning hazards and preventive actions and injury prevention overall.[15] Physicians and public health workers have both an understanding of the epidemiology and risk factors of drowning and easy access to families and the community.[15] As a result, a policy assigning primary health care units to systematically and continuously educate parents and caregivers on drowning prevention should be developed and implemented country-wide in both urban and rural areas as part of standard early childhood programmes responsible for child vaccinations and health interventions.

Conducting targeted awareness raising on drowning - Mass media campaigns have been shown to increase awareness, change attitudes and support face to face communication. Campaigns provide a context in which other strategies, such as the introduction and enforcement of new laws or policies, can succeed.[16] Therefore targeted water safety education is an important activity, particularly since new policy or legislation has a greater chance of being accepted and successful when a larger percentage of the public are already in support of the proposed change.

Wearing personal floatation devices - It has been reported that $90-100 \%$ of drowning victims were not wearing a life jacket.[12] Legislation requiring the use of a life jacket while travelling on water ways should be considered; and such laws should be strictly enforced.[17] Policies detailing the provision of size appropriate and properly designed personal floatation devices for all occupants of ferries and other vessels have the potential to save many lives.

Ensuring the presence of lifeguards/lifesavers at swimming areas - The presence of trained certified lifeguards greatly improves the outcome of non-fatal drowning because of 
immediate resuscitation.[18] The presence of lifeguards also deters risky behaviour and prevents dangerous events in the same way a police presence deters crime.[11] National and corresponding regional or municipal policies or laws that require training and regular certification of both voluntary and paid lifeguards at beaches and public swimming pools will enhance adherence to performance standards.

Reducing blood alcohol content - Alcohol is a risk factor for drowning among adolescents and adults.[12] Consuming alcohol while boating, diving or swimming should be legally prohibited and as strictly enforced as the drink-driving laws for road vehicles that have led to declining numbers of drink-driving incidents in several countries.[19] As well, advertisements promoting the use of alcohol while boating, swimming or diving and the sale of alcohol at water recreational facilities should be restricted to create a socio-cultural environment that promotes safe alcohol use.

Training in immediate resuscitation - Individuals who receive immediate resuscitation by bystanders before the arrival of medical personnel have improved outcomes.[14,20] Therefore, resuscitation training to allow immediate treatment on site is critical for all countries and particularly for LMICs where drowning often takes place in the countryside and more than half of drowning victims die at the scene.[15] It is therefore advisable to set school and community policies to make training on first aid and cardiopulmonary resuscitation available to the general public, including adolescents, so there are trained bystanders in the event of a non-fatal drowning incident. In some communities, first aid and resuscitation training are mandatory components to attaining a valid driving licence. Cultural considerations to reduce barriers to assisting strangers and the opposite sex may be required in some communities and cultures.

\section{What Types of Policy Have Been Adopted to Support Drowning Prevention?}

Countries around the world have adopted various policies on drowning prevention. As stated at the World Congress on Drowning Prevention 2011, in Vietnam, nine relevant Ministries have signed an inter-sectoral plan to address drowning prevention in that country with a 
Government allocated budget.[21] In Thailand, current policies require drowning prevention information to be provided to parents when children receive their in-hospital vaccinations, and relevant agencies are encouraged to bring survival swimming into the elementary physical education curriculum.[22, 23]

In Europe a review of national level child safety policy measures including those addressing water safety/drowning prevention has assessed the level of adoption, implementation and enforcement of 11 policies or laws where there is evidence or expert opinion to support their uptake:

- Requiring barrier fencing for public and private pools;

- Requiring use of personal floatation device/lifejacket while on the water;

- Requiring attainment of a standard for public swimming pools that mandates pool design, operation and maintenance for safety;

- Requiring attainment of a standard for water safety signs and symbols;

- Requiring regular recertification for lifeguards and a minimum number of lifeguards at public pools or on beaches or other area specified for water leisure activities;

- Requiring water safety education, including swimming lessons, as part of compulsory school curriculum;

- Requiring attainment of minimum safety standard for leisure/recreational programming at the community level (e.g., minimum levels of supervision, training or safety equipment, etc.);

- Mandating a national ministry/government department with responsibility for water safety;

- Establishing a government approved national injury prevention strategy with specific targets and timelines related to child and adolescent water safety;

- Establishing a national programme of child home visits that includes education on child water safety; and

- Establishing a national media campaign at least once in the past five years targeting child and adolescent water safety.[24] 
In a review of the policy assessments that were conducted as part of broader Child Safety Report Card assessments with 18 countries in 2007, 24 countries in 2009 and 31 countries in $2011 / 12$, it is evident that to date the recommended policies are not well adopted, implemented or enforced in the majority of countries assessed.[24] As of 2012, only eight countries (Bulgaria, France, Iceland, Israel, Italy, Lithuania Norway and Sweden) have a law that requires barrier fencing for private pools, and the law in Iceland is not well enforced. Eleven countries reported laws requiring barrier fencing around public pools: Austria, Bulgaria, Czech Republic, Iceland, Israel, Italy, Norway, Poland, Slovenia, Spain and Sweden. Only four countries (Bulgaria, Ireland, Latvia and Poland) require and enforce use of personal floatation devices (PFD) while on the water. Portugal has PFD legislation but indicates the law is not fully implemented and enforced. In Estonia, the law is limited to open watercraft of smaller than 24m. Eighteen other countries (Austria, Czech Republic, Denmark, Finland, France, Greece, Hungary, Iceland, Israel, Italy, Lithuania, Luxembourg, Malta, Norway, Romania, Slovakia, Slovenia and Spain) have laws that require only that the PFD be present in the watercraft while on the water. The law does not specify that it should be worn, which is not viewed as providing adequate protection for children.

A comparison between assessments in 2007 and 2012 for 16 countries found that improved scores reflected increased government leadership through clarifying mandated responsibility for child water safety, establishment of government-approved strategies, adoption of national laws addressing lifeguard supervision and recertification and introduction of laws requiring a presence of personal floatation devices; although as noted above the latter need to be strengthened to require actual use.

Uptake of water safety policies did not consistently correspond to lower rates of fatal drowning in participating countries, and the lack of correspondence likely reflects, at least in part, different levels of exposure to risk and variations in implementation and enforcement of policy measures between countries.[24] Enhancing data sources on drowning, and in particular non-fatal drowning and risk exposures would assist in understanding the impact of national strategies. In addition, it is important that specific monitoring take place pre and post policy implementation in countries to determine the effect of specific interventions on the reduction of drowning. 


\section{Research and Practice Recommendations to Advance Water Safety and Drowning Prevention Policies}

- Collect and analyse drowning data that can provide details on the location/communities, mechanism and groups at risk of non-fatal and fatal drowning to determine which policies should be prioritised for adoption, implementation and enforcement. Policy makers typically want numbers to see the size of the problem.

- Establish an evidence-based policy agenda that will impact drowning in communities at greatest risk within each country.

- Develop and foster partnerships with key water safety stakeholders at the national and community level to build a culture of water safety. In order to best influence policy and legislation to support drowning prevention, understanding, knowledge and skills related to water safety need to be formed at all levels, including individuals, community groups, schools, organisations, business and governments.

- Ensure drowning data are monitored consistently across regions (especially if numbers are small) so drowning incidents can be measured pre and post the introduction of a drowning prevention policy; this is critical to policy makers to see if the policy had impact.

- Adapt evidence-based policy interventions to make them appropriate for the target group, setting and culture of the community in order to increase the probability of support and adoption by policy makers and the community and policy effectiveness.

- Research evidence that the intervention is effective but also support from legal authorities that the policy or law can be easily implemented and enforced without excessive new costs and communicate this broadly as part of an education campaign.

- Review and investigate current water safety and drowning prevention policies and legislation to determine if there are gaps or areas that need enhancement to ensure their effectiveness for drowning prevention.

- Maximise efforts to influence policy and legislation. This can be done by having support of one or more advocates to champion the issue. Also, it is very important to time your policy request with current government priorities, drowning incidents, 
80 | Chapter 4

media interest or release of new evidence.

Policies and legislation should provide "practical wisdom" to guide governments, individuals and communities towards positive outcomes. Water safety/drowning prevention advocates can use policy and legislation as a powerful tool in conjunction with engineering and education to build and maintain safe and enjoyable environments for all. 


\section{References}

1. Chehimi S, Cohen L, Chavez V. Prevention is Primary. Strategies for Community Well-Being. 2nd edition. San Francisco: Jossey-Bass; 2007. 464 p.

2. Christoffel T, Gallagher Scavo S. Injury prevention and public health: practical knowledge, skills and strategies. 2nd edition. Sudbury: Jones and Bartlett Publishers; 2006. 495 p.

3. Stone DH. Injury Prevention in Children. A Primer for Students and Practitioners. Edinburgh: Dunedin Academic Press Ltd; 2011. 160 p.

4. Peden M, Oyegbite J, Ozanne-Smith M, Hyder A, Branche C, Fazlur Rahman AKM, et al. World Report on Child Injury Prevention. Geneva, Switzerland: World Health Organization and UNICEF; 2008. 59-78 p.

5. Cohen L, Swift S. The Spectrum of Prevention: Developing a Comprehensive Approach to Injury Prevention. Inj Prev. 1999;5(3):203-207. DOI: 10.1136/ip.5.3.203

6. MacKay JM, Vincenten J. Why isn't more injury prevention evidence-based. Intern Inj Control Safety Prom 2009; 16(2):89-96. DOI: 10.1080/ 17457300902836663

7. Celis A. Home drowning among preschool age Mexican children. Inj Prev 1997;3(4):252-256. DOI: 10.1136/ip.3.4.252

8. Tan RMK. The epidemiology and prevention of drowning in Singapore. Singapore Med J 2004; 45(7): 324-329.

9. Stevenson MR, Rimajova M, Edgecombe D, Vickery K. Childhood drowning: barriers surrounding private swimming pools. Pediatrics 2003;111(2):E115-E119. DOI: 10.1542/peds.111.2.e115

10. Sethi D, Towner E, Vincenten J, Segui-Gomez M, Racioppi F. European Report on Child Injury Prevention. Copenhagen: WHO Regional Office for Europe; 2008. 98 p.

11. World Health Organization. Guidelines for safe recreational water environments Volume 1 Coastal and fresh waters. Geneva: World Health Organization; 2003. 220 p.

12. World Health Organization [Internet]. Geneva: World Health Organization; 2014.Global report on drowning. Key facts. [cited 2020 May 26]. Available from: https://www.who.int/ violence_injury_prevention/global_report_drowning/WHO_Infographic_A4_1PAGE_ToWeb_RE V1.pdf

13. Talab A, Rahman A, Rahman F, Hossain J, Scarr J, Linnan M. Survival swimming - Effectiveness of SwimSafe in preventing drowning in mid and late childhood. In: Scarr J et al editors. World Conference on Drowning Prevention 2011. Leuven: International Life Saving Federation; 2011. p. 49 
14. Wigginton J, Pepe P, Mann D, Persse D, Sirbaugh P. The Critical Role of Lay Persons and Their Actions in Drowning Incidents. In: Bierens J. editor. Drowning. Berlin: Springer; 2014. p 583-587.

15. Bureau of Non-Communicable Diseases, Department of Disease Control, Ministry of Public Health. Situation Analysis of Child Drowning Surveillance in Thailand, Bangkok. Bangkok, Thailand; Ministry of Public Health; 2009. 1010 p.

16. Jernigan DH, Wright PA. Media Advocacy: lessons from community experiences. J Public Health Policy 1996;17:306-330. DOI: 10.2307/3343268

17. Chung C, Quan L, Bennett E, Kernic MA, Ebel BE. Informing policy on open water drowning prevention: an observational survey of life jacket use in Washington state. Injury Prevention 2014; 20:238-243. doi: 10.1136/injuryprev-2013-041005

18. Branche C, Stewart S. Lifeguard effectiveness: a report of the working group. Atlanta: Centers for Disease Control and Prevention, National Center for Injury Prevention and Control; 2001. 36 p.

19. Shults R, Elder RW, Sleet DA, et al. Review of evidence regarding interventions to reduce alcohol-impaired driving. American J Prev Med 2001;21(4):66-84. DOI: 10.1016/SO7493797(01)00381-6.

20. Kyriacou DN, Arcinue EL, Peek C, Kraus JF. Effect of immediate resuscitation on children with submersion injury. Pediatrics 1994;94(2):137-142. DOI:10.1016/0300-9572(95)99671-V

21. Nguyen A. Cross-sectoral approach to child drowning prevention and the coordination role of the Ministry of Labour, Invalids and Social Affairs in child drowning prevention. In: Scarr J et al editors. World Conference on Drowning Prevention 2011. Leuven: International Life Saving Federation; 2011. p. 38.

22. Gerdmongkolgan S, Ekchaloemkiet S. Policy advocacy on child drowning prevention in Thailand. In: Scarr J et al editors. World Conference on Drowning Prevention 2011. Leuven: International Life Saving Federation; 2011. p. 53

23. Ekchaloemkiet S, Gerdmongkolgan S. Arising the immune protection of the children drowned in Thailand. In: Scarr J et al editors. World Conference on Drowning Prevention 2011. Leuven: International Life Saving Federation; 2011. p. 52

24. MacKay M, Vincenten J. Child Safety Report Card 2012: European Summary for 31 Countries. Birmingham: European Child Safety Alliance; 2012. 58 p. 
Knowledge transfer to support evidence implementation in public health systems | $\mathbf{8 3}$ 


\section{CHAPTER 5}

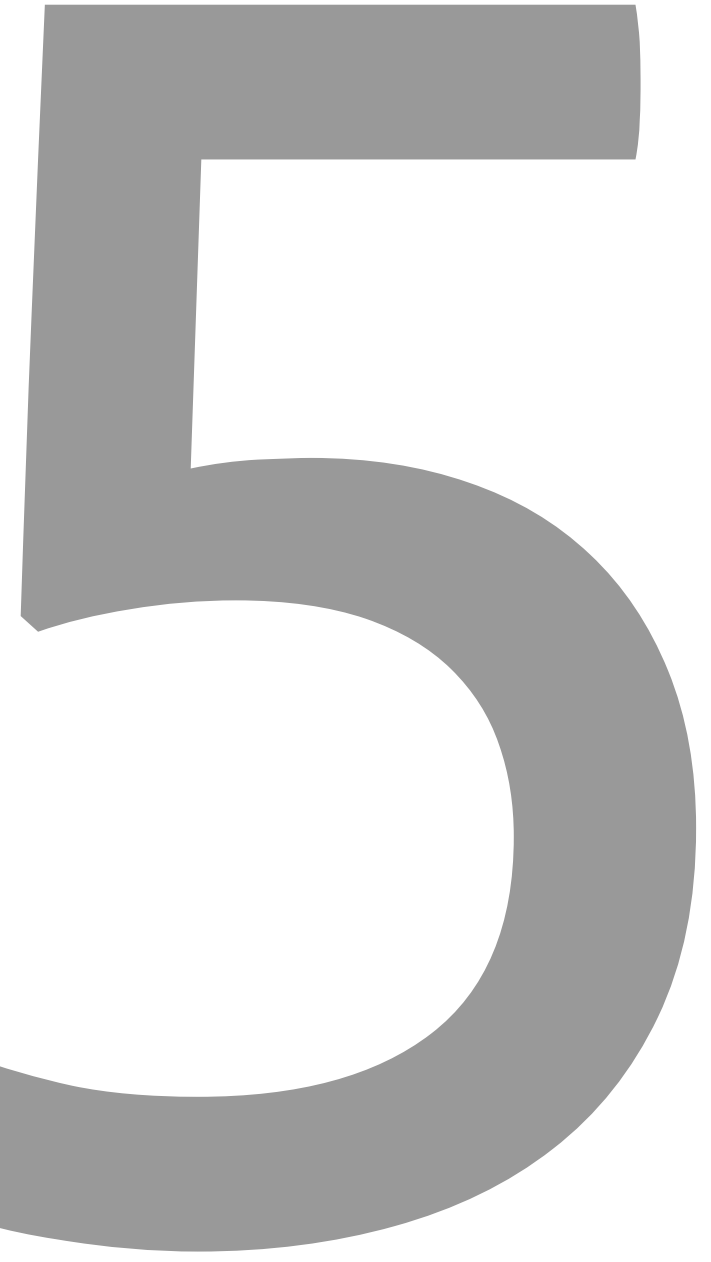




\section{Barriers and facilitators to evidence implementation in public health systems}

Published in the International Journal of Environment Research and Public Health (IF: 2.849)

Vincenten J, George F, Martuzzi M, Schröder-Bäck P, Paunovic E. Barriers and Facilitators to the Elimination of Asbestos Related DiseasesStakeholders' Perspectives. Int J Environ Res Public Health. 2017;14(10). pii: E1269. 


\begin{abstract}
Despite sound scientific knowledge and evidence that any exposure to asbestos fibers in any form is carcinogenic to humans, their presence, use and trade is still substantial, including in the World Health Organization (WHO) European Region. Banning the production and use of all forms of asbestos, as recommended by the International Labour Organization (ILO) and WHO, has been proven as the most efficient evidence-based strategy to eliminate asbestos related diseases (ARDs). To effectively move elimination of ARDs forward, attaining a greater understanding of key stakeholders' perspectives was identified as an important action. The WHO Regional Office for Europe, the European Centre for Environment and Health, undertook semi-structured interviews, and follow-up discussions with diverse representatives dealing professionally with asbestos. The interview questionnaire was developed based on the current ARDs WHO Report, the Evidence Implementation Model for Public Health and categories of the theory of diffusion. Data were attained on three main questions within the interview questionnaire: (1) Identifying barriers to implementation of WHO evidence-based asbestos recommendations; (2) Describing roles of key stakeholders; and, (3) Proposing possible solutions. The results demonstrated use of sound and convincing scientific evidence along with economic evidence and facilitators can be used to achieve evidence-based policy development, and comprehensive diverse actions.
\end{abstract}




\section{Introduction}

Despite sound scientific knowledge and evidence that any exposure to asbestos fibers in all forms is carcinogenic to humans, their presence, use, and trade is still substantial, globally and regionally, including in the World Health Organization (WHO) European Region.[1,2,3] Globally, more than 2 million metric tons of asbestos is still produced annually, with 99 percent generated by four countries-Russian Federation, China, Brazil, and Kazakhstan. Currently, 25 countries consume at least 1000 metric tons of asbestos per year, of which seven are in the WHO European Region (Belarus, Kazakhstan, Kyrgyzstan, Russian Federation, Turkmenistan, Ukraine, and Uzbekistan).[4,5]

Evidence-based strategies for the elimination of asbestos related diseases (ARDs) exist. Banning the production and use of all forms of asbestos as recommended by the International Labour Organization (ILO) and WHO, has been proven as the most efficient evidence-based strategy to eliminate ARDs [6]. Still, the safe removal and disposal of already existing and used asbestos is a continuous threat to human health, even after the introduction of the ban of the use of all forms of asbestos. Although many countries have stopped the use of asbestos for years or even decades, there are many old homes, schools, and public buildings that still contain asbestos insulation, flooring, ceiling tiles, shingles, siding, and other items. Asbestos that is in good condition, does not usually present a hazard. However, worn or damaged asbestos poses a great risk to the health and safety of humans, as fibers may flake off and become airborne, inhaled, and then embedded into the chest of those nearby during renovation or demolition projects if professional safety measures are not consistently used.[6] To date, 37 Member States out of 53 in the WHO European Region have adopted partial or total asbestos ban legislations, while countries not in support of any form of ban are still using and or producing asbestos.[6]

In addition to detecting diseases, establishing appropriate surveillance systems, and protection, while undertaking asbestos removal, appropriate replacement, and safe and efficient waste management should be consistently occurring throughout the WHO European Region, to address inequities created by harmful exposure to asbestos. $[7,8]$ 
Currently, some of the countries that did not introduce the ban of the use of asbestos are challenging this recommendation, often using economic arguments. They argue that the introduction of the ban of the use of all forms of asbestos will have negative economic impacts on national, private sector, and household income at national and regional levels.[4] Yet, available evidence does not support this argument. The WHO recent report "AsbestosEconomic assessment of bans and declining production and consumption" [4], stressed two key findings:

(1) There are no observable mid-or-long-term negative economic impacts from bans or a decline in asbestos production or consumption at the country-level, and no observable persistent negative effects at the regional level;

(2) There are substantial and increasing costs associated with the continuing production and use of asbestos, with the potential to far outweigh the short-term economic benefits.

To effectively move elimination of ARDs forward, attaining greater understanding of key stakeholders' perspectives and needs was identified as an important action. Therefore, the WHO Regional Office for Europe, the European Centre for Environment and Health (WHO/ECEH, Bonn, Germany), undertook in 2016 a stakeholder analysis.

The aim of this analysis was to attain deeper insights of key stakeholders opinions and perspectives across different sectors and policy fields regarding the promotion of evidencebased national policies for the elimination of ARDs and the potential influence and ability of the stakeholders concerned to make the change towards non-asbestos working and living environments. This stakeholder analysis contributed, in particular, to one of the commitments of the Parma Declaration to develop national programmes to eliminate ARDs by 2015 and reconfirmed in the Ostrava Declaration 2017.[9,10] 


\section{Materials and Methods}

The research method was qualitative and explorative, combining interviews and discussions with stakeholders. The questionnaire for the semi-structured interviews was developed based on information from a current ARDs WHO report [6] and the Evidence Implementation Model for Public Health Systems that offers insights into barriers and facilitators of uptake of effective strategies.[11] Furthermore, categories of the theory of diffusion were taken into account in formulating the interview questions.[12] The questionnaire was drafted by the first author and reviewed and edited by the other authors. In the questionnaire, three themes were focused on:

(1) identifying barriers to the implementation of WHO evidence-based asbestos recommendations;

(2) describing necessary and effective roles and actions of key sectors and stakeholders;

(3) proposing possible solutions, facilitators and next steps towards non-asbestos working and living environments, including policies for the elimination of ARDs.

Interviewees were identified by WHO/ECEH and contained a selected sample of country representatives, experts, intergovernmental organisations, nongovernmental organisations, and European Commission (EC) representatives, dealing with asbestos issues in their respective professional area. All of the interviewees gave their informed consent for inclusion before they participated in the interviews and the study was conducted in accordance with the Declaration of Helsinki and WHO protocol. Interviews were conducted using telephone or Skype by the first author. Language of the interviews was English or Russian (with the assistance of a Russian interpreter). The first interview conducted also served as a pre-test and adjustments for clarity were made accordingly. Confidentiality of interviews was communicated to the interviewee and agreed upon. Interviews were transcribed verbatim into a corresponding questionnaire template. Clarifications to the participant's comments were obtained by e-mail where required. 
Content analysis of the interviews was undertaken to provide concise summaries of participants' responses. Findings were grouped corresponding to the three interview themes noted above.[11,13]

A preliminary report of this analysis was circulated and presented to participants of the WHO meeting: "Assessing the economic costs of the health impacts of environment and occupational factors: the economic dimension of asbestos", 18-19 May 2016, Bonn, Germany. The preliminary results were validated by a plenary session, question, and answer discussion period, working group discussions and a final plenary reporting session. The results of the working group and plenary discussions were integrated into a preliminary and final text to prepare this article.

\section{Results}

A total of 21 stakeholders from 18 organisations participated in the stakeholder analysis interview process. A further 24 country representatives from 12 WHO European Countries and 20 temporary advisors from 16 institutions participated in the above cited WHO asbestos meeting. Data from stakeholders are presented on the three main questions within the interview questionnaire.

\subsection{Barriers to the Implementation of WHO Evidence-Based Asbestos Recommendations}

3.1.1. Leadership Barriers - Lack of political will, commitment, clear vision, goals, and targets to effectively address the negative impact of asbestos is often not identified, agreed upon or achieved by policy makers.

3.1.2. Management and Collaboration Barriers - Introducing a total ban of the use of all forms of asbestos is a complex undertaking that requires the collaboration of many sectors and disciplines to achieve effective action. Often collaborators may take some of the tasks or actions within their remit, but responsibility to lead and manage the whole chain of events is lacking.

3.1.3. Funding and Financing Barriers - Often financial and political interests are placed above health concerns, including the assumed important positive economic impact of the 
production, and marketing of asbestos on national, private sector, and household income. Currently the economic health costs of ARDs are predominately the burden of society (e.g., health insurance, pensions) and not industry. Costs for safe asbestos identification, removal, replacement, and waste management are high. Illegal removal of asbestos is underway (at reduced costs) that does not meet safety requirements, leaving the general public exposed to even greater health risks.

3.1.4. Capacity Building Barriers - There is a lack of awareness, understanding and knowledge regarding the issue of the negative health impacts of asbestos. This includes how to effectively address the harmful effects of under-reporting the negative impacts of asbestos and knowledge gaps of the real economic dimension of the use and production of asbestos in parts of Europe. This lack of information, knowledge, and expertise to undertake and finance asbestos removal, safe waste disposal, and replacement with safe alternatives affects many countries at this time.

3.1.5. Data Barriers - Data and registries on exposures, risk groups, mortality, morbidity, trends, short and long-term costs, essential to demonstrate the true impact of asbestos, are not readily available in many countries. Data are also not standardised in Europe to allow for cross-country comparisons. There is a need for evaluation methodologies, such as cost benefit analysis to support policy-solutions. Understanding when and how much asbestos needs to be removed, the associated costs of removal and replacement, and then how that compares to the negative health impact costs are needed.

3.1.6. Evidence-Based Strategies Barriers - Banning the use of all forms of asbestos as recommended by the ILO and WHO can be a challenging strategy to adopt, implement and enforce due to its inherent complexity. Few Member States with no asbestos banning legislation are not in agreement with this recommendation, claiming that in their countries there is no evidence of negative impacts on health from all forms of asbestos. Several Member States stated that more and better knowledge and awareness are required to meet European Union (EU) regulations/directives for occupational health and safety of asbestos removal and building renovations. 
3.1.7. Context Setting Barriers - Currently, there is a lack of political will amongst policy makers from several asbestos producing and using countries in banning asbestos as the most efficient way to eliminate asbestos-related diseases, as the benefits are only realised decades later and not during their immediate political term. Varying economic and social settings in countries create additional barriers to reducing the negative impact of asbestos. These include communities with mines, natural forms of asbestos, extensive existence of asbestos in road infrastructure, and the majority of public and private buildings containing asbestos. Furthermore, research related to health is sometimes financed by the asbestos industry itself, and in some cases are used as questionable "evidence" for policy solutions. As well, an influx of migrant workers with limited language skills in their newly employed location may also lead to limited awareness or knowledge of asbestos risks and a challenge to monitor. This includes lack of training and training material not available in migrant workers' native language and often no migrant worker occupational health protection.

3.1.8. Visibility and Communication Barriers - Key messages to the public and decision makers are lacking regarding: risks, impacts, revealing false claims, illegal trade, international conventions, and declarations not being upheld, prevention measures, safe removal, total real costs, and valid information sources.

\subsection{Roles of Key Stakeholders}

3.2.1. Whole-of-Government and Whole-of-Society Approach - Interviewees and workshop participants expressed their strong opinion that a whole-of-government and whole-of-society approach would be required to successfully address all of the negative impacts of asbestos. This means that all levels of government and all related sectors, using cross-ministerial committees. Governments need to consider the long-term health effects to balance the immediate financial or political demands and interests asbestos appears to provide.

3.2.2. Industry, Employers, Trade Unions, Employees, and Victims - Even in the countries that introduced the total ban of use of all forms of asbestos, removal of the existing asbestos is still potentially a significant risk to health if the appropriate measures are not applied. Having 
that in mind, the responsibility of the industry, both in asbestos producing and asbestos using countries, as well as in the countries with introduced bans, cannot disregard including compensation funds for ARD victims. Industry also needs to share knowledge on safe removal practices and safe alternatives to asbestos to help build a win/win situation.

3.2.3. Experts/Professionals, Intergovernmental and Nongovernmental Organisations Stakeholders with knowledge and information should ensure evidence and good practices are shared, widely communicated, and advocated to increase their adoption, implementation, and monitoring. Research also needs to be accessible and widely communicated, including the use of plain language summaries, tailored to each target audience to help move research into practice and thereby support effective knowledge translation.

3.2.4. Media, General Public and Champions of the Asbestos Cause - Communicators also have a strong role to bring greater attention to the issue and apply pressure to attain action to protect and safeguard workers and the society as a whole. They need to be engaged and empowered as key stakeholders in the process. Therefore, all of society has an important role to play to address the negative impacts of asbestos.

\subsection{Proposed Solutions, Facilitators, and Next Steps to Address Indentified Barriers}

3.3.1. Leadership, Management, Collaboration and Funding Proposed Solutions to Address the Negative Impacts of Asbestos

Government plans, programmes, and policies to support early identification, removal, transition, and waste management of asbestos to new, safer, and efficient alternatives, with the involvement of all key stakeholders should be investigated. This should include investigation of funding schemes, such as a percentage of programme funds for victims' compensation from asbestos producing industries, as already demonstrated in some Member States.

Establishment of an agency/task force/observatory/knowledge centre at the European level to provide support to countries for the adoption and implementation of evidence-based strategies to enhance awareness raising; capacity building; standardisation; and, consistency 
and stability of various approaches for diagnosis, surveillance, trends, policy approaches, funding, and budgeting models was proposed by stakeholders. This would include implementing more effective legislation to protect employees and the health of the general public, as well as, the identification of funding sources and should be discussed in collaboration with WHO, EC, European Agency for Safety and Health at Work (EU-OSHA), ILO, Organization for Economic Co-operation and Development (OECD) (see table 1), and other lead agencies.

Key stakeholders and especially intergovernmental organisations and nongovernmental organisations should jointly advocate for a total ban on the use of all forms of asbestos throughout the WHO European Region. Economic arguments learnt from the Bonn workshop should provide additional evidence and proposals to support this action. 
Table 1. Specific suggestions for partnerships to support elimination of asbestos related diseases (ARDs)

\begin{tabular}{|c|c|c|}
\hline $\begin{array}{l}\text { Facilitator } \\
\text { Method }\end{array}$ & Partners * & Specific Action \\
\hline Leadership & $\begin{array}{l}\text { WHO Regional Offices } \\
\text { International Labour Organization (ILO) }\end{array}$ & $\begin{array}{c}\text { Call for a complete ban on the use and } \\
\text { production of all types of asbestos in the WHO } \\
\text { European Region and link to a global ban. }\end{array}$ \\
\hline Leadership & European Commission (EC) & $\begin{array}{l}\text { Explore means to put more asbestos related } \\
\text { legislation and or stringent conditions in place } \\
\text { as part of country requirements to join the EU. }\end{array}$ \\
\hline Data & $\begin{array}{l}\text { WHO European Region Member States } \\
\text { Organization for Economic Co-operation } \\
\text { and Development (OECD) }\end{array}$ & $\begin{array}{l}\text { Collect and publish data through public report } \\
\text { cards with performance indicators related to } \\
\text { asbestos, including costs assessments by } \\
\text { country. }\end{array}$ \\
\hline $\begin{array}{l}\text { Management } \\
\text { and } \\
\text { coordination }\end{array}$ & WHO European Region Member States & $\begin{array}{l}\text { Support countries to develop and maintain } \\
\text { regularly, their National Programme for the } \\
\text { Elimination of ARDs (NPEAD) with existing } \\
\text { tools. }\end{array}$ \\
\hline Capacity & $\begin{array}{l}\text { WHO European Region Member States } \\
\text { WHO Regional Offices } \\
\text { Non Governmental Organisations (NGOs) } \\
\text { European Environment Agency (EEA) } \\
\text { European Agency for Safety and Health at } \\
\text { Work (EU-OSHA) }\end{array}$ & $\begin{array}{l}\text { Support capacity building with prevention } \\
\text { courses, drafting legislation, and good practice } \\
\text { guidelines such as diagnosis criteria of ARDs, } \\
\text { safe and economical identification, removal, } \\
\text { replacement and waste management of } \\
\text { asbestos. }\end{array}$ \\
\hline Capacity & $\begin{array}{c}\text { WHO European Region Member States } \\
\text { WHO Regional Offices } \\
\text { European Environment Agency (EEA) } \\
\text { European Agency for Safety and Health at } \\
\text { Work (EU-OSHA) } \\
\text { International Labour Organization (ILO) } \\
\text { Organization for Economic Co-operation } \\
\text { and Development (OECD) } \\
\text { Non-Governmental Organisations (NGOs) } \\
\text { Asian Development Bank (ADB) } \\
\text { World Bank (WB) }\end{array}$ & $\begin{array}{l}\text { Support sharing of country case examples and } \\
\text { enhanced data collection and data monitoring, } \\
\text { including health evaluation and using } \\
\text { methodologies to other health end points that } \\
\text { are standardised globally to demonstrate co- } \\
\text { benefits to other sectors such as environment, } \\
\text { labour, justice, and tourism to address health } \\
\text { issues. }\end{array}$ \\
\hline
\end{tabular}

Table contains a listing of facilitator methods partners can undertake through specific actions listed.

* The list of partners is restricted due to limited space 
3.3.2. Evidence-Based Strategies and Proposed Solutions to Address the Negative Impacts of Asbestos

The total impact costs of asbestos at the local, regional, and national levels, including longterm health consequences, asbestos identification, removal, replacement, and waste management are needed, and the cost responsibilities of all the parties should be calculated. This could include, short-mid-long-term budgeting strategies, impact assessments, cost benefit analysis, such as cost of asbestos substitutes, and case examples of building costs with asbestos when compared to safer alternatives, as well as landfill management costs.

Collaboration with industry and other key stakeholders for effective and efficient strategies on identification, safe removal, transition to safe alternatives and waste management of asbestos need further investigation.

Further research on the effective use of new technologies and availability of low cost, safe, and easy to use alternatives should be conducted and communicate results widely. More case studies and good examples of how countries are addressing the issue of asbestos, specifically including removal guidelines/legal criteria and cost examples of safe removal, waste management, and replacement schemes, as compared to the negative health impact costs could be shared.

3.3.3. Data and Context Setting Proposed Solutions to Address the Negative Impacts of Asbestos

Standardised and harmonised data registration systems for ARDs in all of the countries to ensure effective monitoring should be put in place. Countries with long-established, effective data collection systems, could share methodologies for establishing and sustaining such data collection systems. The sharing of misinformation that are contrary to evidence and positions widely accepted and published by the majority of the scientific and expert community need to be immediately addressed. False statements are to be rejected and widely communicated. 
3.3.4. Visibility, Awareness Raising and Capacity Building Proposed Solutions to Address the Negative Impacts of Asbestos

Visibility, awareness, and education of all target audiences, from the general public, workers, professionals, and governments on such topics as early detection and risk group identification for youth and migrant workers exposed to asbestos, require improvement. Targeted tools and resources should be determined on evidence-based strategies and include better use of science.

Further to these proposed solutions and next steps, participants also provided specific suggestions WHO should undertake to facilitate actions to address the negative health impacts of asbestos. These are described in Table 1.

\section{Discussion}

Even though addressing the elimination of ARDs is a challenging issue within a complex system, use of sound and convincing scientific evidence along with different types of economic evidence and or facilitators can be used to achieve evidence-based policy development, and comprehensive diverse actions.[14] Exposure to all forms of asbestos causes high negative health impacts.[15] The substantial and increasing costs associated with the continued production and use of asbestos far outweigh the short-term and often only local economic benefits. [4] There is a trend that countries are moving away faster than before from asbestos use and this pattern needs to be maximised by sharing the lessons learned, including the mid- and long-term potential economic benefits after banning asbestos such as evolvement of sustainable industry and reduced health sector costs.[4,16] The discussion and conclusions that follow are based on the responses of the stakeholders.

Enhanced, early engagement and cooperation of diverse sectors and stakeholders throughout the entire process of adoption, implementation, and monitoring of evidence-based policies and programmes to eliminate ARDs, based on a whole-of-government and whole-of-society approach, will support the knowledge translation process, as seen in other evidence implementation research.[11] Overall, empowering a lead agency so initiatives and actions can be coordinated is essential. [17] With the case of asbestos, a lead role from the Ministry of 
Health, in providing the evidence on health effects, with cooperation and collaboration of multiple diverse ministries, including but not limited to labour, trade, industry, environment, education, customs, financial affairs/economy, would be beneficial. To attain true partner participation, co-benefits to addressing the negative health impacts of asbestos need to be demonstrated to other sectors to secure their political and financial commitment.

Greater efforts to transfer evidence-based strategies and knowledge into practice are essential to reduce ARDs. Particularly, attention in synthesising, translating, and disseminating evidence into concise, clear, easy to understand, and convincing information is needed, such as, economic arguments designed for each specific target audience, context, and cultural setting.[18] This should include the standardisation and harmonisation of easy to use tools and resources that will maximise current technology and should be made available and be provided as part of an awareness raising and mentoring process with key stakeholders, to build capacity and broaden the network needed to address ARDs. In turn this should increase visibility, mentoring, and capacity building of all of the key stakeholders so greater awareness and knowledge is attained about the risks, prevention, and management of asbestos, including strengthening capacity for diagnosis and surveillance.

Well-established national cancer registers and national registers of occupational diseases are the key resources for registering asbestos-related morbidity. Awareness, diagnostic procedures, and criteria, notification and registration of ARDs vary between countries and are in need of strengthening and harmonisation. There is still a need to strengthen research on the prevention, diagnosis, and treatment of ARDs. The main areas for action include capacity building of health care providers for the appropriate diagnostics of ARDs, active surveillance of ARDs; better diagnoses of ARDs; and, epidemiological investigation of individual cases of ARDs. In addition to establishing appropriate links between exposures and ARDs; medical research into the treatment of mesothelioma to improve the quality of life and the survival rate, effective early intervention followed by early detection of ARDs is essential.

Identifying barriers that impact the uptake of policies and programmes for the elimination of ARDs and standardise and harmonise ways these can be addressed is critical.[19,20] Such barriers include business, economic, and political interests; lack of leadership and 
commitment; gaps in data; and insufficient support and funding for transition from asbestos to safe alternatives. Completion and maintenance of national profiles and development, implementation, and monitoring of a National Program for the Elimination of AsbestosRelated Diseases, including time bound, measurable targets in each country are essential to effectively address barriers and provide facilitators for a strategic approach to addressing ARDs.[6]

It should be noted that some contexts in interview statements made may not be precise, as not all of the participants and interviewees were fluent in both English and Russian and should be viewed as a limitation of the study. Assistance of English/Russian interpreters were used to support the data and information gathering for both the interviews and the workshop to allow participants to fully engage and enhance the accuracy of communication.

\section{Conclusions}

The substantial and increasing costs associated with the continued production and use of asbestos far outweigh the short-term and often only local economic benefit. The use of sound and convincing scientific and economic evidence in combination can be used to make convincing arguments to support the uptake of evidence-based policy actions. Key stakeholders, including WHO needs to be empowered to take on a leadership role to advance the uptake of evidence-informed policies and programmes to further the 2030 Agenda for achieving the United Nations Sustainable Development Goals that includes goal number 12, "Responsible Consumption and Production."[21] This should include the important role of forming large consensus stakeholder groups, nationally and internationally, with a common vision to design, implement, and monitor effective policy solutions. Noting that, banning the production and use of all forms of asbestos, as recommended by the International Labour Organization and WHO, continues to be the most efficient and proven evidence-based strategy to eliminate ARDs. 


\section{References}

1. International Agency for Research on Cancer. Arsenic, Metals, Fibers and Dusts. Volume 100C. A Review of Human Carcinogens; International Agency for Research on Cancer, Lyon, France, International Agency for Research on Cancer. Arsenic, Metals, Fibers and Dusts. Volume 100C. A Review of Human Carcinogens. Lyon, France: International Agency for Research on Cancer; 2012. $497 \mathrm{p}$.

2. Offermans NS, Vermeulen R, Burdorf A, Goldbohm RA, Keszei AP, Peters S, et al. Occupational asbestos exposure and the risk of esophageal, gastric and colorectal cancer in the prospective Netherlands Cohort Study. Int J Cancer. 2014;135(8):1970-1977. DOI: 10.1002/ijc.28817

3. Ramazzini C. The 18th Collegium Ramazzini Statement: The global health dimensions of asbestos and asbestos-related diseases. Scand J Work Environ Health. 2016; 42(1):86-90. DOI: 10.5271/sjweh.3541

4. Allen LP, Baez J, Stern ME, George F. Asbestos-Economic Assessment of Bans and Declining Production and Consumption. Copenhagen, Denmark: World Health Organization Regional Office for Europe; 2017. 39 p.

5. Ogunseitan, OA. The asbestos paradox: Global gaps in the translational science of disease prevention. Bull World Health Organ. 2015; 93:359-360. DOI: 10.2471/BLT.14.142307

6. World Health Organization. Towards the Elimination of Asbestos-Related Diseases in the WHO European Region: Assessment of Current Policies in Member States, 2014. Copenhagen, Denmark: World Health Organization Regional Office for Europe; 2015. 26 p.

7. Martuzzi M, Mitis F, Forastiere F. Inequalities, inequities, environmental justice in waste management and health. Eur J Public Health. 2010; 20(1):21-26. DOI: 10.1093/eurpub/ckp216

8. World Health Organization. Environmental Health Inequalities in Europe. Assessment Report 2012. Copenhagen, Denmark: World Health Organization Regional Office for Europe; 2012. 192 p.

9. World Health Organization. WHO Europe Parma Declaration on Environment and Health. Copenhagen, Denmark: World Health Organization Regional Office for Europe; 2010. 10 p. Report No.: EUR/55934/5.1 Rev. 2

10. World Health Organization. WHO Europe Ostrava Declaration on Environment and Health. Copenhagen, Denmark: World Health Organization Regional Office for Europe; 2017.5 p. Report No.: EURO/Ostrava2017/6

11. Vincenten J, Schröder-Bäck P, MacKay $M$, Brand $H$. Factors influencing implementation of evidence-based interventions in public health systems. Cent Eur J Public Health. 2019;27(3):198- 
203. DOI: $10.21101 /$ cejph.a5234

12. Greenhalgh T, Robert $G$, Macfarlane $F$, Bate $P$, Kyriakidou $O$. Diffusion of innovations in service organizations: systematic review and recommendations. Milbank Q. 2004; 82(4):581-629. DOI:10.1111/j.0887-378X.2004.00325.x

13. Scholtes B, Schröder-Bäck P, MacKay J M, Vincenten J, Förster K, Brand H. Facilitators and Barriers for the Adoption, Implementation and Monitoring of Child Safety Interventions: a multinational qualitative analysis. Inj Prev. 2017;23(3):197-204. DOI:10.1136/injuryprev-2016-042138.

14. Hunter DJ. Evidence-informed policy: In praise of politics and political science. Publ Health Panor. 2016;2(3): 268-272.

15. Marsili D, Terracini B, Santana VS, Ramos-Bonilla JP, Pasetto R, Mazzeo A, et al. Prevention of asbestos-related disease in countries currently using asbestos. Int J Environ Res Public Health. 2016;13(5):494. DOI:10.3390/ijerph13050494

16. Le GV, Takahashi K, Karjalainen A, Delgermaa V, Hoshuyama T, Miyamura Y, et al. National use of asbestos in relation to economic development. Environ Health Perspect. 2010;118(1):116-119. DOI: 10.1289/ehp.0901196

17. Yost J, Dobbins M, Traynor R, DeCorby K, Workentine S. Greco L. Tools to support evidenceinformed public health decision making. BMC Public Health. 2014;14(1):728-41. DOI: 10.1186/1471-2458-14-728

18. Oliver K, Lorenc T, Innvær S. New directions in evidence-based policy research: a critical analysis of the literature. Health Res Policy Systems. 2014;12(7):34-45. DOI: 10.1186/1478-4505-12-34

19. Oliver K, Innvar S, Lorenc T, Woodman J, Thomas J. A systematic review of barriers to and facilitators of the use of evidence by policymakers. BMC Health Serv Res. 2014;14(1):2-14. DOI: 10.1186/1472-6963-14-2

20. Humphries S, Stafinski T, Mumtaz Z, Menon D. Barriers and facilitators to evidence-use in program management: A systematic review of the literature. BMC Health Serv Res. 2014;14(1):171-186. DOI: 10.1186/1472-6963-14-171.

21. United Nations [Internet]. New York, United States of America: United Nations; 2015. Transforming Our World: the 2030 Agenda for Sustainable Development. [updated 2019 May 3; cited 2020 May 24]. Available from: https://www.un.org/sustainabledevelopment/sustainabledevelopment-goals/ 
CHAPTER 6

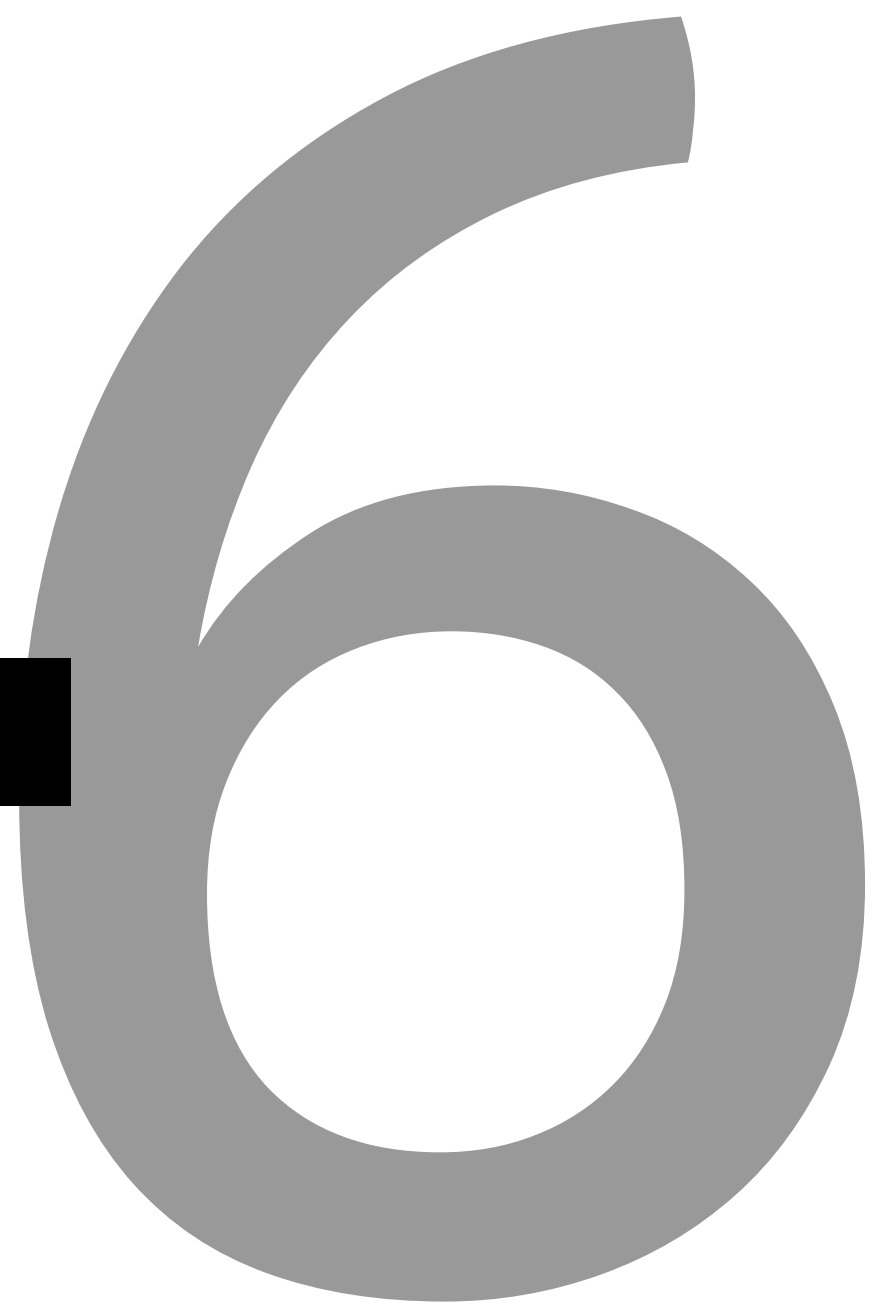


General Discussion and Conclusion 


\section{Chapter 6 - General Discussion and Conclusion}

This thesis aimed to determine the key components, conditions and factors, such as setting targets, identifying actors and stakeholders involved, knowledge transfer, and barriers and facilitators relevant to advance the knowledge base for the implementation of evidence in public heath systems. The thesis focuses on four areas of interest regarding the implementation of evidence within public health systems: structural and process components to support evidence implementation (Chapter 2); key stakeholders involved in evidence implementation and impacts on target setting (Chapter 3); knowledge transfer to support evidence implementation (Chapter 4); and barriers and facilitators to evidence implementation (Chapter 5). In the discussion that follows, the key findings of the research undertaken are summarized and the research questions posed are answered. An overview of the main findings of this thesis is provided in Table 1. A discourse then shares how this research addresses the value and complexities of evidence implementation, examples of current policy and programme actions supporting the thesis main findings, and suggested conditions that could support the advancement of the knowledge base for the implementation of evidence in public health systems. 
Table 1. Main findings for this thesis: Advancing the implementation of evidence in public health systems in Europe and globally

\begin{tabular}{|c|c|c|c|c|}
\hline $\begin{array}{c}\text { Thesis four } \\
\text { areas of } \\
\text { focus }\end{array}$ & $\begin{array}{c}\text { Model/Framework } \\
\text { Chapter } 2\end{array}$ & $\begin{array}{c}\text { Actors/Targets } \\
\text { Chapter } 3\end{array}$ & $\begin{array}{c}\text { Knowledge } \\
\text { Transfer } \\
\text { Chapter } 4\end{array}$ & $\begin{array}{c}\text { Barriers/Facilitators } \\
\text { Chapter } 5\end{array}$ \\
\hline $\begin{array}{l}\text { Chapter } \\
\text { titles of } \\
\text { the four } \\
\text { focus areas }\end{array}$ & $\begin{array}{l}\text { Structure and process } \\
\text { components to } \\
\text { support evidence } \\
\text { implementation in } \\
\text { public health systems. }\end{array}$ & $\begin{array}{c}\text { Key stakeholders } \\
\text { involved in evidence } \\
\text { implementation in public } \\
\text { health systems. }\end{array}$ & $\begin{array}{c}\text { Knowledge } \\
\text { transfer to } \\
\text { support evidence } \\
\text { implementation } \\
\text { in public health } \\
\text { systems. }\end{array}$ & $\begin{array}{c}\text { Barriers and } \\
\text { facilitators to } \\
\text { evidence } \\
\text { implementation in } \\
\text { public health } \\
\text { systems }\end{array}$ \\
\hline $\begin{array}{c}\text { Chapter } \\
\text { publication } \\
\text { titles }\end{array}$ & $\begin{array}{l}\text { Factors influencing } \\
\text { implementation of } \\
\text { evidence-based } \\
\text { interventions in public } \\
\text { health systems - a } \\
\text { model }\end{array}$ & $\begin{array}{c}\text { Priorities for improving } \\
\text { chemicals management } \\
\text { in the WHO European } \\
\text { Region - Stakeholders' } \\
\text { views }\end{array}$ & $\begin{array}{l}\text { The role of policy } \\
\text { in prevention }\end{array}$ & $\begin{array}{c}\text { Barriers and } \\
\text { facilitators to the } \\
\text { elimination of } \\
\text { asbestos related } \\
\text { diseases - } \\
\text { stakeholders' } \\
\text { perspectives }\end{array}$ \\
\hline $\begin{array}{l}\text { Main } \\
\text { findings }\end{array}$ & $\begin{array}{l}\text { The model's four } \\
\text { concepts (targets; } \\
\text { actors involved; } \\
\text { knowledge transfer; } \\
\text { and barriers and } \\
\text { facilitators) provide a } \\
\text { condensed yet broad } \\
\text { framework that } \\
\text { highlights multiple } \\
\text { factors and linkages } \\
\text { within and between } \\
\text { concepts that } \\
\text { influence evidence } \\
\text { implementation in } \\
\text { public health systems. }\end{array}$ & $\begin{array}{l}\text { Priorities raised differed } \\
\text { depending on } \\
\text { knowledge, professional } \\
\text { background and } \\
\text { stakeholder type. Factors } \\
\text { influencing priority } \\
\text { identification at the } \\
\text { national level include } \\
\text { international and global } \\
\text { context, information } \\
\text { available, knowledge of } \\
\text { the current situation and } \\
\text { evidence-based good } \\
\text { practice, and risks and } \\
\text { priorities identified } \\
\text { through national } \\
\text { assessments. }\end{array}$ & $\begin{array}{l}\text { Introducing } \\
\text { policies for } \\
\text { evidence-based } \\
\text { good practice } \\
\text { interventions } \\
\text { should be } \\
\text { investigated to } \\
\text { determine their } \\
\text { level of success in } \\
\text { a specific location } \\
\text { and setting to } \\
\text { support } \\
\text { knowledge } \\
\text { transfer and } \\
\text { evidence } \\
\text { implementation. }\end{array}$ & $\begin{array}{l}\text { Use of sound and } \\
\text { convincing scientific } \\
\text { evidence along with } \\
\text { different types of } \\
\text { economic evidence } \\
\text { and/or facilitators } \\
\text { that reduce } \\
\text { barriers, can be } \\
\text { used to achieve } \\
\text { evidence-based } \\
\text { policy development } \\
\text { and comprehensive } \\
\text { diverse actions. }\end{array}$ \\
\hline
\end{tabular}




\subsection{Summary of main research findings and research questions}

6.1.1. Chapter 2 - Structure and process components to support evidence implementation in public health systems

Research Question: What key components, factors and concepts have an influence on the evidence implementation process within public health systems that need to be better understood?

Over the course of this investigation the aim was to understand the factors and concepts, and the interlinking of these concepts, that influence the implementation of evidence within public health systems. Depth of information was gained by examining the critical literature from the existing body of work on evidence implementation and leading institutions websites and knowledge centers known for generating, preparing and translating the evidence base for policy making. A further review included relevant findings of 32 real time evidence-based interventions across 24 countries to test and refine the concepts, provide greater insight to practical aspects, and complex political realities of evidence implementation.

The main findings related to this thesis from this investigation resulted in the creation of the Evidence Implementation Model for Public Health Systems. (Figure 1, Chapter 2) The model is composed of four concepts or themes: 1) Evidence implementation target (first circle), critical to set joint aims to be achieved for implementation; 2) Actors involved in implementation (second circle), included the key stakeholders of decision makers, researchers, knowledge brokers and implementers to support the desired target audience of the evidence implementation; 3) Knowledge transfer (third circle) includes stages in a recursive process that has no set start or ending, but rather stages that are continually examined and addressed while moving back and forth between each of the stages: identifying and assessing the problem; gathering, analysing and synthesising evidence; using evidence; and assessing evidence uptake; 4) Barriers and facilitators to evidence implementation (fourth circle) is a diverse set of factors that at any point in the knowledge transfer process can influence the success of evidence implementation. These include leadership, management and collaboration, funding, capacity, data, visibility of the issue 
being addressed, the evidence-based intervention itself and the context setting. Overall, the model provides a simplified, yet broad framework that highlights multiple factors and back and forth inter-linkages within and between the concepts that influence the uptake of evidence into public health systems policy and practice.

This research has contributed to the thesis sub and main research question by exploring the factors that influence evidence implementation and then identifying concepts and themes that are interlinked to form a model that considers the complexity of public health systems, yet provides practical guidance to support the uptake of evidence in policy and practice.

Concluding remark and summary statement: Understanding the factors discussed within and amongst the four concepts of this model will ultimately help to positively influence the uptake of evidence in real world public health systems. This model has relevance for decision makers, researchers, knowledge brokers and implementers to impact change for the implementation of evidence into public health systems.

6.1.2. Chapter 3 - Key stakeholders involved in evidence implementation in public health systems

Research Question: What are the roles and responsibilities of key stakeholders involved, and how do these influence setting priorities and targets for improving chemicals management in the WHO European Region?

In this study the aim was to understand if diverse stakeholders had different perspectives on chemical safety management for: 1) Priority issues to be addressed; 2) Roles and responsibilities of various stakeholders; and 3) How science and knowledge on chemicals can be translated into policies more effectively, and which barriers were the greatest to overcome within the WHO European Region. The framework for this study was based on the Evidence Implementation Model for Public Health Systems (Figure 1, Chapter 2).

The main findings from this study related to this thesis were derived from key stakeholder representative interviews from Central Asia, Central and Eastern Europe and Caucasus, and 
Member States of the European Union. Interview probing took place to obtain specific information for the country context, professional role of each stakeholder, as well as interviewees views, values and beliefs relating to chemical safety, with the intent to gain greater depth of information and understanding of how key stakeholders influence setting priorities and targets within the process of evidence implementation.

Respondents from different sectors of chemical safety management had variation in their priorities. Government representatives' priorities were focused on chemicals legislation, industry and private sector raised the priority for increased collaboration, researchers identified the need for further research to fill identified gaps as a priority and nongovernmental organisation raised the priority of specific chemical hazards to food, water, air and soil in addition to the need for greater transparency. The respondents had the same vision on roles and responsibilities of different stakeholders. Overall respondents supported and in principle their views corresponded to international policy frameworks and priorities to increase chemical safety adopted by the United Nations. Cross cutting issues, such as legislation strengthening and enforcement, enhanced collection of information, capacity building, education and awareness raising were considered priorities, by all actors and key stakeholders. However, national context and settings influenced the views of the respondents in terms of chemical groups of specific concern. The greatest barrier to adoption, implementation and enforcement of evidence-based policies reported by respondents was leadership and political commitment by stakeholders and actors to chemical safety.

This research has contributed to the thesis sub and main research question by investigating and gaining further understanding of how actors' knowledge, skills, perspectives and views influence setting priorities and targets to the evidence implementation process.

Concluding remark and summary statement: Priorities raised differed depending on knowledge, professional background and type of stakeholder. Factors influencing priority identification at the national level include international and global context, availability of information, knowledge of the current situation and evidence-based good practice, and risks and priorities identified through national assessments. Early, active, and respectful, sustained engagement of diverse actors, sectors and key stakeholders is required to understand views 
and values, and to enhance knowledge, capacity, leadership and commitment for effective evidence implementation.

6.1.3. Chapter 4 - Knowledge transfer to support evidence implementation in public health systems

Research Question: What role can policy have to support knowledge transfer in existing evidence-based drowning prevention interventions?

In this study the aim was to examine what evidence-based drowning prevention interventions existed and determine how polices and legislation could be applied to each intervention to further support drowning prevention measures globally.

The main findings related to this thesis were derived through examination of the evidencebased drowning prevention interventions that exist and determine how policies and legislations could be applied to each intervention to further support implementation of drowning prevention measures globally. Overall, it was determined that it is essential that policies are well crafted and to adapt evidence-based interventions to make them appropriate for the target group, context setting, and time needed, in order to increase the probability of support and adoption by policy makers to sustain and scale up the intervention in the community, country or region. Governments have been given the responsibility to intervene in order to protect the public when clear risk of injury has been identified and evidence for an appropriate response is available. As well, governments and elected officials' need to demonstrate greater leadership and commitment to drowning prevention intervention measures including the role policy can contribute. Further, a comprehensive approach to drowning prevention should consider adequate planning and action for policy adoption, implementation and enforcement for existing evidence-based drowning prevention educational and engineering interventions. Specific monitoring and evaluation should take place pre and post policy implementation in countries to determine the effect of specific interventions on the reduction of drowning and sustainability and scaling up of actions. In principle, policies and legislation should provide practical wisdom to guide 
governments, individuals and communities towards knowledge transfer, evidence implementation and positive outcomes.

This research has contributed to the thesis sub and main research question by investigating and gaining further understanding of the various stages of knowledge transfer for evidencebased policy interventions. This includes how evidence implementation is impacted by the engagement of actors and barriers to the process through the specific actions of policy and legislation formation, adoption, implementation, enforcement, evaluation, sustainment and scaling up.

Concluding remark and summary statement: Experts agree that effective, well-enforced policies are a valuable tool in reducing injuries and that there are proven or promising drowning prevention evidence-based interventions involving engineering and education approaches. Therefore, introducing policies for these interventions should be investigated to determine their level of success in specific locations and adapted to the target population, in selected settings, at the appropriate time to support knowledge transfer and evidence implementation.

6.1.4. Chapter 5 - Barriers and facilitators to evidence implementation in public health systems

Research Question: What barriers and facilitators impact the implementation of evidencebased interventions to reduce and eliminate the harm caused by asbestos in the WHO European Region.

In this study the aim was to gain greater understanding of the specific types of barriers that impact evidence implementation to eliminate and reduce harm from asbestos and determine how these can be transformed throughout the evidence implementation process into facilitators and solutions. The framework for this study was based on the Evidence Implementation Model for Public Health Systems (Figure 1, Chapter 2). 
The main findings from this study related to this thesis were derived from key stakeholder interviews from a selected sample of country representatives, experts, intergovernmental organizations, nongovernmental organizations and European Commission representatives, dealing with asbestos issues in their respective professional areas. In the interviews, three themes were focused on: 1) identifying barriers to the implementation of WHO evidencebased asbestos recommendations; 2) describing necessary and effective roles and actions of key stakeholders; and 3) proposing possible solutions, facilitators, and next steps towards non-asbestos working and living environments, including policies for the elimination of Asbestos Related Diseases (ARDs). Barriers to the implementation of the WHO evidencebased asbestos recommendation to ban the use of all forms of asbestos were categorized into the areas: leadership, management and coordination, funding and financing, capacity building, data, evidence strategy uptake, context setting and visibility. Respondents noted that barriers could take place at any point in the process of knowledge transfer. Furthermore, barriers could be turned to facilitators to provide solutions to move uptake of evidence-based interventions forward or even advance the process. Enhanced and early engagement, and cooperation of diverse sectors and stakeholders throughout the entire process of adoption, implementation and monitoring of evidence-based policies and programs to eliminate ARDs, based on whole-of-government and whole -of-society approaches, was identified to support the knowledge translation process and reduction of barriers. This included the collaboration of multiple diverse ministries through political and financial commitments.

This research has contributed to the thesis sub and main research question by investigating and gaining further understanding if common barriers to evidence implementation exist, how they impact the overall evidence implementation process and opportunities to change barriers into facilitators to provide practical real life means to advance or even accelerate knowledge translation and evidence implementation.

Concluding remark and summary statement: Even though addressing the elimination of asbestos related diseases is a challenging issue within a complex system, use of sound and convincing scientific evidence along with different types of economic evidence and/or facilitators that reduce barriers, can be used to achieve evidence-based policy development, and comprehensive diverse actions. 


\subsection{Discourse - the way forward}

The theme of evidence implementation and creation of models and frameworks to support uptake of evidence is not new. However, the research done in this thesis and summarized in the introduction have revealed a number of weaknesses and suggests needs to address some of these gaps that exist in our collective efforts to enhance implementation of evidence into public health systems. Such gaps included the use of simplistic models, unclear or no measurable targets, limited engagement of diverse actors, non-tested knowledge translation processes, and less defined determinants of barriers and use of facilitators to evidence implementation. The discourse to follow discusses the following 3 themes: reaffirms the essential value of evidence implementation and the complexities to accomplish this undertaking; provides reflections of how the thesis research and findings are being applied in current program and policy initiatives while addressing gaps related to public health evidence implementation, and proposes advancing conditions that could support moving the process of evidence implementation forward within public health systems.

\subsubsection{Values and complexities of evidence implementation}

Implementation of what has been demonstrated to work in public health should improve the health and wellbeing of society.[1-4] However, the existence of evidence-based health strategies alone does not seem to be convincing or compelling enough to have decisionmakers put evidence into practice.[ 5-9] One of the most consistent findings from clinical and health services research is the failure to translate research into policy and practice.[10,11] For example, a Lancet study in 2014 estimated \$200 Billion (USD) wasted research funding from not realizing the full potential of the research evidence.[12] Further, it has been estimated that the lag time to put research evidence into practice is approximately 17 years.[13] Researchers have stated that the complexity of public health systems requires more diverse, interconnected actions and consideration of various factors to increase knowledge translation and the implementation of evidence. Besides the evidence itself. $[14,15]$ 
However, an increased output of evidence alone is insufficient to generate meaningful changes in public health policy and practice.[16,17] Evidence generation, its dissemination and use needs to be seamlessly integrated into the knowledge translation process to be effective. $[17,18]$. This can be a challenge, as policy making is an inherently political process in which research evidence is only one factor that influences decision-making.[17,19,20] Scientific evidence often competes with other factors, such as beliefs, personal interests, political considerations, traditions, past experience, and financial constraints.[17,18,21-25]

Experts have also acknowledged that improving health outcomes through successful uptake of evidence-based interventions or knowledge translation is not a simple or quick task. $[1,2,14,26]$ This is particularly the case, as public health systems are complex and there are many interdependencies involved that are embedded in the system as a whole.[13,27,28] However, a recent science business report suggests long-term payback on research evidence and innovation could be 20 percent a year.[29] To date it is clear that evidence-based interventions exist. We now need to maximise public health research and the implementation of evidence in as many ways as possible, that provides a clear flow for connecting public health knowledge to practice and policy action. [16]

First and foremost, it needs to be recognised and acknowledged that implementation of evidence is essential to the attainment and sustainability of the health, safety and wellbeing of societies. Knowledge derived from research and or experience may be of little value unless it is put into practice.[19] When research and knowledge demonstrate effectiveness and efficiency, we need to embrace the findings and implement what has been proven to work. If not, then we risk a path of operating in the unknown and repeating mistakes that could have been avoided.[1,3,22,30] While the implementation of evidence into general operations will provide many benefits such as: reduces duplication of less effective and efficient approaches; fosters innovative research approaches to address complex public health issues; stimulates and translates a new generation of evidence into policy and practice; increases the transfer and quicker uptake of lessons learned from others; increases an equitable and sustainable access to health knowledge for all; supports capacity building for public health systems and knowledge translation; enhances the scaling- up of effective evidence based strategies; 
stimulates new monitoring tools and actions to demonstrate achieved targets; and ensures an ethical base to just, equitable and fair health policy-making.[2,28,31-33] Therefore, advancing evidence implementation in public health systems is an important endeavor and investment in all societies to attain, maintain and sustain health and wellbeing.

\subsubsection{Current application of thesis results in public health systems}

Examination and reflection have taken place to determine how this thesis research and main findings are being applied in current program and policy initiatives related to public health to advance evidence implementation. The example provided is the most recent COVID-19 pandemic.

\section{Example - Application of the thesis results in the COVID-19 pandemic}

There is mounting pressure that responses to humanitarian crisis situations should demonstrate the use of research evidence in their decision making and actions. [34-36] However, the level of evidence implementation occurring during the COVID-19 pandemic is inconsistent. [36,37] The year 2020 will be remembered in history for the COVID-19 pandemic, an urgent public health crisis at the global scale with tremendous impacts. The negative effects go well beyond that of health care and have touched every part and aspect of society and economy. [37] Yet, pandemics are not a new occurrence and warnings were given for the rise of such events. [38] "Nothing has killed more human beings than the viruses, bacteria and parasites that cause diseases, like the Black Death, smallpox, the Spanish flu and malaria. In fact, infectious diseases are still a leading cause of death worldwide."[39]

During the preparations of the first round of countries to move to end the COVID-19 lockdown in the spring of 2020, reviews and comparisons were discussed, as to how well countries have managed the crisis and how the implementation of evidence has contributed to their current health, safety and economic outcomes. To date, countries, such as Germany and New Zeeland that have used scientific evidence as a key component of their decision-making process have also reported lower numbers of positive COVID 19 cases and deaths per capita globally.[40] 
Setting clear and measurable targets have been a cornerstone in the fight against the pandemic that requires timely and accurate data to answer numerous questions. What is the infection rate? What are the number of deaths? How many tests have been conducted? How quickly are the number of positive cases doubling? The data provide research evidence in which targets can be set as a key foundation for agreed evidence-based decision-making, as noted in this thesis chapters 1 and 2. [17,25] However, great challenges exist as many countries struggle to attain data and implement their targets based on evidence. For example, the United Kingdom set a target for a testing rate of 100,000 case per day but had extreme challenges in meeting their targeted number of tests, which raised public mistrust to the country's ability to effectively manage the situation.[41] As countries move toward aspirations of COVID-19 recovery, new targets are being discussed to have countries return to some level of normality and a sustainable economic means to the future. For example, the Organization for Economic Cooperation and Development (OECD) has been advocating for a unique opportunity for many countries to implement a green and inclusive recovery that includes not only income and jobs, but also integrates the SDGs and climate change Paris Agreement targets. Such alignment would create win-win opportunities across multiple sectors.[42] By linking goals and targets the aim would be to consolidate efforts and build from lessons learned, best available evidence and most effective implementation processes, for effective knowledge transfer, as echoed in this thesis chapters 1-4 and OECD.[42] The city of Paris has already initiated such targets by providing public funding for bicycle repairs and increased dedicated bicycle lane use to support COVID-19 social distancing needs for reduced space on public transport and meeting SDGs to reduce CO2 emissions.[43] Clear targets with multi sector engagement can provide major health and environmental benefits as noted by the Lancet 2020 in the European Green Deal when using careful design and evaluation of policy choices.[17,18,44]

Research evidence can support decision makers across multiple sectors to address situations in an informed and timely way.[22] Researchers have advocated for the use of strong research evidence in decision-making to ensure evidence-based decisions occur and to minimize the COVID-19 pandemic impacts.[45] Overall, addressing COVID-19 has called for broad engagement of all levels of government and diverse actors involved in policy making and its implementation across multiple sectors to build strong networks and partnerships to advance 
working together and evidence implementation.[17,22,25,37] Also during times of crisis and great uncertainty, the need for increased research evidence is sought with the aim of making the best-informed decisions possible in the circumstances. This is the basis of evidence-based policymaking, which creates a foundation for society that decisions of authorities and leaders are being made with informed judgement rather than personal interests.[17,18,23-25] Therefore, during such crisis times science and evidence experts become more engaged in supporting the creation of policy responses and in some countries even co-share this leadership role such as in Germany and New Zeeland. In these countries the partnerships have led to co-creation of policy solutions and evidence-based decision making for the betterment of public health as promoted in this thesis chapters 2 and 3.[17,25] Broad actor engagement beyond researchers and decision makers to include practitioners and knowledge brokers for example was also raised in the thesis results again in chapters 2 and 3.[17,25] Practitioners roles within a pandemic emphasizes the critical importance of those on the front lines to put evidence into practice, such as good hygiene behaviors in hospitals, pharmacies and grocery stores, and police services for managing transit requirement and re-enforcing social distancing measures. During times of crisis knowledge brokers can fill gaps as intermediaries to assist with the translation of research to action statements, that in turn support evidence implementation.[17,22]

During the COVID-19 pandemic specific barriers have already been raised and efforts to create solutions in the form of facilitators to evidence implementation are underway. Of noteworthy attention is the point that all eight barrier/facilitator categories listed in the thesis chapters 2 and $5[17,18]$ have also been identified as barriers to evidence implementation to address the COVID-19 pandemic. Leadership barriers or even failures have been identified to have great impact on implementation of evidence, to the extent where political values and beliefs for personal gain, and poor or controversial communication have weakened countries ability to move forward. Some countries delay or choice to not make decisions have created as important an impact as making a decision. This has been seen with delayed action in countries to put strict policies for public shutdowns in place, such as the USA and UK.[37] Management and coordination have been identified as clear barriers when trying to address ground level medical services, as well as upper level coordination and management of political and administrative actions.[37] Funding and the economic downfall the virus has 
created is very evident and plans for recovery require strategic joined up efforts for the road ahead. Capacity building has been identified as having a critical role in building one's ability to understand, influence and address complex issues such as the pandemic.[37] Therefore, enhancing knowledge through capacity building can support the uptake of evidence implementation.[22] Data as noted earlier is a critical need to determine targets and how they are being met in the efforts to address the virus. While some of the evidence interventions or strategies themselves can serve as a barrier [18]; with no vaccine yet available in the immediate horizon, the use of nonpharmaceutical interventions are the best evidence to date. Studies have shown that common nonpharmaceutical interventions, such as social distancing, good hygiene, face mask use, stay-at-home orders, closing of public facilities, especially when put in place rapidly after initial detection of a new virus can reduce transmission, if applied effectively.[38] However, the evidence for the use of masks and the communication of that evidence has created a number of barriers and confusion. Context setting has also been clearly identified as a barrier to evidence implementation within the pandemic to date and understanding how critical it is to continue to adapt the interventions to each community, region and country. For example, it is paramount to determine how good hygiene can be attained and maintained when a clean water supply is not available for hand washing in some settings. Clear and consistent messaging and communication information based on evidence is critical, so it is well understood what action is to be taken, such as good hygiene and social distancing in the case of the pandemic.[46] Communication can be a facilitator in a crisis situation when there is a clear and evidence-based understanding of what the risk is, how serious this risk is and what can and should be done to reduce the risk.[37] This requires sufficient, timely, accurate and non-contradictory information, which has been lacking in countries, such as the USA and Brazil, where country leaders have been downgrading the seriousness of the virus and not following recommended hygiene practices or even advising contrary unsafe actions. Such as bad advice to use an unapproved medicine, which then caused a needless death in the USA.[36]

The use of research evidence and increasing the effectiveness of its implementation will support efforts to address the negative impacts of COVID-19, and current action complements the research results shared in this thesis.[17] 


\subsubsection{Advancing conditions for evidence implementation}

"Research can be a game-changer in dealing with even the most pressing global challenges if it is used to its full potential at all three crucial phases: understanding the problems, formulating policies, and assuring that those policies are implemented effectively." $(U N, 2016)[47]$

Upon reflection of application of the thesis main findings to the examples of current policy and program actions within the 2030 Agenda for Sustainable Development and COVID-19 pandemic, further suggestions are provided of four conditions that could support the advancement of the knowledge base for the implementation of evidence in public health systems. The four proposed advancing conditions to support enhanced evidence implementation in public health systems in Europe and globally being: good governance, context setting, investment in public health, and a multi-sectoral approach (see Table 2). 
Table 2. Summary of thesis results and advancing conditions for enhanced evidence implementation in public health systems in Europe

\begin{tabular}{|c|c|c|c|c|}
\hline $\begin{array}{l}\text { Thesis four areas } \\
\text { of focus }\end{array}$ & $\begin{array}{l}\text { Model/Framework } \\
\text { Chapter } 2\end{array}$ & $\begin{array}{l}\text { Actors/Targets } \\
\text { Chapter } 3\end{array}$ & $\begin{array}{l}\text { Knowledge } \\
\text { Transfer } \\
\text { Chapter } 4\end{array}$ & $\begin{array}{l}\text { Barriers \& } \\
\text { Facilitators } \\
\text { Chapter } 5\end{array}$ \\
\hline $\begin{array}{l}\text { Key } \\
\text { Results of } \\
\text { Chapters } \\
2-5\end{array}$ & $\begin{array}{l}\text { Clear interlinking of } \\
\text { the model's four } \\
\text { concepts (targets; } \\
\text { actors involved; } \\
\text { knowledge } \\
\text { transfer; and } \\
\text { barriers and } \\
\text { facilitators) moves } \\
\text { beyond simplistic } \\
\text { linear models } \\
\text { providing how- to } \\
\text { support for } \\
\text { evidence } \\
\text { implementation in } \\
\text { complex public } \\
\text { health systems }\end{array}$ & $\begin{array}{l}\text { Early, active, and } \\
\text { respectful, } \\
\text { sustained } \\
\text { engagement of } \\
\text { diverse actors, } \\
\text { sectors and key } \\
\text { stakeholders is } \\
\text { required to } \\
\text { understand views } \\
\text { and values, and to } \\
\text { enhance } \\
\text { knowledge, } \\
\text { capacity, } \\
\text { leadership and } \\
\text { commitment for } \\
\text { effective evidence } \\
\text { implementation }\end{array}$ & $\begin{array}{l}\text { Comprehensive } \\
\text { understanding and } \\
\text { application of who, } \\
\text { what, where, } \\
\text { when, why and } \\
\text { how of evidence- } \\
\text { based } \\
\text { interventions are } \\
\text { essential } \\
\text { throughout the } \\
\text { knowledge transfer } \\
\text { process }\end{array}$ & $\begin{array}{l}\text { Clear identification } \\
\text { of relevant barriers } \\
\text { to evidence } \\
\text { implementation } \\
\text { then require } \\
\text { strategic and } \\
\text { innovative } \\
\text { thoughts and } \\
\text { actions to transfer } \\
\text { these barriers into } \\
\text { facilitators } \\
\text { throughout the } \\
\text { entire } \\
\text { implementation } \\
\text { process }\end{array}$ \\
\hline $\begin{array}{l}\text { Four advancing } \\
\text { conditions to } \\
\text { support evidence } \\
\text { implementation }\end{array}$ & $\begin{array}{l}\text { \#1 Good } \\
\text { Governance }\end{array}$ & \#2 Context Setting & $\begin{array}{l}\text { \#3 Investment in } \\
\text { Public Health }\end{array}$ & $\begin{array}{c}\text { \#4 Multi-Sectoral } \\
\text { Approach }\end{array}$ \\
\hline Goal & \multicolumn{4}{|c|}{ Enhanced evidence implementation in public health systems in Europe and globally. } \\
\hline
\end{tabular}

\section{Advancing condition for evidence implementation \#1 - Good governance}

In order to maximize evidence and enhance its uptake for our collective abilities - including governments - good governance is a condition that can advance this cause. Governance is the process of decision-making and the process by which decisions are made.[48]

"Good governance is participatory, consensus oriented, accountable, transparent, responsive, effective and efficient, equitable and inclusive and follows the rule of law." It assures that corruption is minimized, the views of minorities are taken into account and that the voices of the most vulnerable in society are heard in decision-making. It is also responsive to the present and future needs of society.[49] 
To advance public health evidence implementation key stakeholders, including governments, will need to rethink their organizations and working methods, including the use of good governance. Strong political commitments and leadership are preconditions for fostering whole-of-government action and policy coherence.[50,51] Such commitments then need to be supported by a coordinated and measurable systems thinking approach to be actioned by all key actors.[51]

Research evidence and information benefits societies and improves health outcomes, when used in policy and practice decision-making. Therefore, governments, intergovernmental organizations, universities and funders should aspire to institutionalize knowledge translation and evidence implementation within policy and decision-making processes, [52] as part of good governance for public health systems. Achievement of goals and targets for societies are more attainable and drive momentum when there is agreement on priorities and joint efforts to accomplish them, as noted throughout thesis chapters 2-5 such as priority-setting in line with the 2030 sustainable development agenda and the Paris climate change agreement.[53] This will require for example good governance to support and advice on policy formulation for public health evidence implementation; responding to new findings on priority public health issues through the development of advice on evidence-based strategies to address them; and facilitating the coordination of research agendas to address gaps in evidence and knowledge in priority areas.

Norms and standards are also vitally important in setting the conditions and requirements to ensure consistency and quality of evidence and its implementation within public health systems as part of good governance.[53] Ethically-sound application of knowledge is critical when determining what knowledge is to be generated, translated and implemented, to which target audiences and for what purpose.[16,17,24,54] The effectiveness of evidence implementation also requires ethical assessment, so unproductive actions are identified and improved to ensure ineffective actions do not continue. $[16,54]$ It is also ethically meaningful that the social, political and economic conditions that determine health impact on communities and countries are not overlooked when undertaking knowledge translation research and its implementation.[55] 
Advancing condition for evidence implementation \#2 - Appropriate context setting

"First, implementation is a function of the interaction between intervention and context. Second, sustainability is equal to the degree to which the intervention becomes part of the context, i.e. - just the way we do business." David C Aron 2020 [56]

Evidence-based interventions also require a good fit to the context and settings they will be introduced to advance their implementation as noted in this thesis chapters 2-5 as well as by Ingold and Monaghan, 2016.[57] For example, a focus on country capacity for use of local data, pilot testing and scaling-up of innovations and interventions in a sustainable manner are all critical actions to successfully implementing evidence to the specific context and setting characteristics, including but not limited to community residents, built and natural environments, geography, culture, history, religion and values. This is more than a communication and dissemination activity, this is a critical component of understanding the research and to transfer the evidenced research findings and knowledge to another situation that is tailored to the country or community needs.[17,58] This includes the development of standardized tools and resources that are multilingual and multi-format to gather, synthesize and use evidence to support knowledge transfer and evidence implementation as emphasized in chapter 2 .

Interventions should be chosen or created based upon a broad understanding of context, including the causes to gaps in implementation, assessment of the barriers and facilitators to implementation, and an understanding of the ways and means required to address them. $[19,59]$

According to Baker et al in 2015, a systematic review found that Interventions tailored to address barriers and facilitators demonstrated to be more effective than no intervention or those that were not tailored to the context and setting.[60] Furthermore, comparison of old and new context and settings are important at an early stage of implementation assessment to support the adaptation required to be successful in a new situation. In particular, focus should be provided with characteristics of the community and population that are divergent between the old and new setting. When adapting an evidence-based intervention for use in 
a completely new setting, greater attention will be needed to address a broad range of characteristics.[25,61]

Advancing condition for evidence implementation \#3 - Investment in public health; people over profits

"To address the serious and challenging public health issues faced by communities, countries, regions and the world we need to mobilize financial resources and enhance the capacity of key stakeholders to plan, coordinate and act collectively to implement evidence." OECD 2019 [62]

In order to increase the production and implementation of current, new and innovative solutions from science, technology, social, business and or the financial sectors, to achieve and even accelerate public health goals and targets, research capacity and its effective transfer and implementation within countries needs to be an investment and commitment of central focus.[17,25,58,63] Cost information and economic evaluation is also needed to inform decision makers to support decisions to be undertaken and how to organize resources as efficiently as possible.[63] This includes advocating for investment and improving in countries public health research capacity and quality, and bringing evidence-based innovations rapidly to scale while integrating them into public health systems in a sustainable manner. Fostering and investing in a systems approach is important to ensure connectedness between diverse public health research issues and other associated research issues to gain multiplier effects, as the impacts of health research touch upon all aspects of public health systems and beyond.[27,28] Linking and engaging researchers, decision makers, knowledge brokers and practitioners, to collaborate on the research process to support the generation of issue driven and more useable evidence for public health is also required. This realization means that future knowledge translation approaches in public health policy must better account and invest to address the barriers of the complex political realities that policy making create. Specifically, they must account for the importance of a public health systems approach, diffused decision-making, institutional hierarchies and policy networks, and the multiple inputs and types of evidence that go into policy making.[52] Fortunately it has been noted that leaders whom support, promote and invest in innovative research and knowledge translation see a greater uptake of evidence within their organizations.[16] 
Investment to have a sufficient workforce in countries with the necessary understanding and skill sets of knowledge translation and implementation science, tailored to their local needs, will advance the ability to systematically and transparently use the best available evidence.[64] Capacity deficiencies create gaps in needed skill sets and trigger further barriers to occur.[3,65] Enhancing capacities of core and support team members is necessary at the local, national and regional levels to ensure public health action can be taken and maintained. This will enable follow through on national action plans, as well as using evidence for the development, implementation and monitoring of policy and practice that will accelerate the achievement of agreed upon goals and targets as noted in this thesis chapters 2 and 3.[17,25]

Ensuring access for health decision-makers to timely and authoritative evidence-informed strategic information on high priority policy issues and matters that affect population health, is critical to making informed decisions. $[30,53]$ This should include an increase in economic evaluations of implementation interventions, providing decision makers with more information to guide their decisions and actions.[59] Ultimately, the results of evidence should support decisions that are informed by knowledge.[66,67] The current need for accessible and affordable research is on the rise. Even the Cochrane Library, which is a repository of high-quality research to support health care decision-making globally, allows only one-time access before requiring payment, including researchers from low- and middleincome countries.[68] Such barriers to information access are especially problematic for governments and researchers in low- and middle-income countries, who often contribute their own resources towards further development of these products. Therefore, continued investment to assure access to evidence is needed to support the achievement and acceleration of agreed upon targets such as the SDGs, Paris Climate Agreement and so forth.

\section{Advancing condition for evidence implementation \#4 - Multi-sectoral approach}

As the well-worn African proverb goes, "If you want to go fast, go alone. If you want to go far, go together." [69] 
To advance the implementation of evidence, progress will require key stakeholders including governments to work across policy domains and overcome common barriers to achieve a whole of society approach.[17,18,25] For example, current and pressing economic and social pressures frequently take precedence over longer term strategic cross-cutting policy initiatives. Accountability systems and budgets are usually aligned by department structure and have challenges tracking outputs and outcomes from multiple policy areas and across multiple levels of government. Further, a large array of public and private stakeholders should be engaged in both policy creation and implementation around the public health issue to be addressed. Therefore, it will be critical for institutional mechanisms and policy coherence to support a shift from traditional siloed policy making to more integrated approaches to advance evidence implementation.[62,70]

Sound management and collaboration, including the right multisectoral partners, will support evidence implementation.[71]Cross-sectoral approaches are critical in the achievement and advancement of public health initiatives, as solutions to many challenges often belong to the domain of other sectors. $[17,24,72]$

A wealth of information and evidence is scattered across communities, countries and regions, but it needs to be collated, complete, made accessible and implemented to be effective.[53,58] Think tanks, academic institutions, platforms and networks, that serve as knowledge brokers, can enhance the availability and use of evidence to support the acceleration of goals and targets to be achieved. [19,62,72]

Sustainable scaling-up of ingenious research for public health and knowledge translation approaches can also be fostered and advocated by innovative partnerships, innovators and innovation funders with governments and coordinating with regional partners for integration within their public health systems.[58] Partnerships can create funding opportunities to advance priority issues [30] and benefits to early and partnered engagement can lead to increased knowledge user capacity to use research; produce research that is more useful to knowledge users; increase the use of research and evidence in practice and policy decisions; and improve individual and public health system outcomes.[33,53,70] 


\subsection{Limitations}

Upon review of this thesis there are some limitations to be identified within the context of the findings presented. It should be noted that the Evidence Implementation Model for Public Health Systems is currently at the initial application phase. The development of the model was informed on an analysis of 32 case studies of interventions in 24 countries and builds on empirical findings through a critical review of the literature, the model at this point has some initial application. The model did have its first applications and use with two WHO European Region Health and Environment projects that each involved more than 15 countries.[18,25] Further testing and validation in practice will add to enhance the further usability to support how-to evidence implementation in real world settings. Further, within the model itself, a number of the definitions were prepared by the lead author, based on current literature, as one definitive resource defining all relevant concepts for the model was not available or acknowledged at that time. It should be noted that during the stakeholder interviews of two studies within the thesis research some contexts within the interview statements made may not be precise, as not all of the participants, interviewees and interviewer were fluent in both English and Russian. To address this challenge the assistance of English/Russian interpreters were used to support the data and information gathering for both the interviews and the corresponding health and environment workshops that took place, to allow participants to fully engage and enhance the accuracy of communication. Further both studies from chapter 3 and $5[18,25]$ were not representative of the whole WHO European Region. However, a large and broad set of interviews were performed with key stakeholders from diverse sectors, and individuals and organisations with representation at the national, EU and WHO European Region levels. Interviews were performed in each study until saturation was achieved and the stakeholders did not identify any new themes. Finally, throughout the thesis the critical review and literature accessed was limited to English language publications and documents, yet the primary literature on this theme has to date been published in English. 


\subsection{Recommendations and concluding remarks}

Within the introduction and general discussion of this thesis it has been clearly stated that implementating evidence-based interventions support improved health and wellbeing for society. Effective and efficient implementation of evidence will reduce duplication, foster innovation, move knowledge to practice, speed transfer of lessons learned and scaling-up, support capacity building and knowledge translation, and provide an ethical base for fair health policy-making. Even though putting evidence into practice may seem to be a simple and logical task, we only need to observe the recent actions to lead and manage the implementation of evidence to control and reduce the impact of the COVID-19 pandemic to understand that public health systems are complex. The complexity to address public health issues requires mulitiple components, conditions and factors that are interlinked, such as targets, actors to be involved, knowledge transfer, and barriers and faciliators, in order to effectively take up evidence.

Many models and theories exist to support evidence implementation within public health systems; however, a number of gaps to implementation still remain that impacts effectiveness and efficacy to uptake as noted in this thesis introduction, chaper 2 and general discussion. This includes dependency on linear cause and effect models without understanding and use of more diversifed approaches that addresses the complexity of public health systems. The Evidence Implementation Model for Public Health System attempts to reduce gaps to move beyond a linear model, includes broader actors than researchers and decision-makers, intergrates the knowledge transfer process and recommends continally addressing specfically identified barriers by turning them into facilitators throughout the implementation process. This model also uses a how-to practical approach to support real world evidence implementation. This means a practical application of evidence in communities, regions and countries, rather than reports or proposals that remain on office shelves. The model recommends interlinking the components identified in the model and ensure adaptation of the evidence for the specific context and setting of the implementation application. For example, the Evidence Implementation Model for Public Health has already 
had initial application with two multi-national studies, each with more than 15 countries and based on real time evidence implementation cases in 24 countries.

Early, active and respectful sustained engagement of diverse actors across multiple sectors throughout evidence implementation and understanding their associated values, perspectives and beliefs is essential to enhance effectiveness as described in chapter 3 of this thesis. Awareness and collaborative actions will be needed to bring and maintain the diverse actors to share and support an agreed upon aim and associated targets as some actors will have other or even contrary perspectives to your intented aim. It is also important to align and guide actions on shared aims and targets to support focused actions, priority setting and continued commitment to action of all actors. This thesis recommends the actors included in evidence implemenation also need to go beyond researchers and decision/policy-makers to include knowledge brokers and practioners to all be engaged in co-production and support a more effective approach.

Evidence alone is not compelling enough in many cases to ensure it is adequately take up in practice. Comprehensive understanding and the interlinking application of who, what, where, when, why and how of evidence-based interventions are essential throughout the knowledge transfer process as detailed in chapters 2 and 4 of this thesis. This process is not a simple linear or circular cycle due to the true complexity of public health; often, the order of events can be more chaotic to deal with because of the multiple influences and diverse actions invovled, such as in pandemics and natural disaster management. It is a recursive process that has no set start or ending, but rather stages that are continually examined and addressed while moving back and forth between each of the stages: identifying and assessing the problem; gathering, analysing and synthesising evidence; using evidence; and assessing evidence uptake. To further support evidence uptake, the set targets, actors involved and barriers and facilitators to be addressed also need to be kept simultaneously in focus within the process of knowledge transfer. This is demonstrated in the Evidence Implementation Model for Public Health Systems.

Throughout chapters 2 - 5 and within the general discussion of this thesis, barriers to evidence implementation have been clearly defined and specified to highlight the myriad of challenges that can negatively impact the uptake of evidence-based interventions. These barriers include 
leadership, management and collaboration, funding/financing, capacity, data, evidence strategy, context setting and visibility. To be effective, clear identification of relevant barriers to evidence implementation then require strategic and innovative thoughts and actions to transfer these barriers into facilitators throughout the entire implementation process. By identifying barriers and then specifically addressing each by designing and applying an appropriate facilitator to address this challenge supports a process of practical guidance in real world settings. It must also be understood that within complex systems, such as public health, the barriers and facilitators are not necessarily independent of one another and there is often interplay and co-dependencies also between them. The probability of successful implementation is higher when leadership provides commitment to address a public health issue, with good coordination, adequate financing, qualified and an adequate number of skilled professionals, timely and accurate data, an evidence-based approach adapted for the context setting and communicated in a clear, factual and transparent manner. Such was the approach of New Zealand to address the barriers within the COVID-19 pandemic.

As noted in this thesis discourse, a number of advancing conditions are poised to support evidence implementation in real world settings, such as good governance, context setting, investment in public health, and multi-sectoral approaches. Inclusive, consensus oriented, accountable, transparent, responsive, effective, efficient, and equitable actions of those governing will enhance environments for succeful evidence implementation. Yet it must also be understood that even though an evidence-based intervention has be proven to work, it maynot be successfully taken up if it is not adequately adapted to the context and setting of the community, country or region it is intended for. As well, leadership is required to make a commitment to invest in public health at all levels of information and operation. This investment is needed to maintain and improve country knowledge capacity and quality, including the ability to bring evidence-based interventions and innovations more rapidly to scale in a sustainable manner. All this work needs to occur collectively, beyond the traditional silos, to gain broader information and operation that will also foster and support innovation across the stages of planning, implementation, evaluation, sustainability and scalability throughout the overall process. 
A number of evidence-based interventions exist and pubic health systems would greatly benefit to a have a larger number of these good practices taken up in communities, countries and regions in Europe and globally. The area of evidence implementation provides good guidance to support such action and this thesis research recommends further interlinking of key factors and components of targets, actors, knowledge transfer, barriers and facilitators to drive successul implementation forward. 


\section{References}

1. Liverani M, Hawkins B, Parkhurst JO. Political and institutional influences on the use of evidence in public health policy. A systematic review. PLoS One. 2013;8(10): e77404. DOI: 10.1371/journal.pone.0077404

2. Orton L, Lloyd-Williams F, Taylor-Robinson D, O'Flaherty M, Capewell S. The use of research evidence in public health decision making processes: Systematic review. PLoS One. 2011;6(7): e21704. DOI: 10.1371/journal.pone.0021704

3. Oliver K, Lorenc T, Innvær S. New directions in evidence-based policy research: a critical analysis of the literature. Health Res Policy Systems. 2014;12(7):34-45. DOI: 10.1186/1478-4505-12-34

4. Campos-Matos I, Stannard J, de Sousa E, O'Connor R, Newton JN. From health for all to leaving no-one behind: public health agencies inclusion health, and health inequalities. Lancet Public Health. 2019;4(12):E601-603. DOI: 10.1016/S2468-2667(19)30227-0

5. Holmes BJ, Best A, Davies H, Hunter D, Kelly MP, Marshall M, Rycroft-Malone J. Mobilising knowledge in complex health systems: a call to action. Evidence \& Policy. 2017;13(3):539-60. DOI: $10.1332 / 174426416 X 14712553750311$

6. Rycroft J. From linear to complicated to complex; Comment on "Using complexity and network concepts to inform healthcare knowledge translation" Int J Health Policy Manag. 2018;7(6): 566-568. DOI: 10.15171/IJHPM.2018.02

7. Straus SE, Tetroe JM, Graham ID. Knowledge translation is the use of knowledge in health care decision making. J Clin Epidemiol. 2011;64(1):6-10. DOI: 10.1016/j.jclinepi.2009.08.016.

8. Hanson D, Allegrante JP, Sleet DA, Finch CF. Research alone is not sufficient to prevent sport injuries. Br J Sports Med. 2014;48(8):682-684. DOI: 10.1136/bjsports-2012-0914349.

9. Bauer MS, Kirchner J. Implementation science: What is it and why should I care? Psychiatry Res. 2020;283:112376. DOI: 10.1016/j.psychres.2019.04.025

10. Grimshaw JM, Eccles MP, Lavis JN, Hill, SJ, Squires JE. Knowledge translation of research findings. Implementation Sci.2012;7(1):50-67. DOI: 10.1186/1748-5908-7-50

11. Hines P. Why fund research? A guide to why EU-funded research and innovation matters. Science Business [Internet]. 2017 Jun [cited 2019 Dec 23]. Available from: https://sciencebusiness.net/system/files/reports/Why-fund-research_.pdf

12. Macleod M, Michie S, Dirnagl U, Chalmers L, loanniis J, Salman R, et al. Biomedical Research: increasing value, reducing waste. Lancet 2014;383(9912):101-104. DOI: 10.1016/S01406736(13)62329-6 
13. Gentry S, Milden L, Kelly MP. Why is translating research into policy so hard? How theory can help public health researchers achieve impact? Public Health. 2020;178:90-96.

DOI:10.1016/j.puhe.2019.09.009

14. Glasgow RE, Green LW, Taylor MV, Stange KC. An evidence integration triangle for aligning science with policy and practice. Am J Prev Med. 2012;42(6): 646-654. DOI:

10.1016/j.amepre.2012.02.016

15. Best A, Holmes B. Systems thinking, knowledge and action: Towards better models and methods. Evidence \& Policy. 2010;6(2):145-159. DOI:10.1332/174426410X502284

16. Acadia S. Knowledge translation and ethics in public population health from a knowledge management perspective. Ethics Med Public Health. 2016;2(2):302-309. DOI: 10.1016/j.jemep.2016.04.012

17. Vincenten J, MacKay JM, Schröder-Bäck P, Schloemer T, Brand H. Factors influencing implementation of evidence-based interventions in public health systems-a model. Cent Eur J Public Health 2019;27(3)198-203. DOI: 10.21101/cejph.a5234

18. Vincenten J, George F, Martuzzi M, Schröder-Bäck P, Paunovic E. Barriers and Facilitators to the Elimination of Asbestos Related Diseases-Stakeholders' Perspectives. Int J Environ Res Public Health. 2017;14(10). pii: E1269. DOI: 10.3390/ijerph14101269

19. Turner T, El-Jardali F. Building a bright, evidence-informed future: a conversation starter from the incoming editors. Health Res Policy Sys. 2017;15:88. DOI: 10.1186/s12961-017-0257-x

20. Redman S, Turner T, Davies H, Williamson A, Haynes A, Brennan S, et al. The SPIRIT Action Framework: A structured approach to selecting and testing strategies to increase the use of research in policy. Soc Sci Med. 2015;136-137:147-55. DOI: 10.1016/j.socscimed.2015.05.009

21. Satterfield JM, Spring B, Brownson RC, Mullen EJ, Newhouse RP, Walker BB, et al. Toward a transdisciplinary model of evidence-based practice. Milbank Q. 2009; 87(2), 368-390. 10.1111/j.1468-0009.2009.00561.x

22. Khalid AF, Lavis JN, El-Jardali F, Vanstone M. Supporting the use of research evidence in decision-making in crisis zones in low- and middle-income countries: a critical interpretive synthesis. Health Res Policy Sys. 2020;18(21):1-12. DOI: 10.1186/s12961-020-0530-2

23. Carney P. The politics of evidence-based policy making. London: Palgrave Macmillan; 2016. 137 p.

24. Vincenten J, Gerdmongkolgan S. The role of policy in prevention. In: Bierens J, editor. Drowning - Prevention, Rescue, Treatment. Switzerland: Springer; 2014. p. 261-268. 
25. Vincenten JA, Zastenskaya I, Schröder-Bäck P, Jarosinska DI. Priorities for improving chemicals management in the WHO European Region-stakeholders' views [published online ahead of print, 2020 May 8]. Eur J Public Health. 2020 May 8;ckaa074. DOI:10.1093/eurpub/ckaa074

26. Head BW. Reconsidering evidence-based policy: Key issues and challenges. Policy \& Society. 2010;29(2):77-94. DOI: 10.1016/j.polsoc.2010.03.001

27. Moulin J, Sabater-Hernández D, Fernandez-Llimos F, Benrimoj S. A systematic review of implementation frameworks of innovations in healthcare and resulting generic implementation framework. Health Res Policy Sys 2015;13:16. DOI: 10.1186/s12961-015-0005-z.

28. Field B, Booth A, Ilott I, Gerrish K. Using the knowledge to action framework in practice: a citation analysis and systematic review. Implementation Sci. 2014;9:172. DOI: 10.1186/s13012014-0172-2.

29. Hines P. Why fund research? A guide to why EU-funded research and innovation matters. Science Business [Internet]. 2017 Jun [cited 2019 Dec 23]. Available from: https://sciencebusiness.net/system/files/reports/Why-fund-research_.pdf

30. Graham I, Kothari A, McCutcheon C. Moving knowledge into action for more effective practice, programmes and policy: protocol for a research programme on integrated knowledge translation. Implementation Sci. 2018;13:22.DOI 10.1186/s13012-017-0700-y

31. Grimshaw JM, Eccles MP, Lavis JN, Hill, SJ, Squires JE. Knowledge translation of research findings. Implementation Sci.2012;7(1):50-67. DOI: 10.1186/1748-5908-7-50

32. El-Jardali F, Lavis J, Moat K, Pantoja T, Ataya N. Capturing lessons learned from evidence-topolicy initiatives through structured reflection. Health Res Policy Syst. 2014;12:2. DOI: $10.1186 / 1478-4505-12-2$

33. Gagliardi AR, Berta W, Kothari A, Boyko J, Urquhart R. Integrated knowledge translation (IKT) in health care: a scoping review. Implement Sci. 2016;11:38. DOI: 10.1186/s13012-016-0399-1

34. Blanchet K, Ramesh A, Frison S, Warren E, Hossain M, Smith J, et al. Evidence on public health interventions in humanitarian crises. Lancet. 2017;390(10109): 2287-96. DOI: 10.1016/S01406736(16)30768-1

35. 35. Ager A, Burnham G, Checchi F, Gayer M, Grais RF, Henkens M, et al. Strengthening the evidence base for health programming in humanitarian crises. Science. 2014;345(6202):1290-2. DOI: $10.1126 /$ science. 1254164

36. Bero LA. Producing Independent, Systematic Review Evidence: Cochrane's Response to COVID19. Am J Public Health;110(7):952-953. DOI: 10.2105/AJPH.2020.305734 
37. Weible, CM, Nohrstedt D, Cairney P, Carter DP, Crow DA, Durnová AP, et al. COVID-19 and the policy sciences: initial reactions and perspectives. Policy Sci. 2020;53:225-241. DOI: 10.1007/s11077-020-09381-4

38. Hartley DM, Perencevich EN. Public Health Interventions for COVID-19: Emerging Evidence and Implications for an Evolving Public Health Crisis. JAMA. 2020;323(19):1908-1909. DOI:10.1001/jama.2020.5910

39. European Commission [Internet]. Brussels, Belgium: European Commission; 2020 April 1. Using prediction models to manage the corona virus outbreak; 2020 April 1 [cited 2020 May 5]. Available from: https://cordis.europa.eu/article/id/415792-using-prediction-models-tomanage-the-coronavirus-outbreak

40. BBC [Internet]. Corona virus: How the pandemic in US compares with the rest of the world. May 27, 2020. 2020 April 1 [cited 2020 May 5]. Available from: https://www.bbc.com/news/worldus-canada-52771783

41. BBC [Internet]. UK misses testing target 4 days in a row. May 7, 20202020 April 1 [cited 2020 May 5]. Available from: https://www.bbc.com/news/live/world-52553430

42. OECD [Internet]. An inclusive, green recovery is possible: time to act is now. 22-04-20. 2020 April 1 [cited 2020 May 5]. Available from: https://www.oecd.org/coronavirus/en/

43. BBC [Internet]. Corona virus: France offers subsidy to temp lockdown cyclists. April 30, 2020. 2020 April 1 [cited 2020 May 5]. Available from: https://www.bbc.com/news/world-europe52483684

44. Haines A, Scheelbeek P. European Green Deal: a major opportunity for health improvement. Lancet. 2020;395(10233):1327-1329. DOI: 10.1016/S0140-6736(20)30109-4

45. Foddai A, Lindberg A, Lubroth J, Ellis-Iversen J. Surveillance to improve evidence for community control decisions during the COVID-19 pandemic - Opening the animal epidemic toolbox for Public Health. One Health. 2020;9(100130). DOI: 10.1016/j.onehlt.2020.100130.

46. Anderson RM, Heesterbeek $\mathrm{H}$, Klinkenberg D, Hollingsworth TD. How will country-based mitigation measures influence the course of the COVID-19 epidemic? Lancet. 2020;395(10228). DOI: 10.1016/S0140-6736(20)30567-5.

47. Scientific Advisory Board of the United Nations Secretary-General. The Future of scientific advice to the United Nations: a summary report to the Secretary-General of the United Nations from the Scientific Advisory Board. Paris, France: United Nations; 2016. 33 p.

48. Hawkins B, Parkhurst J. The 'good governance' of evidence in health policy. Evidence \& Policy. 2016;12(4):575-92. DOI:10.1332/174426415X14430058455412 
49. Sheng YK. United Nations Economic and Social Commission for Asia and the Pacific. What is good governance [Internet]. Bangkok, Thailand: United Nations [cited 2020 May 21]. Available from: https://olev.de/g/UNESCAP-governance.pdf

50. Agere S. Promoting Good Governance: Principles, Practices and Perspectives, Managing the Public Service: Strategies for Improvement, No. 11. London: Commonwealth Secretariat; 2000. $144 \mathrm{p}$.

51. Parkhurst J. The politics of evidence: from evidence-based policy to the good governance of evidence. Routledge Studies in Governance and Public Policy. Oxon, UK: Routledge, Abingdon; 2017. 182 p.

52. Fafard $P$, Hoffman SJ. Rethinking translation for public health policy. Evid Policy. 2018;16(1):165-175. DOI: 10.1332/174426418X15212871808802

53. World Health Organization. European Health Report 2018: More than numbers - evidence for all. Geneva, Switzerland: World Health Organization; 2018. 147 p.

54. Sisk BA, Mozersky J, Antes AL, DuBois JM. The "Ought-Is" Problem: An Implementation Science Framework for Translating Ethical Norms Into Practice. Am J Bioethics. 2020;20:4,6270, DOI: 10.1080/15265161.2020.1730483

55. Huzair F, Borda-Rodriquez A, Upton M, Mugwagwa JT. An interdisciplinary and development lens on knowledge translation. Sci Public Policy. 2013;40(1):43-50. DOI: 10.1093/scipol/scs119

56. Aron DC. The Complexity of Context. In: Aron, DC, editor. Complex Systems in Medicine. Switzerland: Springer, Cham; 2020. 101-114 p.

57. Ingold J, Monaghan M. Evidence translation: an exploration of policy makers' use of evidence. Policy Polit. 2016;44(2):171-90. DOI: 10.1332/147084414X13988707323088

58. World Health Organization. Thirteenth general programme of Work 2019-2023. Geneva, Switzerland: World Health Organization; 2019. 54 p.

59. Powell BJ, Fernandez ME, Williams NJ, Aarons GA, Beidas RS, Lewis CC, et al. Enhancing the Impact of Implementation Strategies in Healthcare: A Research Agenda. Front Public Health. 2019;7(3). DOI: 10.3389/fpubh.2019.00003

60. Baker R, Comosso-Stefinovic J, Gillies C, Shaw EJ, Cheater F, Flottorp S, et al. Tailored interventions to address determinants of practice. Cochrane Database Syst Rev. 2015;4:1-118. DOI: 10.1002/14651858.CD005470.pub3

61. Craig P, Di Ruggiero E, Frohlich KL, Mykhalovskiy E and White M. Context Guidance Authors Group. Taking account of context in population health intervention research: guidance for producers, users and funders of research. Southampton: NIHR Evaluation, Trials and Studies Coordinating Centre; 2018. 50 p. 
62. OECD. Governance as an SDG Accelerator: Country Experiences and Tools. Paris, France: OECD Publishing; 2019. $164 \mathrm{p}$.

63. Eisman AB, Kilbourne AM, Dopp AR, Saldana L, Eisenberg D. Economic evaluation in implementation science: Making the business case for implementation strategies. Psychiatry Res. 2020;283:112433. DOI: 10.1016/j.psychres.2019.06.008.

64. Ellen ME, Léon G, Bouchard G, Ouimet M, Grimshaw JM, Lavis JN. Barriers, facilitators and views about next steps to implementing supports for evidence informed decision-making in health systems: a qualitative study. Implementation Sci. 2014;9(1):179-191. DOI: 10.1186/s13012-0140179-8

65. Humphries S, Stafinski T, Mumtaz Z, Menon D. Barriers and facilitators to evidence-use in program management: A systematic review of the literature. BMC Health Serv Res. 2014;14(1):171-186. DOI: 10.1186/1472-6963-14-171

66. Lavis JN, Catallo C. Bridging the worlds of research and policy in European health systems. Copenhagen: European Observatory on Health Systems and Policies; 2013. 246 p.

67. Gilson L. Health policy and systems research: a methodology reader. Geneva: World Health Organization; 2012. 473 p.

68. Teerawattananon Y, Luz AC, Culyer A, Chalkidou K. Charging for the use of survey instruments on population health: the case of quality-adjusted life years. Bull World Health Organ. 2020;98(1):59-65. DOI:10.2471/BLT.19.233239

69. Huff Post [Internet]. If you want to go quickly, go alone. If you want to go far, go together. London: Huff Post; 2017 Dec 3 [updated 2017 Dec 6; cited 2020 May 5]. Available from: https://www.huffpost.com/entry/if-you-want-to-go-quickly_b_9352480

70. Lyon AR, Comtois KA, Kerns SEU, Landes SJ, Lewis CC. Closing the science-practice gap in implementation before it widens. In: Albers B, Shlonsky A, Mildon R, editors. Implement Science 3.0. Switzerland: Springer, Cham; 2020. 295-313 p.

71. Huzair F, Borda-Rodriquez A, Upton M, Mugwagwa JT. An interdisciplinary and development lens on knowledge translation. Sci Public Policy 2013;40(1):43-50. DOI: 10.1093/scipol/scs119

72. Jha A, Kickbusch I, Taylor P, Abbasi K, Group SDW. Accelerating achievement of the sustainable development goals. BMJ. 2016;352:i409. DOI: 10.1136/bmj.i409 
CHAPTER 7

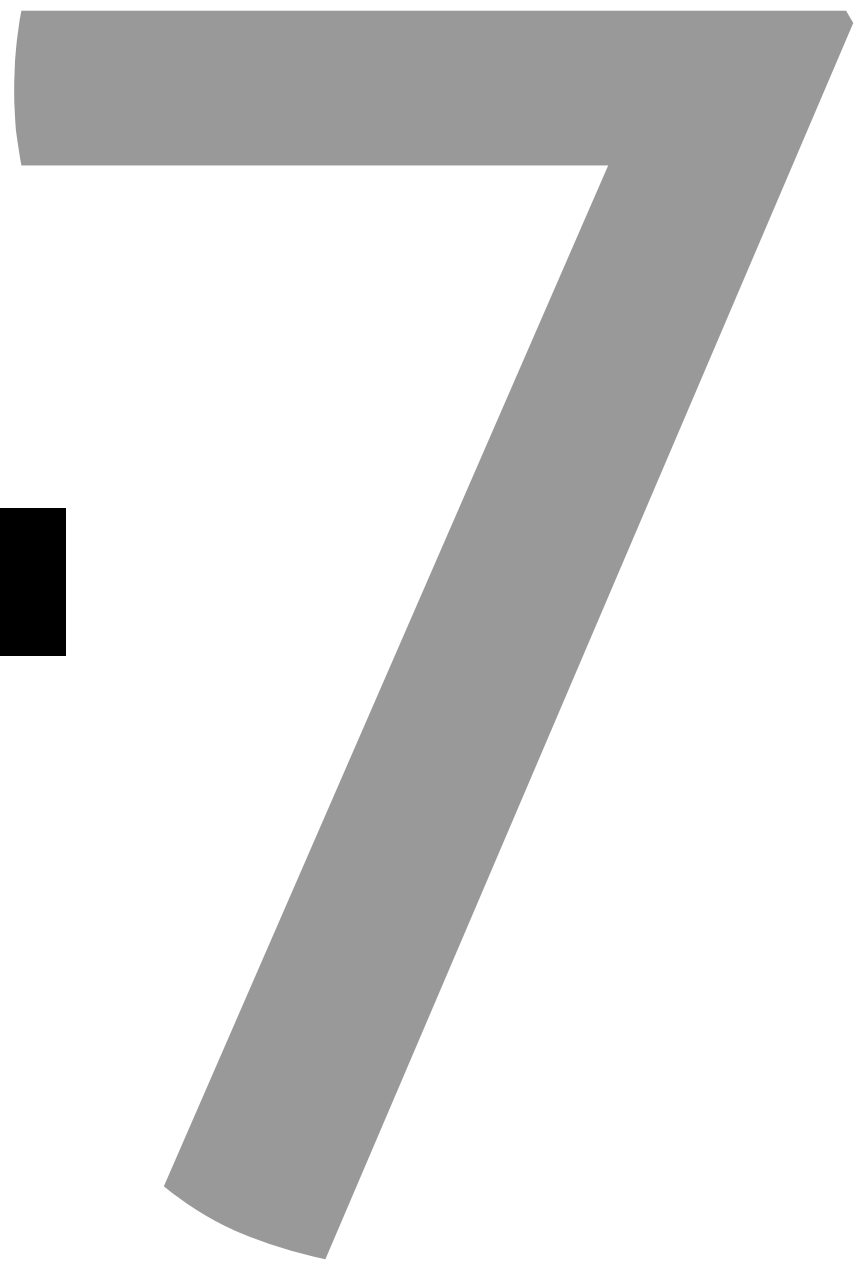


Valorisation 


\section{Chapter 7 - Valorisation}

This thesis has stated the importance and essential value of public health and the critical need to provide, promote and even accelerate the implementation of what has been proven to work, such as evidence-based interventions, that are intended to protect and promote the health and wellbeing of individuals and society as a whole.[1-3] Within the discourse, current applications of the thesis results were shared through the recent events and actions to manage and reduce the impacts of COVID-19. Further, four advancing conditions were proposed that could occur in societies to support the advancement of evidence implementation in public health systems including: 1) Good governance; 2) Context setting; 3) Investment in public health; and the use of 4) Multi-sectoral approaches. The text to follow now describes the valorisation activities of the results of this thesis. These valorisation activities occurred over the course of the investigation studies of this thesis, with the intent to make the research findings available to raise awareness, enhance knowledge and encourage action to support implementation of evidence in public health systems in Europe and globally.

The valorisation chapter uses the same structure as the thesis to address the areas of four areas of focus:

- Model/framework;

- Actors involved and impacts on targets and priorities;

- Knowledge transfer; and

- Barriers and facilitators to evidence implementation.

\subsection{Model/framework}

Even though a number of models and frameworks have been created to support knowledge translation and evidence implementation, it has been shared in this thesis that many models do not reflect the complexity of addressing public health and are not practical in application.[4-7] Therefore, it was an important step to include knowledge, experience and lessons learned from evidence implementation real world cases to support the model 
creation, in addition to critical literature reviewed and applied. As part of a European Union funded initiative, review and assessment of 32 evidence-based interventions across 24 European countries provided insight to key components to evidence implementation, how they interlink and the recursive process that occurs within the complexity of multiple interactions that are at play within public health to take action. $[7,8]$ Early findings of these key components were shared with the country stakeholders as part of lessons learned within the initiative case studies workshop and final reporting to support future actions for evidencebased intervention implementation.

As the model was being developed, opportunities to share early versions were discussed during presentations at Maastricht University, MSc Governance and Leadership in European Public Health.

Revised and enhanced versions of the model evolved and continued to be presented and discussed each year during the master's course over a 3-year time period. Some students found the model helpful to their studies and two students selected this model as the foundation for their Master's degree thesis. Furthermore, the model was also used as the foundation for two World Health Organization environment and health studies, along with key technical background documents related to the study themes. $[9,10]$ The use of the model was included and widely disseminated within the WHO reports methods sections for both studies and the results sections of the studies followed the model structure to include findings on the four areas of focus: 1) Implementation targets; 2) Actors involved; 3) Knowledge transfer; and 4) Barriers and facilitators to evidence implementation.

\subsection{Actors involved and impacts on targets and priorities}

For many years publications have stated the importance of researchers and decision makers working together.[11-14] However, within the multifaceted complexity of public health, this thesis recommends an even broader and more diverse set of actors and stakeholders, that are actively engaged, are needed to implement evidence-based interventions, including knowledge brokers and practitioners as detailed in chapter 3 . While undertaking this study a 
number of opportunities occurred to attain input from and inform key actors regarding diverse views and their impact on priorities for improving chemicals management in the WHO European Region. In preparation for the Sixth Ministerial Conference on Environment and Health in Ostrava, Czech Republic, June 2017, the WHO Regional Office for Europe organised a meeting with diverse national and international experts from more than 15 countries to identify short- and medium-term actions to be implemented. This included coordinating and leading panel sessions by the thesis author to discuss roles, views, beliefs and perspectives of priority actions within chemical safety amongst the varied stakeholders and actors as a collective. In addition to semi-structured interviews that were undertaken with 18 diverse stakeholders to determine their views on priority actions for chemical safety management in the European Region, a final report of the findings were published and shared at the Ministerial Conference on Environment and Health noted above, as well as posted to the WHO website for open access viewing and continues to be accessible.[10,15]

\subsection{Knowledge transfer}

Evidence-based interventions exist but this does not necessarily mean all interventions will be effectively put into practice as detailed in chapter 4.[16-20] When an evidence-based intervention has been validated, sharing, context adapting and advocating the uptake of this good practice are important processes that requires concerted efforts. As preparation for the publication of chapter 4 took place, critical review and listing of recommended drowning prevention good practices were published by the thesis author for the WHO European Report for Child Injury Prevention-Drowning chapter, WHO Summary of the World Report for Child Injury Prevention and the UNICEF/WHO child friendly version to the World Report on Child Injury Prevention, which have been widely shared and remain accessible on the websites of both international organizations.[21-23] As well, a review of drowning good practice policy assessments were conducted as part of the broader Child Safety Report Card assessments funded by the European Commission, with 18 countries in 2007, 24 countries in 2009 and 31 countries in $2011 / 12$, also led by the thesis author and widely published through European and national level media, websites and project reports.[24] Furthermore, good practice implementation sessions were led by the thesis author at the 2013 World Drowning Congress 
in Potsdam, Germany and input and lessons learned from these workshop sessions were incorporated into the conclusions and recommendations of chapter 4.

\subsection{Barriers and facilitators to evidence implementation}

Barriers to evidence implementation can occur at any point in time during the knowledge transfer process. $[4,25,26,27]$ Increased awareness of determined barriers can be gained and then anticipated in order to undertake efforts to reduce the impact of such barriers. In ideal situations these barriers can even be turned into facilitators to support evidence implementation in public health systems as further detailed in chapter 5 of this thesis. As part of this chapter investigation a total of 21 diverse representatives dealing professionally with asbestos from 18 organisations globally participated in the stakeholder analysis interview process conducted by the thesis author.[9] A further 24 country representatives from 12 WHO European countries and 20 temporary advisors from 16 institutions participated in a WHO asbestos meeting and the thesis author presented the main results of the interview questionnaire. This included the coordination and facilitation of workshop sessions to discuss key aspects of barriers and means to change these issues to solutions and facilitators for evidence implementation. A meeting report and results of the workshop sessions were provided to all meeting participants. Furthermore, the stakeholder analysis described in chapter 5 contributed in particular, to one of the commitments of the Parma Declaration to develop national programmes to eliminate asbestos-related diseases by 2015 and reconfirmed in the Ostrava Declaration 2017.[28,29] During the Sixth Ministerial Conference of Environment and Health in 2017 a workshop session was held by WHO that shared the main results detailed within chapter 5 .

\subsection{Conclusion}

This chapter describes how a variety of channels have been used to share and discuss the results of this thesis with researchers, decision makers, knowledge brokers, practitioners and the general public related to evidence implementation in public health systems. A wide variety of actions were undertaken to disseminate and advocate the key components and 
factors that influence the uptake of evidence-based interventions, and how they interlink to impact effectiveness. These actions included awareness raising, knowledge enhancement and advocacy of evidence implementation through journal publications, national and global reports, ministerial declarations, national resolutions, conference presentations, website postings, and policy makers' workshop sessions. The broad dissemination and strategic communication activities described in this valorisation chapter demonstrates the level of integration the thesis results have had within key public health organizations and their networks, such as the World Health Organization. This has set the groundwork for advancing the implementation of evidence in public health systems in Europe and globally. 


\section{References}

1. United Nations [Internet]. New York, United States of America: United Nations; 2015. Transforming Our World: the 2030 Agenda for Sustainable Development. [updated 2019 May 3; cited 2020 May 24]. Available from: https://www.un.org/sustainabledevelopment/sustainabledevelopment-goals/

2. Acheson D. Health 21: the health for all policy framework for the WHO European Region. Copenhagen: World Health Organization Europe; 1999. 224 p.

3. Centers for Disease Control and Prevention (CDC) [Internet]. Atlanta, GA: U.S. Department of Health and Human Services, CDC; 2014. Introduction to Public Health, Public Health 101 Series. [updated 2018 November 15; cited 2020 May 3] Available from: https://www.cdc.gov/ publichealth101/public-health.html

4. Nilsen P. Making sense of implementation theories, models and frameworks. Implementation Sci. 2015;10:53. DOI: 10.1186/s13012-015-0242-0

5. Gentry S, Milden L, Kelly MP. Why is translating research into policy so hard? How theory can help public health researchers achieve impact? Public Health. 2020;178:90-96. DOI:10.1016/j.puhe.2019.09.009

6. Greenhalgh T, Fahy N. Research impact in the community-based health sciences: an analysis of 162 case studies from the 2014 UK Research Excellence Framework. BMC Med. 2015;13:232. DOI: 10.1186/s12916-015-0467-4

7. Vincenten J, MacKay $M$, Schröder-Bäck P, Schloemer $T M$, Brand H. Factors influencing implementation of evidence-based interventions in public health systems. Cent Euro J Public Health 2019; 27(3):198-203. DOI: 10.21101/cejph.a5234

8. Scholtes B, Schröder-Bäck P, MacKay J M, Vincenten J, Förster K, Brand H. Facilitators and Barriers for the Adoption, Implementation and Monitoring of Child Safety Interventions: a multinational qualitative analysis. Inj Prev. 2017;23(3):197-204. DOI:10.1136/injuryprev-2016-042138.

9. Vincenten J, George F, Martuzzi M, Schröder-Bäck, P, Paunovic E. Barriers and facilitators to the elimination of asbestos related diseases-stakeholders' perspectives. Int J Environ Res Public Health. 2017;14(10). pii: E1269. DOI: 10.3390/ijerph14101269.

10. Vincenten JA, Zastenskaya I, Jarosinska D.I. Analysis of stakeholder views on future development in chemical safety in the WHO European Region Report. Copenhagen, Denmark: World Health Organization Regional Office for Europe; 2017. 38 p. 
11. Damschroder LJ, Aron DC, Keith RE, Kirsh SR, Alexander JA, Lowery JC. Fostering implementation of health services research findings into practice: A consolidated framework for advancing implementation science. Implementation Sci. 2009;4(1):50-65. DOI: 10.1186/1748-5908-4-50

12. Greenhalgh T, Robert G, Macfarlane F, Bate P. Kyriakidou O. Diffusion of innovations in service organizations: Systematic review and recommendations. Milbank Q. 2004;82(4):581-629. DOI: 10.1111/j.0887-378X.2004.00325.x

13. Oliver K, Innvar S, Lorenc T, Woodman J, Thomas J. A systematic review of barriers to and facilitators of the use of evidence by policymakers. BMC Health Serv Res. 2014;14(1):2-14. DOI: 10.1186/1472-6963-14-2

14. Lavis J, Moynihan R, Oxman A, Paulsen E. Evidence-informed health policy 4 - Case descriptions of organizations that support the use of research evidence. Implementation Sci. 2008;3(12): 1-9. DOI: 10.1186/1748-5908-3-56

15. Vincenten JA, Zastenskaya I, Schröder-Bäck P, Jarosinska DI. Priorities for improving chemicals management in the WHO European Region-stakeholders' views [published online ahead of print, 2020 May 8]. Eur J Public Health. 2020 May 8;ckaa074. DOI:10.1093/eurpub/ckaa074

16. Orton L, Lloyd-Williams F, Taylor-Robinson D, O'Flaherty M, Capewell S. The use of research evidence in public health decision making processes: Systematic review. PLoS One. 2011;6(7): e21704. DOI: 10.1371/journal.pone.0021704

17. Kneale D, Rojas-García A, Thomas J. Obstacles and opportunities to using research evidence in local public health decision-making in England. Health Res Policy Sys. 2019;17(61): DOI: 10.1186/s12961-019-0446-x

18. Liverani M, Hawkins B, Parkhurst JO. Political and institutional influences on the use of evidence in public health policy. A systematic review. PLoS One. 2013;8(10): e77404. DOI: 10.1371/journal.pone.0077404

19. Oliver K, Lorenc T, Innvær S. New directions in evidence-based policy research: a critical analysis of the literature. Health Res Policy Systems. 2014;12(7):34-45. DOI: 10.1186/1478-4505-12-34

20. Fafard P, Hoffman SJ. Rethinking translation for public health policy. Evid Policy. 2020;16(1):165175. DOI: 10.1332/174426418X15212871808802

21. Sethi D, Towner E, Vincenten J, Segui-Gomez M, Racioppi F. European Report on Child Injury Prevention. Copenhagen: WHO Regional Office for Europe; 2008. 98 p.

22. Vincenten J, MacKay M. World report on child injury prevention: Summary and fact sheets. Geneva: World Health Organization; 2008. 213 p.

23. Vincenten J, MacKay M. Companion to the World Report on Child Injury Prevention 2008. Have Fun, Be Safe! New York: UNICEF; 2008. 26 p. 
24. MacKay M, Vincenten J. Child Safety Report Card 2012: Europe Summary for 31 Countries. Amsterdam: European Child Safety Alliance; 2013. 58 p.

25. Glasgow RE, Green LW, Taylor MV, Stange KC. An evidence integration triangle for aligning science with policy and practice. Am J Prev Med. 2012;42(6):646-654. DOI: 10.1016/j.amepre.2012.02.016

26. 26. Moulin J, Sabater-Hernández D, Fernandez-Llimos F, Benrimoj S. A systematic review of implementation frameworks of innovations in healthcare and resulting generic implementation framework. Health Res Policy Syst. 2015;13:16. DOI: 10.1186/s12961-015-0005-z.

27. Grimshaw JM, Eccles MP, Lavis JN, Hill, SJ, Squires JE. Knowledge translation of research findings. Implementation Sci. 2012;7(1):50-67. DOI: 10.1186/1748-5908-7-50

28. World Health Organization. WHO Europe Parma Declaration on Environment and Health. Copenhagen, Denmark: World Health Organization Regional Office for Europe; 2010. 10 p. Report No.: EUR/55934/5.1 Rev. 2

29. World Health Organization. WHO Europe Ostrava Declaration on Environment and Health. Copenhagen, Denmark: World Health Organization Regional Office for Europe; 2017. 5 p. Report No.: EURO/Ostrava2017/6 


\section{Acknowledgements}

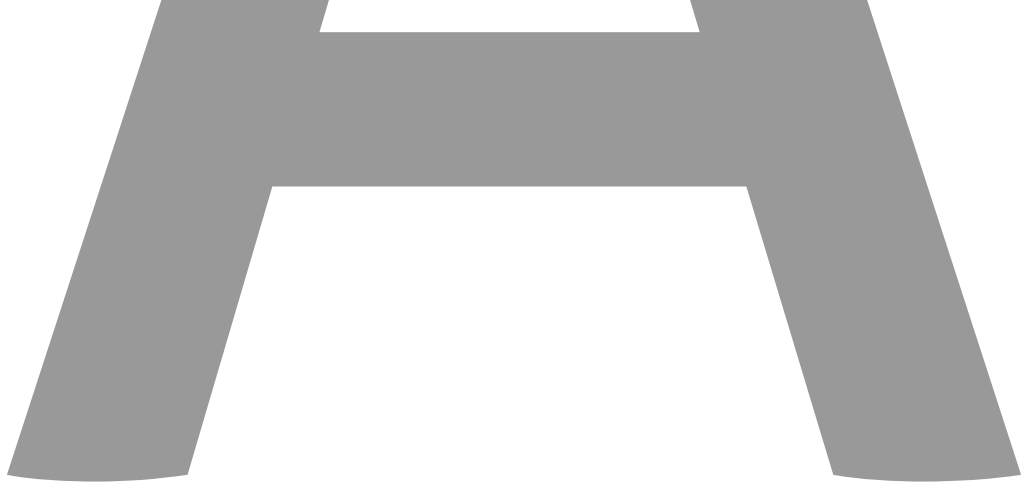


Acknowledgements 


\section{Acknowledgements}

Many years ago, thoughts of undertaking and completing a PhD came and then went, as my time became consumed with career opportunities, family commitments, cross continent moves and life adventures. However, the chance to take up this challenge came back to me. Now the successful journey and completion was only possible with the tremendous support of so many.

First, my extreme gratitude to my Supervisor Professor Dr. Helmut Brand and Co- Supervisor Dr. Peter Schröder-Bäck for their guidance and oversight throughout the entire process; accepting to take me on board as a part-time distance PhD student while I continued juggling work and family commitments. I am thankful to you both for your posing of critical questions for my reflection, encouraging appreciation and understanding of various research methods, providing opportunities to test my ideas, and engaging me to guest lecture your master students to further process and refine my thesis model.

Thanks also to Maastricht University for providing access to online courses and tutorials, literature searches, publication support and thesis production assistance, all greatly appreciated. A special thank you to Anita Creusen, who provided great care and attention to numerous details to support this thesis production and public defense.

Over the past four years while consulting for United Nation agencies, the research projects undertaken provided excellent opportunities to apply and test the model of this thesis and its various components. My thanks to WHO and UNICEF for supporting the use of this new model to underpin timely research actions and proposals for current application for knowledge translation and science implementation.

I am also grateful to all of my co-authors for their knowledge, guidance and contributions to our published papers within this thesis. With each question and rewrite the content became clearer and stronger, and my learning increased. This also includes my warm thanks to my close colleagues and friends who supported me on this PhD journey for many years, Mathilde 
Sengölge as a great mentor, Kidist Kebede Bartolomeos a tremendous advocate and professional model and Morag MacKay for her technical acumen and encouragement. Sharon Marie Mavko and Joanna Bovio for their continued patience and positive contribution to continuously redesign the model graphic, which evolved after each published paper and presentation.

Finally, last but not least, to my family Andrej and Anna for your patience with my continued reading, writing, submissions and resubmissions. Furthermore, for your understanding and valuing my need to undertake and complete this PhD. Thank you for your love and support!

It does not matter how slowly you go so long as you do not stop.

- Confucius (551-479 BC) philosopher 


\section{Curriculum Vitae}

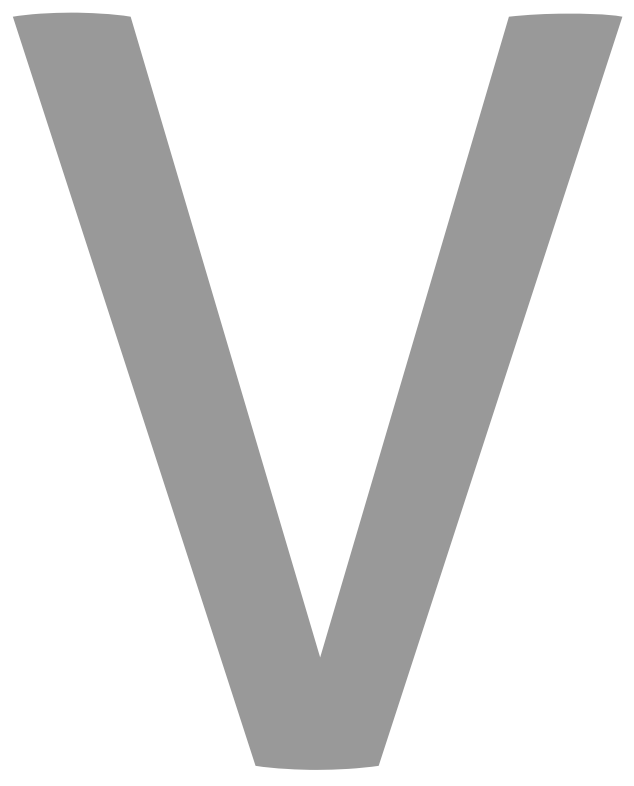


Curriculum Vitae

Joanne Adrienne Vincenten 


\section{Joanne Adrienne Vincenten - Curriculum Vitae}

Address: Hofstatt 8, 88662 Überlingen, Germany

Email: joanne.vincenten@gmail.com

Nationality: Canadian

\section{Employment}

Health Specialist - Child Injury Prevention and Environmental Health, UNICEF 2020-present

Responsible to support child injury prevention and the built-environment portfolio globally, including development and dissemination of technical guidance documents on child injury, and provide support to regional and national offices in policy engagement to influence national investments on the 'survive and thrive agenda'. Responsible for advocacy with WHO and partners, as well as to provide technical support to governments in evidence generation and evidence-based policy. Support mainstreaming of child injury prevention and healthy built environments within national development plans, strategies, and initiatives, and to strengthen health, education, social welfare and other systems to address the risks of injuries and drowning among children, adolescents and women.

\section{Private Consultancy (Focus health and environment) 2015 - 2020}

Consultant and knowledge broker for translating evidence into policy and practice, to make needed change take place in complex political environments. Regular consultation for the World Health Organization and UNICEF, and engagement with multi-sectoral, multidisciplinary groups with more than 30 plus countries. Expertise and services include: evidence implementation strategies and guidance; strategic and operational planning; leadership coaching and capacity building; meeting facilitation and reporting; needs assessment and stakeholder analysis, design and implementation; indicator framework development and impact monitoring; science translation, communications and campaigning; policy analysis and advocacy action; grant writing and critiquing; project, event and organization management and governance; and evaluation design, monitoring and reporting.

\section{Director, European Child Safety Alliance 2000 - 2014}

Responsible for the leadership and management of the European network with more than 30 country partners, including the areas of: strategy planning, implementation and governance; finance, prevention investments and costing; evidence informed policy formation, implementation and monitoring; research and evaluation; programme management; science communications and advocacy; strategic partnerships, network development and capacity building, to support evidence uptake.

\section{Director, Alberta Centre for Injury Control and Research, Department of Public Health Sciences, Faculty of Medicine and Dentistry, University of Alberta $1998-2000$}

Responsible for the leadership, management, governance and quality of the applied research centre, human resources and activities within the Faculty of Medicine. Developed, implemented and managed the evaluation of strategic, financial and operational plans. 
Directed the development and maintenance of data surveillance systems, prevention programmes and evaluation studies. Developed and nurtured networks and partnerships with key stakeholders and cross sectors for collaborative research, knowledge translation, capacity building, science communication and advocacy, and policy development, implementation and monitoring. Also served as an adjunct public health professor, University of Alberta, Faculty of Medicine.

Director, SAFE KIDS Program, Children's Health Centre, University of Alberta Hospital 1995 $-1998$

Responsible for the overall leadership and management of the child injury prevention programme, within healthy and safe built environments, under the direction of the Children's Health Centre. Also, guest lecturer, University of Alberta, Faculty of Medicine.

\section{Education}

2016 - 2020 PhD Programme Studies Maastricht University, Faculty of Health, Medicine and Life Sciences - Care and Public Health Research Institute (CAPHRI) - Department of International Health, the Netherlands

- PhD theme: Factors influencing implementation of evidence-based interventions into policy and programmes

2011 European Health Leadership Programme (scholarship recipient); INSEAD Graduate Business School, France

1992 - 1996 Master of Arts, Administrative Leadership (Honours) San Diego State University, United States of America

- Focus Area: Public Health Policy and Promotion

- Thesis: Sport and recreation emergency department injuries: establishing baseline data and proposed injury surveillance model

\section{Professional affiliations}

- Advisor EU Joint Action Reducing Alcohol Related Harm and RESPONSE project addressing gender- based violence

- Child Injury Prevention expert, UNICEF Technical Advisory Group - Home Visiting for Young Child Health and Wellbeing

- Member of the European Public Health Association sections: Child and adolescent public health, Environment and health, Ethics in public health, Injury prevention and safety promotion, Migrant and ethnic minority health, and Public health policy and politics 


\section{Awards}

- European Health Award - European Health Forum Gastein

- Lifetime Achievement Award - European Public Health Alliance

- Hutchinson Medal for Social Responsibility - American Society for Quality, United States of America

- European Health Leadership Programme Scholarship - INSEAD Graduate Business School, France

- The J.A. Vincenten Injury Prevention Student Scholarship Award - Established by the Faculty of Medicine, University of Alberta, Canada

- J.T. Watson Academic Scholarship - University of Winnipeg, Canada

\section{Selected professional experiences}

\section{Strategic leadership, management and partnerships}

- Consultant, WHO Europe Health and Development SDGs Road Map implementation strategy and knowledge translation tools development for 53 Member States.

- Strategic advisor, WHO Europe implementation support of the WHO Migrant and Health Strategy and Action Plan, and the development of a Knowledge Hub for Migration and Health with the European Commission and country partners.

- Expert Advisor for Migration and Health EU grant proposal preparations and writing for WHO Euro Office awarded 850,000 Euro; WHO Serbia Country Office awarded 4,000,000 Euro; and WHO Jordan Country Office awarded 32,000,000 Euro.

- Expert Advisor, Government of Kazakhstan and UNICEF leading the child injury prevention needs and policy assessment, stakeholder analysis, Knowledge, Attitudes and Practice study of 3,000 parents, technical support, and strategy plan including recommendations.

- Led, developed, implemented and monitored, strategic and operational plans for 6 professional employment positions and 2 NGO chair positions, meeting key performance indicators.

- Founding director and launched start-ups for: a faculty of medicine applied research centre, a university hospital outreach resource centre for patients and families, and an international network with more than 30 participating countries with representatives from national governments, academia, IGOs and NGOs.

- Secured and served as the Project Leader to 6 EU funded grant projects, with more than 20 country partners, ensuring sound management, meeting timelines, outputs, outcomes and budget criteria.

- European NGO Health and Environment Representative to 3 Ministerial Conferences for Environment and Health with senior government officials of 53 European countries.

- Negotiator of a tri-ministerial agreement and led a team to develop, publish, implement and monitor, evidence-based Safety Guidelines for Physical Activity in Schools, serving as a Canadian legal precedent.

- European Public Health Alliance Board Member, President and Governance Committee Member over a 10-year period, working collaboratively with public health NGOs, patient groups, researchers, health and environment professionals, government officials and disease groups to improve health and wellbeing. 


\section{Evidence-based policy and programme strategies and tools}

- Consultant, WHO Headquarters Geneva, WHO Bulletin Editorial Team.

- Editor, WHO Global Pandemic Influenza Preparedness Framework technical guidance/capacity building tool, for planning and deployment of pandemic influenza vaccines and antivirals.

- Consultant, WHO Kobe Centre for Health and Development, to support capacity building of government decision makers from Bangladesh with the use of evidence for sustainability of local health development and sustainable environments.

- Rapporteur and report formation for WHO Regional Office for Europe on Climate Change, E-Waste and Circular Economy.

- Creator of plain language summaries for the European Parliament High Level meetings on the WHO Framework Convention on Tobacco Control.

- Technical guidance and co-authored "Child Injury Prevention Good Practice Guide" an evidence-based policy and programme intervention used by more than 25 countries worldwide and published in 3 editions in 3 continents.

- Developed in cooperation with more than 30 countries, National Action Plans/Strategies, benchmarking, and country assessment tools and technical resources, with multi-sectoral and multi-level governments, and NGOs where no previous national plans existed for child injury prevention.

- Created, implemented and monitored Child Safety Report Cards, with indicators mapping good practice policy adoption, implementation and enforcement in more than 30 countries, 3 times over a 10-year period, with trend analysis showing improvement in policy uptake in the majority of participating countries.

- Led and published the first comprehensive child intentional injury policy report across 25 countries supported by the European Commission Vice President, DG Justice, DG Health and the European Children's Ombudsman.

- Coordinator and co-author of the WHO/UNICEF World Report on Child Injury Prevention Executive Summary and Fact Sheet Series/Policy Briefs, for national policy and decision makers, advocating key recommendations globally.

- Led and coordinated a team on the development and publication of the child friendly version WHO/UNICEF World Report on Child Injury Prevention, "Have Fun, Be Safe" as part of a global campaign, working collaboratively with technical and communications staff of UNICEF New York and WHO Geneva.

- Expert Advisor, UNICEF Europe and Central Asia Regional Office, and author to the Home Visiting for Young Child Health and Wellbeing Module "Home Environment and Safety".

- Led and coordinated a team on the development of "Children as Agents of Change - How children influenced health and environment policy" in partnership with the European Environment Agency, European Public Health Alliance, OECD, UNICEF and the European Commission; published and presented for policy makers at the Ministerial Conference for Environment and Health with participation of senior policy makers in 53 countries.

- Served as Communications and Dissemination Work Package Leader in 4 large EU multisectoral, multi-cultural and multi-level, six-figure funded public health projects, responsible for maximising the exposure of project results, approval of publications, building lasting outcomes and support use of evidence and sustainability to impact needed change in countries. 


\section{Selected publications relevant to this thesis}

Vincenten JA, Zastenskaya I, Schröder-Bäck P, Jarosinska DI. Priorities for improving chemicals management in the WHO European Region-stakeholders' views. Eur J Public Health. 2020 May 8;ckaa074. DOI:10.1093/eurpub/ckaa074

Vincenten J, MacKay JM, Schröder-Bäck P, Schloemer T, Brand H. Factors influencing implementation of evidence-based interventions in public health systems-a model. Cent Eur J Public Health. 2019;27(3):198-203. DOI: 10.21101/cejph.a5234

Schröder-Bäck P, Vincenten, J. Ethical tools for decision-makers in environment and health. Environmental Health Risks, Ethical Aspects. $1^{\text {st }}$ ed. New York: Routledge, Taylor and Francis Group; 2019.

Vincenten J, George F, Martuzzi M, Schröder-Bäck P, Paunovic E. Barriers and Facilitators to the Elimination of Asbestos Related Diseases-Stakeholders' Perspectives. Int J Environ Res Public Health. 2017;14(10). pii: E1269. DOI: 10.3390/ijerph14101269

Scholtes B, Schröder-Bäck P, Mackay M, Vincenten J, Brand H. Child Safety Reference Frameworks: A Policy Tool for Child Injury Prevention at the Sub-national Level. Cent Eur J Public Health. 2017;25(2):120-128. DOI: 10.21101/cejph.a4477

Scholtes B, Schröder-Bäck P, MacKay J M, Vincenten J, Förster K, Brand H. Facilitators and Barriers for the Adoption, Implementation and Monitoring of Child Safety Interventions: a multinational qualitative analysis. Inj Prev. 2017;23(3):197-204. DOI: 10.1136/injuryprev2016-042138.

Scholtes B, Schröder-Bäck P, Förster K, MacKay M, Vincenten J, Brand H. Multisectoral action for child safety-a European study exploring implicated sectors. Eur J Public Health. 2017;27(3):512-518. DOI: 10.1093/eurpub/ckx010

Scholtes B, Schröder-Bäck P, Mackay M, Vincenten J, Brand H. A practical tool to assess the cross- cutting nature of child injury prevention as a basis for policy making at the local level. SEEJPH. 2014; posted 22 February 2014. DOI: 10.12908/SEEJPH-2014-08

Vincenten J, Gerdmongkolgan S. The role of policy in prevention. In: Bierens J, editor. Drowning - Prevention, Rescue, Treatment. Switzerland: Springer; 2014. p. 261-268.

Turner SL, Lyons RA, Macey SM, MacKay M, Vincenten J. Progress on child safety action in Europe: the results of the 2012 child safety country profiles. Inj Prev.2012;18:Suppl 1 A118 (Abstract). DOI: 10.1136/injuryprev-2012-040590d.69

MacKay M, Vincenten J, Lyons RA, Macey S, Turner S. Benchmarking Progress on Child Safety Action in Europe - the Results of the 2012 Child Safety Report Cards. Inj Prev. 2012;18:Suppl 1 A16 (Abstract) DOI: 10.1136/injuryprev-2012-040580b.5 
MacKay M, Macpherson AK, Pike I, Vincenten J, McClure R. Action indicators for injury prevention. Inj Prev. 2010 Jun;16(3):204-7. DOI: 10.1136/ip.2008.021444

MacKay M, Vincenten J, Heller O, Peden M. Water safety education as compulsory part of school curricula in Europe: a potential model for low- and middle- income countries? Inj Prev. 2010;16:Suppl 1 A239 (Abstract) DOI: 10.1136/ip.2010.029215.850

MacKay M, Vincenten J. Leadership, infrastructure and capacity to support child injury prevention: can these concepts help explain differences in injury mortality rankings between 18 countries in Europe? Eur J Public Health. 2012;22(1):66-71. DOI:10.1093/eurpub/ckq192

MacKay M, Vincenten J. Impact and lessons learned from the first 5 years of the Child Safety Action Plan (CSAP) initiative in 26 countries in Europe. Inj Prev. 2010;16:Suppl 1 A275A276 (Abstract) DOI: 10.1136/ip.2010.029215.979

MacKay M, Vincenten J. Why isn't more injury prevention evidence-based? Int J Inj Contr Saf Promot. 2009;16(2):89-96. DOI: 10.1080/17457300902836663

Sethi D, Towner E, Vincenten J, Segui-Gomez M, Racioppi F. European Report on Child Injury Prevention. Copenhagen: World Health Organization, Regional Office for Europe, 2008. 98 p. 
